\title{
“I Don't Really Look Very Asian": Transracially and Transnationally Adopted Asian Youth in Rural Appalachia
}

\author{
Sandra L. Rodeheaver \\ slrodeheaver@mix.wvu.edu
}

Follow this and additional works at: https://researchrepository.wvu.edu/etd

Part of the Curriculum and Instruction Commons, and the Secondary Education and Teaching

Commons

\section{Recommended Citation}

Rodeheaver, Sandra L., "'I Don't Really Look Very Asian": Transracially and Transnationally Adopted Asian Youth in Rural Appalachia" (2020). Graduate Theses, Dissertations, and Problem Reports. 7603.

https://researchrepository.wvu.edu/etd/7603

This Dissertation is protected by copyright and/or related rights. It has been brought to you by the The Research Repository @ WVU with permission from the rights-holder(s). You are free to use this Dissertation in any way that is permitted by the copyright and related rights legislation that applies to your use. For other uses you must obtain permission from the rights-holder(s) directly, unless additional rights are indicated by a Creative Commons license in the record and/ or on the work itself. This Dissertation has been accepted for inclusion in WVU Graduate Theses, Dissertations, and Problem Reports collection by an authorized administrator of The Research Repository @ WVU.

For more information, please contact researchrepository@mail.wvu.edu. 
"I Don't Really Look Very Asian":

Transracially and Transnationally Adopted Asian Youth in Rural Appalachia

Sandra L. Rodeheaver

\author{
Dissertation submitted \\ to the College of Education and Human Services \\ at West Virginia University \\ in partial fulfillment of the requirements for the degree of \\ Doctorate in Education \\ Curriculum \& Instruction/Literacy Studies
}

\author{
Melissa Sherfinski, Ph.D., Chair \\ Sharon Hayes, Ph.D. \\ Jessica Troilo, Ph.D. \\ Denise Lindstrom, Ph.D.
}

Department of Curriculum \& Instruction

Morgantown, West Virginia

2020

Key words: transracial adoption, transnational adoption, model minority stereotype, Asian adolescents, Appalachia, rural education, Whiteness, funds of knowledge, third space

Copyright 2020 Sandra L. Rodeheaver 


\begin{abstract}
“I Don't Really Look Very Asian”:

Transracially and Transnationally Adopted Asian Youth in Rural Appalachia
\end{abstract}

Sandra L. Rodeheaver

Transracially adopted Asian children in rural Appalachia find themselves adopted into places where there is little or no racial and ethnic diversity. In this context, it may be difficult to transgress the model minority stereotype and systemic racism in schools and the community. There are particular issues and concerns related to racial identity for TRAAs that may make the task of becoming fully integrated members of the community challenging. Building on the literature on transracial and transnational adoption, this study aims to better understand the lives and perspectives of two transracially adopted Asian (TRAA) girls living in rural Appalachia and how they are constructed and positioned in their families and their education community. In order to receive a clearer picture of these students, two research questions were posed:

${ }^{\circ}$ How do transracially adopted Asian (TRAA) youth see themselves within the contexts they negotiate in rural Appalachia?

${ }^{\circ}$ How do teachers and administrators position TRAAs?

A case study was conducted and the data analyzed using third space theory and additional critical and sociological theories of identity and agency such as funds of knowledge and border pedagogies. Participants included the girls, their parents, their school administrators, and many teachers at their schools (total $n=23$ participants). Data were collected through surveys, interviews, focus groups, and observations. A traditional case study analysis using coding and memoing was completed.

Analysis of the information revealed five major challenges for the students in schools that served nearly all White students yet were growing in cultural and linguistic talents and racial/ethnic diversity: (1) Assuming assimilation, (2) deflecting race talk, (3) exoticizing particular differences, (4) minimizing bullying, and (5) positioning teachers and administrators in schools. The challenges supported school and community homogeneity instead of heterogeneity, which transferred to how TRAAs saw themselves in the context of rural Appalachia in complicated ways.

The dissertation concludes by considering positive curricular and pedagogical supports for rural and Appalachian communities. These supports are necessary to co-construct third spaces of understanding in communities to support TRAAs and all students. 
To

My Family:

My husband Mark (my rock)

My children Ben, Tad and EunAe (my vision)

My father-in-law Lonnie (my loss)

My mom Eva (my cheerleader)

Countless parents, students, friends, and colleagues 


\section{Acknowledgements}

None of this would have been possible without my chairperson Melissa Sherfinski's leadership. Her original guidance and support of ideas for research allowed me to pursue this study. Since that time, she has been there every step of the way in developing this project and flushing out the best in me. I also would like to say my thanks to my committee who also lent their guidance to make me a better researcher and writer. Their comments allowed me to self-reflect and reexamine my own thoughts and biases. They also welcomed my perspectives and believed in my research. I stand amazed at the helpfulness of the support team that has been behind me in the West Virginia University Curriculum and Instruction/Literacy Studies Department to make sure all my i's were dotted and classes completed so that a graduation could occur. Those unsung heroes would be Connie Miranov and Char Allen.

Personally, outside my university colleagues, there have been many others. The biggest cheerleaders have been my family, specifically my husband Mark and my mother Eva. They have continually supported my crazy ideas of wanting to know more and fully took on roles at home that allowed me to continue less stressed. The parents at every venue being sporting, musical, theater or academic that tapped my shoulder while reading so I would know my kid was up. My colleagues who also, through and to the journey's end, have been my cheerleaders without exception. Many of them donated time and information that has been included here. Finally, my church family who prayed me through the years and have cheered ever milestone.

Finally, the transracially adopted community that answered my questions openly and showed me that this study needed to be done. Special thanks goes out to Mark Hagland, a moderator of the Facebook Group Transracial Adoption Perspectives, who provided insight into the lives of being a transracially adopted Asian American. Also, special thanks to Shelby Redfield Kilgore, who's work on film with adoptees and foster care in Appalachia has been thought provoking to adoptees and their families.

This, all this help and guidance, has helped this study come to fruition. May it be a stepping stone to someone else who can add to the knowledge of this part of the educational field. 


\section{Table of Tables}

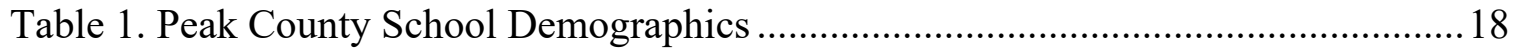

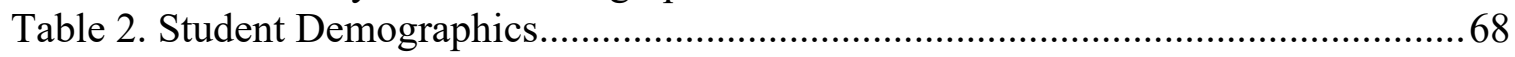

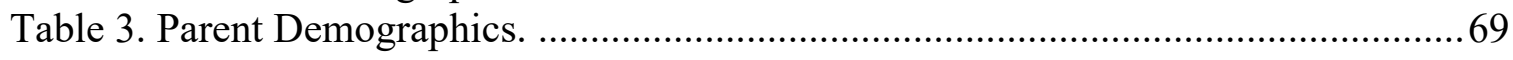

Table 4. Teacher/Administrator Demographics of School participants of TRAA's-

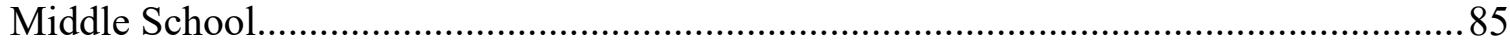

Table 5. Teacher/Administrator Demographics of School participants of TRAA's- High

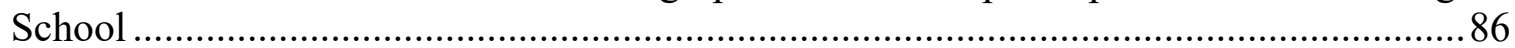




\section{Table of Figures}

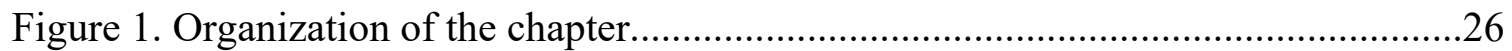

Figure 2. TRAA children's potential ecologies .................................................. 28

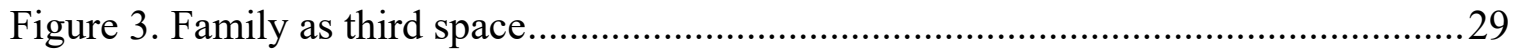




\section{Table of Contents}

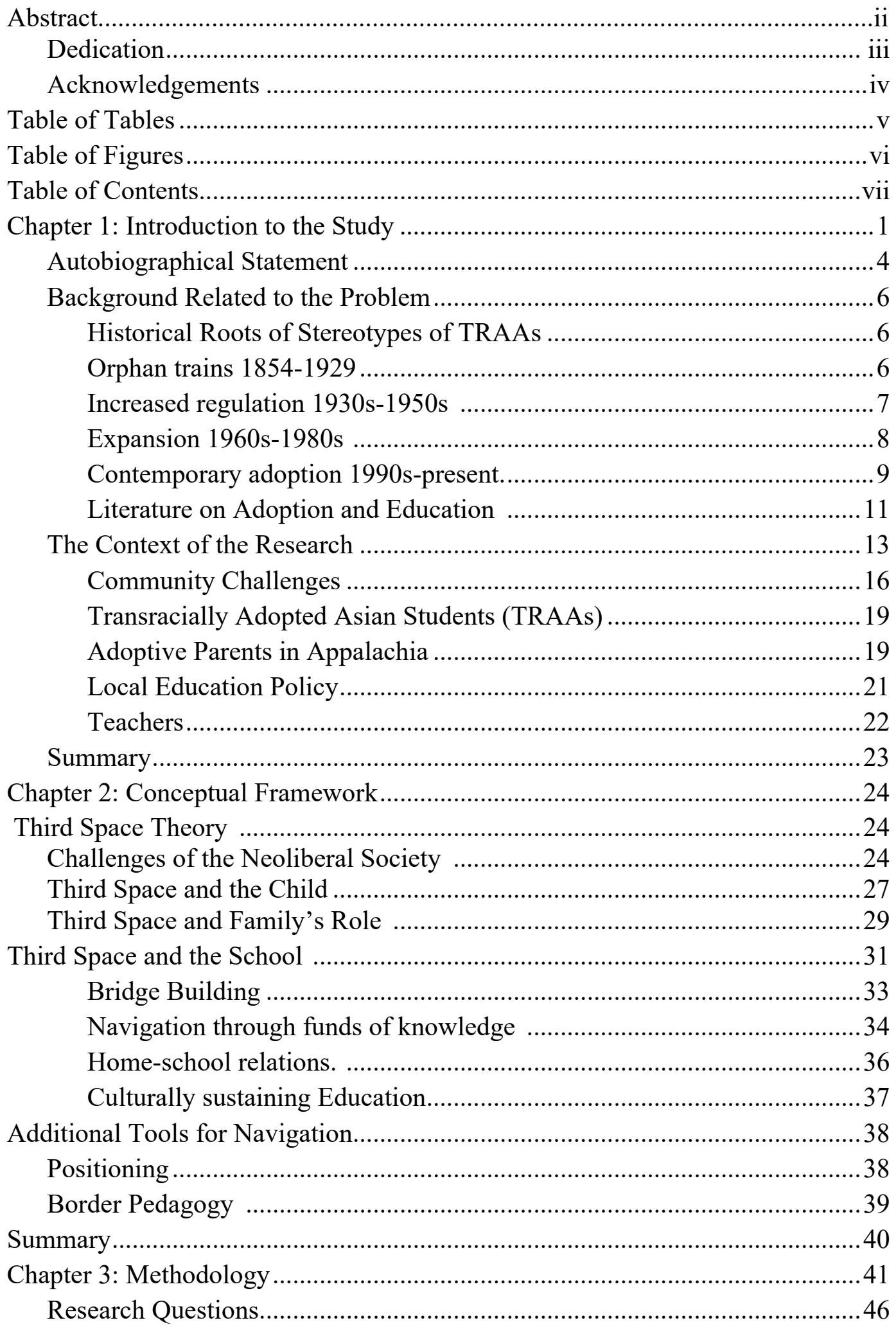


Epistemology and Theory........................................................................... 47

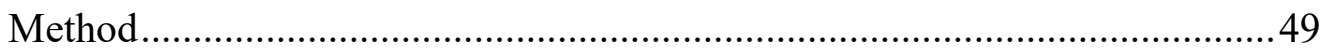

Case Study Method................................................................................ 49

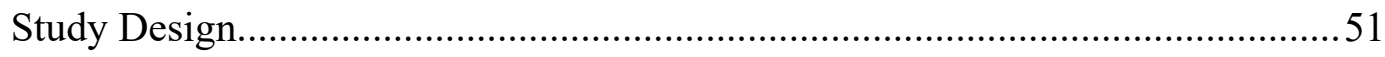

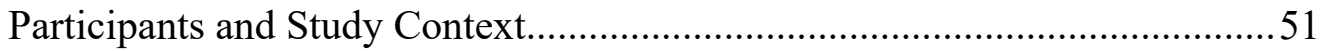

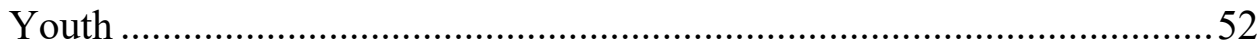

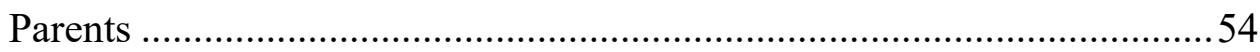

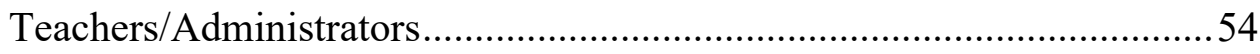

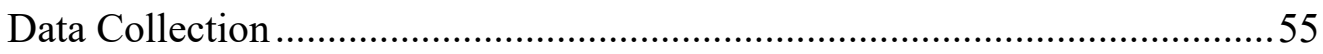

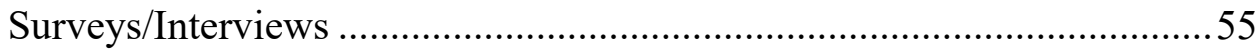

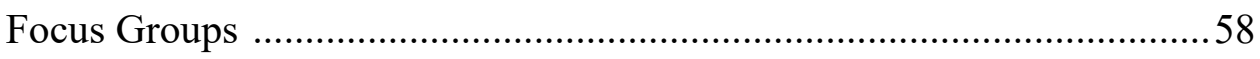

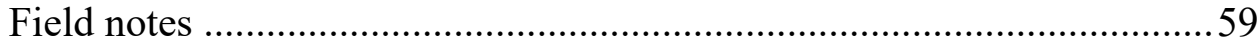

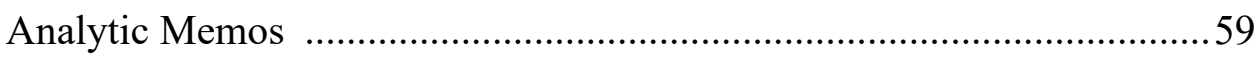

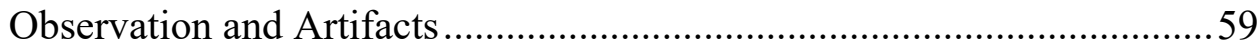

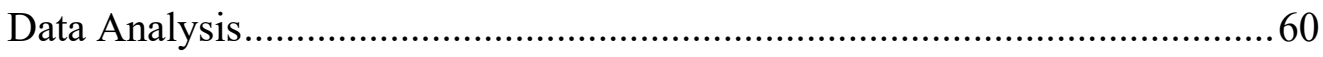

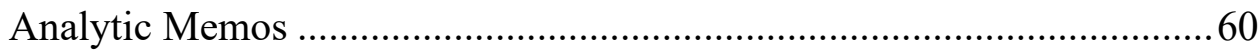

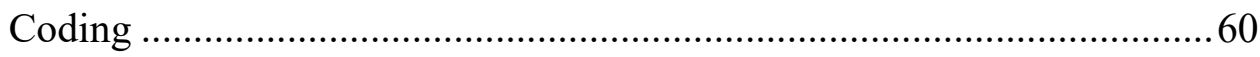

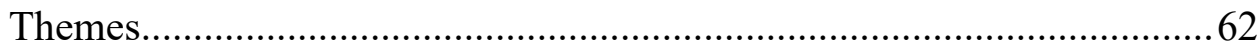

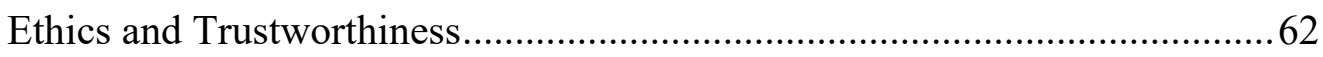

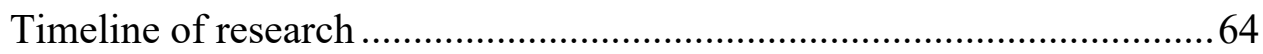

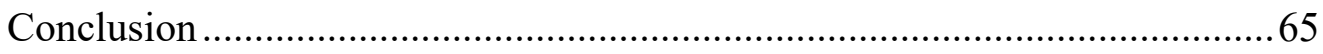

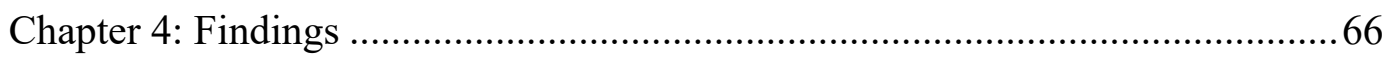

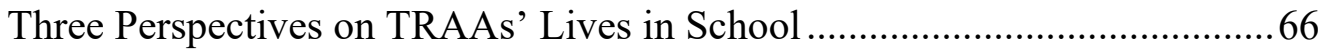

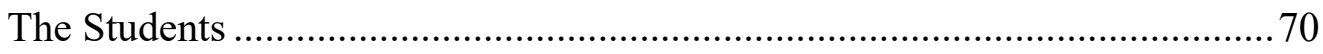

Blending Into the Home Community ……………………......................73

Context and Naming the Location of Culture ...........................................

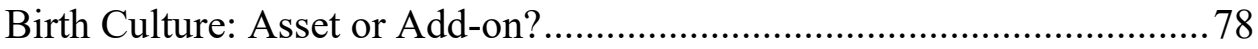

Rural "Idyll"- Racism Viewed as Exception, Not the Rule .......................79

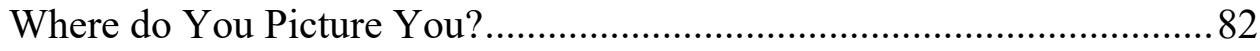

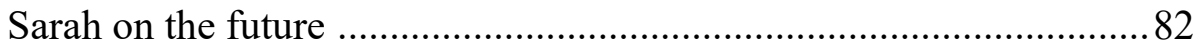

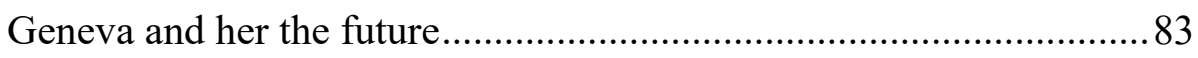

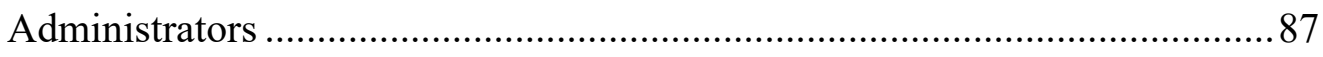

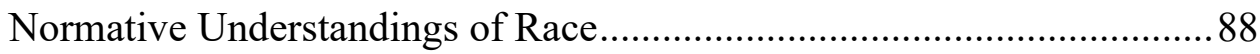

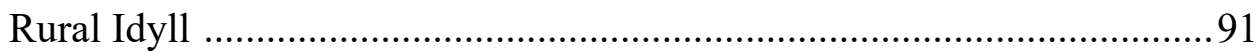

What is the Role of the School Relative to the Rural Idyll?.....................92

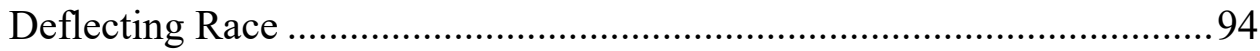

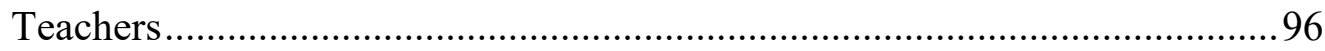

The Blessing of TRAAs ......................................................................97

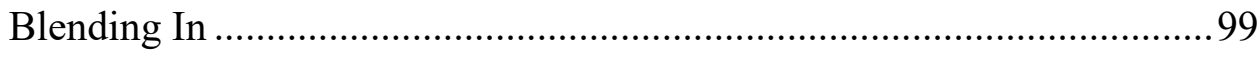

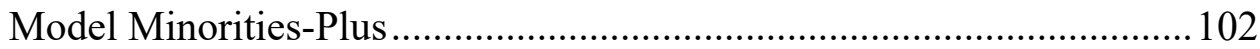




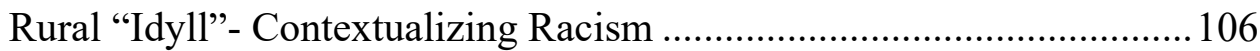

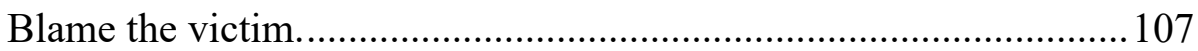

Demonizing difference.................................................................... 107

Teachers' Perspectives of the Students' Racial Identities ............................... 108

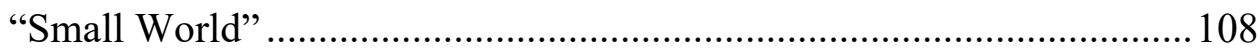

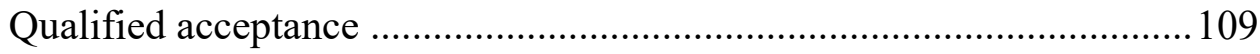

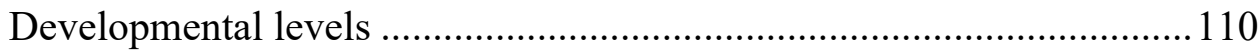

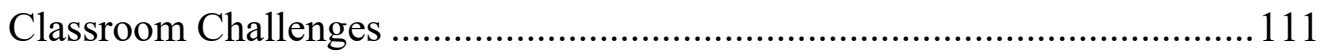

Challenge 1. Assuming assimilation of TRAAs......................................111

Challenge 2. Deflecting race talk affects TRAAs. ................................... 112

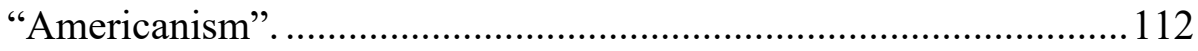

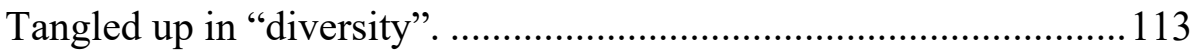

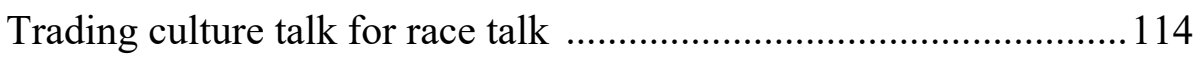

Challenge 3. Exoticizing particular differences affects TRAAs .............114

Challenge 4. Bullying TRAAs minimized ……………………….........116

Challenge 5. Teachers do teaching, administrators do race .....................117

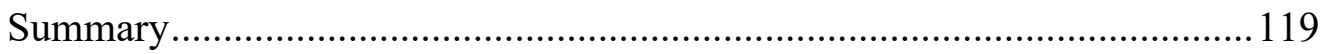

Chapter 5: Discussion, Implications, and Conclusion ....................................... 120

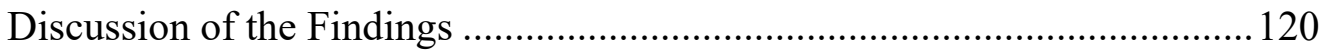

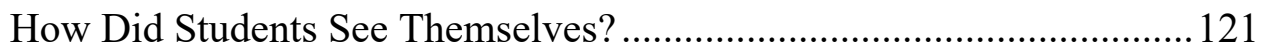

How did Educators Support TRAAs? ……………………................... 122

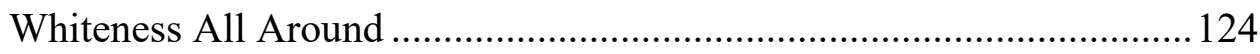

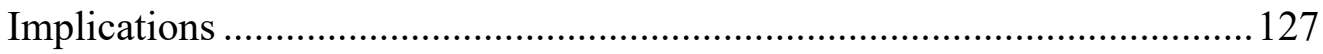

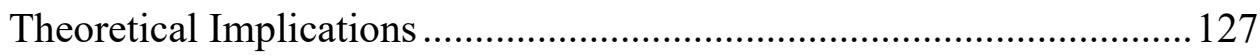

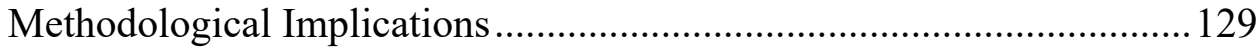

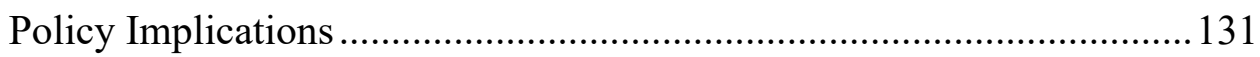

Implications for Practice ..................................................................... 132

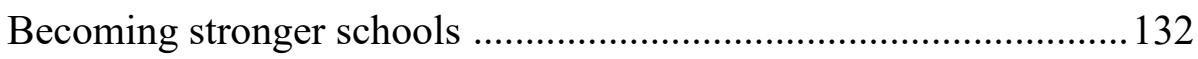

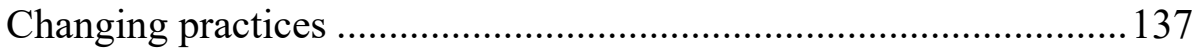

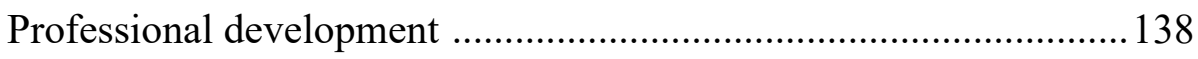

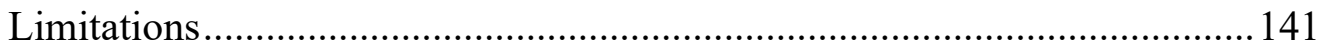

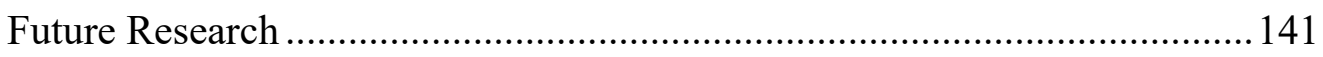

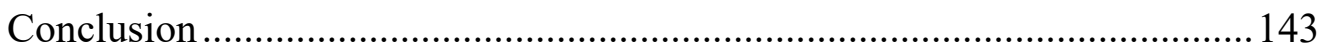

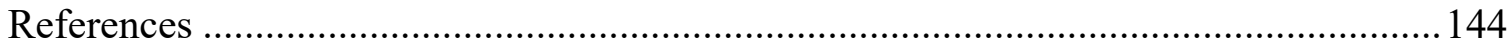

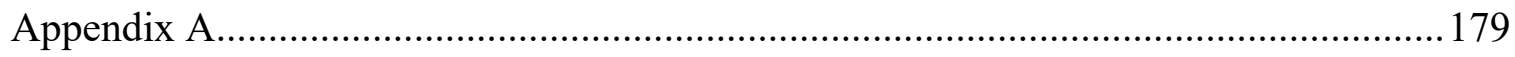

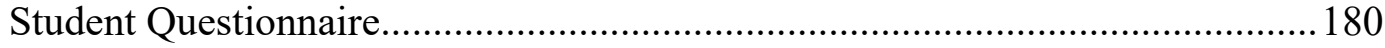

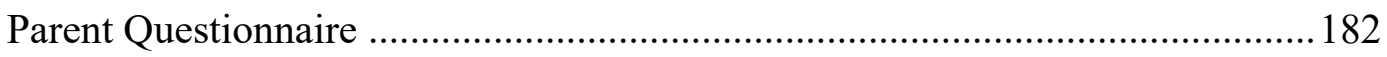

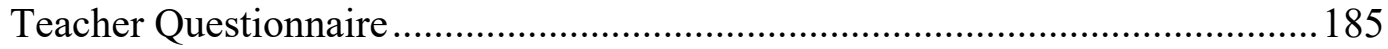

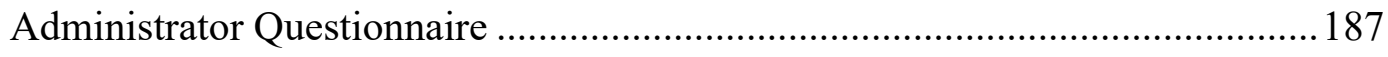

Appendix B 


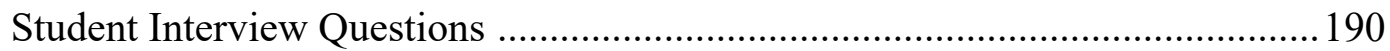

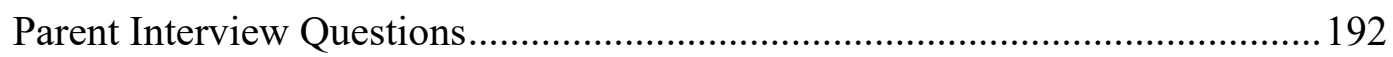

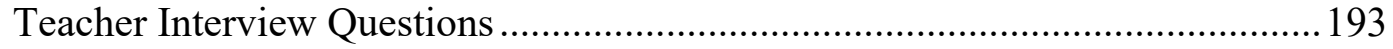

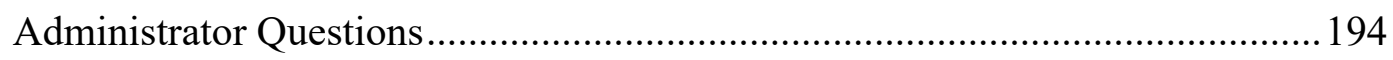

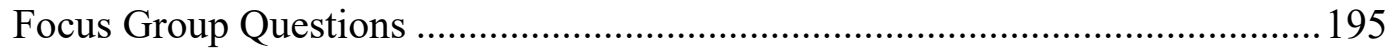




\section{Chapter 1: Introduction}

The title of this dissertation, "I Don't Really Look Very Asian": Transracially and Transnationally Adopted Asian Youth in Rural Appalachia, comes from a conversation with a transracially and transnationally adopted Asian (TRAA) student, a young woman named Geneva (a pseudonym) who was a participant in this research. Her self-perception of "not really looking Asian" struck me because it seemed outside the norm of the ubiquitous model minority stereotype, which I will describe. Surrounded by White faces in Appalachia, Geneva seemed to believe that she looked very White. That Asian children may see themselves as phenotypically "Whiter" than they really are is not without support in the literature, although references are few. Hurly (2005) in her article, "Seeing White: Children of Color and the Disney Fairy Tale Princess" stated that being surrounded in Whiteness, as is the case for many girls of color in the United States, affects them through both visual and verbal representations of themselves in books, media and everyday life. If not countered with strong messages that support their complex racial, cultural, and gender identities, TRAAs will have increased challenges in being in the presence of others throughout their lives.

All students of color experience challenges being in the presence of others and particularly they experience some degree of harassment due to their race (Lin, 2010; Picower \& Kohli, 2017; Sue, 2010). As the U.S. has become politically polarized, "permission" to harass students of color has grown; 90 percent of educators report that school climate has been negatively affected (Southern Poverty Law Center, 2017). To illustrate this, a Mexican student at the school I teach in was tormented to the point of sickness. Another child at my school called former President Obama a "monkey". Asian 
students are not immune to racism. TRAAs' injuries from verbal insults can be compounded due to their adoption (Kim \& Hall, 2016) and the current intensive political context. For example, before the last U.S. presidential election, a Chinese adoptee who is nine years old asked her mother if she would have to go back to her orphanage in China if Trump was elected (Southern Poverty Center, 2016). All of this has happened in rural Appalachia, my own backyard, a place known for peace and simplicity.

Although negative racial stereotypes of TRAAs and other Asian students are pervasive, seemingly positive stereotypes can also be very detrimental to a child's identity development (Kwong \& Lee, 1998). The term "model minority" was coined in a 1966 article by psychologist William Petersen in his article "Success Story: Japanese American Style" for the New York Times Magazine (Pettersen, 1966). In the research, the hard work of Japanese Americans was seen as an asset in setting the Japanese free of discrimination. It was also used as a means of "us against them" in that it posited Black Americans specifically as lazy and creators of their own poverty; therefore, Asians became seen to be almost the opposite of Blacks following the logic of, "See, they [Asians] are not successful. Why aren't you?" Such a neoliberal (business-minded) viewpoint is still in operation today. This viewpoint seems to have spread to Asians in most East Asian countries such as China, South Korean and Japan. The connotation is that Asians are good enough to be almost American. This image of the model minority is projected into various comments that can be very isolating and deny the success of a student on their own terms. Their abilities are viewed to be almost "magical". Attached to the idea of "almost good enough to be American" is the idea of forever being viewed as a foreigner. Students who are Asian American often have to explain their presence in the 
classroom and answer the question, "Where are you from?" In this example, Asians are depicted as American, but never truly a part of the community despite historical evidence to the contrary. Asians also experience these racial stereotypes in schools (Kim \& Yeh, 2002; Park, 2011). These stereotypes can emphasize specialized abilities such as math, science or the arts (Tashiro \& Conrad, 2009; Wong, 2012). For example in a personal experience, a fellow teacher believed that my daughter was good at music because it was "in her [Asian] blood." Constructing an "exoticism" of Asian girls continues to be common. In a recent comment from a parent, an Asian adoptee was referred to as a "China doll." The idea of a doll is one that is an object that is both compliant and docile. Asian children are expected to work hard, study, and be obedient at all times. When this illusion is placed on Asian students, the inability to achieve it can cause stress and selfdoubt (Lee, 2004). Other less savory stereotypes also invade Asian selfhood. Asian girls are 'exotic' and Asian boys are 'weak', unless of course they do martial arts (Kubo, 2010; Lin, Kwan, Cheung, \& Fiske, 2016; Zhang, 2015). When an Asian doesn't fit these stereotypes, which is often the case, dissonance and a sense of failure occurs.

The effects of racism through microaggression and stereotypes that this group faces, both in and outside of school, are frequent and stark in Appalachia (Sue, 2010). Microaggression, which means subtle yet harmful bias, is manifested through verbal and nonverbal slights, snubs or insults. It can be intentional or unintentional, antagonistic or insulting, and is focused on the objectification (also called "othering") of a group of people. The main difference between racism and microaggression is that racism is perceived as more overt and identifiable whereas microaggression is more covert and often framed as a compliment. An example would be, "You speak very good English," 
or, "Where are you from?" when addressing an Asian American (Sue, 2015). Other stereotypes about Asian Americans that can fall under the heading of a microaggression are: "model minority," "invisibility," "all Asians are alike," "second-class citizen," "perpetual foreigner," and the "over-sexualization of Asian women" (Lin, 2010). Asians in school are subjected to the stereotypes of being good at math or music, not that they work hard to get that way (Chai \& Weseley, 2017; O'Connor, Hill, \& Robinson, 2009). Other adoption stereotypes that create conflict are words such as "lucky," "saved," "chosen," "given up," "unwanted," "abandoned," and "real parents" (Javier, Baden, Biafora \& Camacho-Gingerich, 2007). These words have the strength to disempower this group of students.

Given the literature on model minority students' experiences around race and the potential of rural Appalachia creating a unique context through which to understand the challenges and opportunities for TRAAs, I propose to address the emergent nature of the literature through the following research questions that structure this paper:

${ }^{\circ}$ How do Transracially Adopted Asian (TRAA) youth see themselves within the contexts they negotiate in rural Appalachia?

${ }^{\circ}$ How do teachers and administrators position TRAAs?

Next, I lay out the historical and contextual elements that serve as background for my research, beginning with my own story.

\section{Autobiographical Statement}

Although I grew up in Appalachia, until now I did not acknowledge its effects on my perspective. I started life as the daughter of a single mother in the wrong side of town, the sister of two brothers and two sisters, the youngest child. I went into education at a 
time when there was money to send poor, disadvantaged White youth to local colleges. I became a teacher, a profession recognized to be a bridge out of poverty. I traveled and was able to live abroad for a year through a Rotary International Scholarship. I became more educated and got married. Most recently, I have had children of my own. Children have their own story, yet each one has helped to shape my story. One child is by marriage, a stepson; one child is by birth, a preemie son; and one child, by international adoption from Korea, is a daughter. It is the last child that has been the constant in this doctoral journey and the motivation of this dissertation study of educational opportunities for internationally adopted youth in rural Appalachian Maryland.

I have had many experiences with education. Perhaps the earliest was reading to and playing with the children I babysat. I was a lifeguard and taught swimming lessons for many years. My most recent and longest position has been as a public school teacher for 33 years. As a mother of a transracially adopted child I have modified our home to be welcoming to my daughter. I have gathered pictures, books, food, clothing and other artifacts not only of her culture, but of other cultures including our family culture. I have worked to keep cultural mentors in her life who share her birth culture. I have worked to meld spaces of navigation for her and us as a family. I have watched as my community has changed over the years. It has gone from being an all-White district to a district reflecting a hint of the growing diversity of the nation. My daughter is part of this change. Peak County (a pseudonym) is a small geographic area (647.10 square miles) that 29,460 residents call home. Within the county, $.5 \%$ of the population (147 individuals) are Asian (United States Census Bureau, 2015). Of that percentage, at least 22 are adoptees from Asia. They constitute $15 \%$ of all Asians in the county. With the changing demographics 
of the community, I have noticed increased racism, microagressions, and bullying. I have come to question how the middle and high school space, the space I have a front-row seat to observe through my teaching, influences Transracially Adopted Asian (TRAA) children.

\section{Background Related to the Problem}

The following historical information provides a background for understanding transracial and transnational adoption historically and in its contemporary state. This is important for placing the experiences of TRAAs that I have researched and report on in Chapter Four. The historical and contemporary trajectories of adoption also provide a background for understanding how adoption creates a nested context for looking at the specific community, home, and school contexts in which the participants in this study are situated.

\section{Historical Roots of Stereotypes of TRAAs}

Although it is not well understood, the roots of stereotypes of TRAAs run deep through the history of the adoption enterprise and its logics of the child and meanings of childhood. Specifically, it has been understood that immigrant children are children "at risk", whose families are deficient and unable to provide them with proper care in line with American norms of socialization (Sokoloff, 1993). The following section examines three movements tracing the history of adoption for TRAAs in the U.S. as a means of historical support for the claims made related to the positioning of contemporary TRAAs.

Orphan trains 1854-1929. Adoption has long been a part of the fabric of American rural culture. Perhaps the most famous exodus of adoption to rural areas were the Adoption Trains to the American West between 1854-1929. Started by minister 
Charles Loring Brace, the motive was to provide homes and education to the poor, immigrant, homeless, hungry and often abused youth that wandered the streets of New York City in the 1850's (Cook, 1995; O'Connor, 2017). The orphans, children of poor immigrants, were seen as a "plague to be dealt with" and eventually removed from overpopulated areas through the trains which carried them West to newly forming states and territories that were largely rural (Cook 1995). This was, perhaps, a first step to "Americanize" these children. The orphans were matched with Catholic families; the idea was that they might flourish in open rural spaces, receive a good education, and training in "wholesome" work (Administration for Children \& Families, n. d.). In essence, the purpose the orphan trains was to "save" children both physically and spiritually. Eventually, children from the city would be sent to rural areas in 47 states (McCullough, Waletzky, Marritz, Steele, Bacon, Edward Gray Films, Public Broadcasting Service, \& Gray, 2011).

Increased regulation 1930s-1950s. Due to unscrupulous practices, and sometimes abusive treatment of adoptees, greater regulation of adoption and the emergence of social workers occurred (Cook, 1995). Parents looking to adopt during this period experienced more stringent criteria (Nelson, 2009). Racial, cultural and intelligence matching were well established (Esposito \& Biafora, 2007b). Adoption became a narrower, more difficult process.

Transnational adoption, or adoption across the borders of two countries, began to occur after World War II. Children of soldiers, some left without families, were adopted from European countries and Japan, oftentimes via a proxy adoption (Herman, 2012). A proxy adoption allowed a representative of the adoptive parents to initiate the adoption in 
the home country of the child and then transport the child to new parents in the US. This geopolitical pattern was to continue with other conflicts with which the US was involved. It became more prevalent with the Korean War, but also included Vietnam, the Philippines and Cambodia to name a few (Nelson, 2009).

The rise and formal establishment of transracial adoption and specifically Asian adoption is linked to the 1955 adoption of eight Korean children by rural farmers Harry and Bertha Holt, who went on to found the Holt Adoption Agency (Administration for Children \& Families, n.d.; Holt International, 2016; Meese, 2002; Nelson, 2009). Transracial adoption from Korea has been occurring since 1948, midway through the Korean War. From 1948- 2009, "roughly half of all individuals who were adopted as children outside the United States have come from Asia... South Korea alone accounts for $25 \%$ of all children ever adopted from abroad" (Tuan \& Shiao, 2011, p. 4). A total of 244, 539 children of Asian descent have been adopted into the United State since 1953, with 166,832 of these children being adopted between 1999-2013 (Johnston, 2014).

Expansion 1960s-1980s. Adoption of Korean children became prevalent, as previously mentioned, in part because of the Holts. People from across the U.S. became enamored with their story, and asked the Holts to help them adopt too. The Holts went on to create their own adoption agency that was less demanding about who could adopt. This loosening of the rules made transracial and transnational adoption for U.S. parents a viable solution for family creation (Melosh, 2002; Nelson, 2009).

During the mid-1970's, Native American communities spoke out against the increasingly prevalent practices of the adoption of Native American babies by non-Native parents (Herman, 2008). In 1978, the Indian Child Welfare Act was passed, making clear 
that tribal courts have jurisdiction over matters pertaining to Native children (Herman, 2008). Parents who previously may have sought to adopt Native American children turned to the prospect of adopting Asian children (Jerng, 2010).

Contemporary adoption 1990s-present. From 1999 to 2016, there were 114,825 adoptions from East and Southeast Asia of a total of 267,098 worldwide. This represents $42 \%$ of all international adoptions (Bureau of Consular Affairs, 2017). There are currently between 120,000 and 160,000 Korean adoptees residing in the United States, ranging in age from infancy into the fifties (Tuan, 2011) and another 78,257 more recent Chinese adoptees from 18 months to 18 years of age (Bureau of Consular Affairs, 2017).

Originally, Asian adoption agencies were rescue missions to save Amer-Asian and/or orphaned children of homogeneous nations from neglect, life on the streets, and the after-effects of war in their familial countries (Esposito \& Biafora, 2007a). The Amerasian children were looked upon as defective because their parents were of different races. More recently, transnational adoptions were criticized as channels of American exceptionalism imbibed with the Christian ethic of saving children from dire circumstances (Quiroz, 2008a, 2008b). They also reflect dropping birthrates among White middle-class families in the U.S. (Schuster Institute for Investigative Journalism, 2011).

Whereas Korean adoption was originally supported by the after-effects of war, Chinese adoptions increased with the initiation of the "One Child" family policy, which allowed couples to have only one child per family without financial penalty. This idea was initiated to curb the dramatic rise in population (Tuan, 2008). The preference for male children in China is due to social and cultural factors. For example, sons carry the 
family name and take responsibility for their parents in old age (Dowling \& Brown, 2009). Poor farmers could not afford to keep their female children due to government penalties and insufficient welfare support (Dowling \& Brown, 2009; Johnson, 2016; Tuan, 2008). In the eyes of many rural, low income Chinese families with baby girls, doing the right thing for the child and the family would be to make sure their female child would be taken into an orphanage, and then to establish a male heir (Johnson, 2016; Lihua, 2001; Meulenberg, 2004).

U.S. international adoptions have steadily decreased from 1999 (with 22,726 recorded adoptions) to 2016 (with 5,370 recorded adoptions). Adoptions from Korea have dropped from 1,628 in 2005 to 260 in 2016. And adoptions from China have decreased from 7,903 in 2005 to 2,231 in 2016 (Bureau of Consular Affairs, 2017).

The numbers of Korean adoptions started to fall in 1988, after the Winter Olympics were held in Seoul and a controversial news story by NBC's Bryant Gumble announced that South Korea's "number one export was its children". This story created public humiliation for Korea (Dolan \& Frost, 2017; Lewin, 1990; Liem \& O'Brien, 2000). This, in turn, led to changing regulations in birth countries to promote in-country adoption of infants (Voigt \& Brown, 2013). Many Korean and Chinese children adopted by American parents are now older at the time of adoption and may have physical and/or cognitive disabilities (Dolan \& Frost, 2017; Javier, Baden, Biafora, \& CamachoGingerich, 2007). This has implications for the present-day education of children adopted transnationally and transracially. The number of children adopted internationally from Asian countries is shrinking. Instead of seeing more individuals like them mirrored in their classrooms, TRAAs are seeing fewer peers. 
In China, beginning in May of 2007, changes in the criteria for adoption have limited the ability of Americans to adopt from this nation. More stringent regulations include a younger maximum age for parents and no longer allowing single mothers to adopt (Dowling \& Brown, 2009). As international adoption from Asia and other parts of the world grew and spread, global policies were adopted in the interest of child protection. The Hague Convention was established in 1993 and the institutional application of its policies commenced in 1995 (Bureau of Consular Affairs, U.S.; 2016; Hague Conference on Private International Law, n. d). This convention established many boundaries and requirements by the home country of prospective adoptees, their adoption agencies, the adopting country, its adoption agencies, and adopting parents. The purpose of this convention was to ensure that inter-country adoptions take place in the best interests of the child and with respect for the child's fundamental rights (Bureau of Consular Affairs, U.S., 2016; Hague Conference on Private International Law, n. d.). As a result, standards have been established on the pre-education of parents who are adopting transnationally. The Hague convention ushered in a transition from assimilation to cultural preservation that will be shown in more detail later.

The next section of the chapter explains in detail what is known about education for TRAAs and points to the need to study in-depth the school experiences of adolescents.

\section{Literature on Adoption and Education}

There are many factors that affect schooling for TRAAs. Very few studies focus on this topic. Studies have explored issues of transracial adoption for African American youth and Asian American youth in psychology, sociology and counseling (Davenport, 
2013; Goldstein, 2002; Raleigh, 2016, Schofield, 1982). TRAAs are not specifically mentioned in these studies, despite the fact that transnationally adopted Asian Americans from East Asia and Southeast Asia represented $42 \%$ of all transnationally adopted children from 1999-2016 (Bureau of Consular Affairs, 2017).

There is little if any research that focuses specifically on Asian children adopted into Appalachia and other rural areas from the educational perspective. Studies of the education of transnationally adopted youth have focused on urban and suburban locations, despite the fact that a great number of these types of adoptions have historically occurred in Appalachia and other rural areas (Appalachian Regional Commission, N.D.; Carp, 2009, Child Welfare Information Gateway, 2018; Myers, 2008). Although there is literature and research about international adoption and Asian adoption, most of that research focuses on post-adoption developmental outcomes, for example psychological adjustment, self-esteem, academic achievement, and behavior problems (Vashchenko, D'Aleo, \& Pinderhughes, 2012).

Witenstein and Saito (2015) have explained that studies about TRAAs are present in the fields of Ethnic and Cultural Studies, Counseling, and Psychology, along with the Adoption literature and Identity Studies, but not in education research (Witenstein \& Saito, 2015). This suggests that research as proposed in this study is necessary to help to close this gap.

As an educator, I recognize that teachers have complex and challenging jobs. Unfortunately, rarely if ever have they been educated either formally or informally about adoption and how it might impact their students' learning. Smith (2006) states that a teacher's lack of knowledge of international adoption can have unforeseen consequences 
for TRAA's. Teachers trying to create in-depth questions and lessons connecting to children's lives may inadvertently create uncomfortable situations for TRAAs through projects such as creating a family tree and mapping genes. Smith goes on to clarify that teachers need to be constructive listeners to transnationally adopted children. One suggestion is to provide open questions that students can answer in terms of race, culture or ethnicity from their own perspective instead of directed questions that may be harmful. Questioning how they as TRAAs would feel if they returned to their birth country (Smith, 2006) would be one example of this. Although articles and personal conversations with adult adoptees have indicated that these situations do occur, educational studies are hard to find through research. This is yet another indicator of the need for more scholarly research about this phenomenon. Another important facet of this research is the importance of teacher education to support their understandings of TRAAs and how best to support them.

In the next section I will discuss the context of the research, the people, community and the schools that form the study. The context informs the rationale for conducting this study.

\section{The Context of the Research}

In order to fully understand the problem of international adoption of TRAAs in rural Appalachia, and particularly the challenges of education in rural Appalachia, it is important to consider the context of the region in some depth. Appalachia, as defined by the Appalachian Regional Commission (ARC), is a 205,000-square-mile region that follows the spine of the Appalachian Mountains from southern New York to northern Mississippi. It includes all of West Virginia and parts of 12 other states: Alabama, 
Georgia, Kentucky, Maryland, Mississippi, New York, North Carolina, Ohio, Pennsylvania, South Carolina, Tennessee, and Virginia. Forty-two percent of the region's population is rural, compared with 20 percent of the national population. It includes 420 counties in 13 states, extends more than 1,000 miles, and is home to more than 25 million people.

Once considered vastly poor, Appalachia has made considerable strides in recovery, reducing the overall poverty of the area from $31 \%$ in 1960 to $17.1 \%$ in 2015 . Peak County, the county under study, is a "transitional county" (ARC). A transitional county is one identified as being midway through the process out of poverty, of moving from a weak economy to a stronger economy. As we shall see later on in this chapter, however, complex economic changes significantly impact education and community life in Appalachia and in Peak County.

According to McGrath and Brennan (2011), because Appalachian communities have a strong sense of family and community, a high value is placed on family over individual goals. Families in Appalachia are diverse, but often include large extended families. Babysitting, financial help, and meals are some benefits of the communitarian orientation of these families. Even those who move away to larger cities often continue to maintain close connections to family and return for extended visits, reunions, or other celebrations (Newsome, Hennon, Peterson, \& Wilson, 2008). One example of the community "feel" of the region that I see regularly has to do with how locals think and claim spaces. Locals will say, for example, "I am from Peak County, Maryland.” Even though there are specific towns throughout the expanse of the county, people are "from" the whole county. Adoptees from this area also, in my experience, refer to themselves 
this way. Local families, such as the one I married into, claim family from all over the county. We are all family, we are all from the same place. Perhaps due to the isolation of the county itself and the isolation between residents because they are spread between the hills and valleys this connection to the space of Peak County maintains a sense of "wholeness" for the area residents.

The converse of this idea of oneness is the idea of "outsiders" penetrating the county. Perhaps due to isolation and exploitation in Appalachia, a general fear of the outside coming into the area is also a part of Appalachian culture (Anglin, 2016). Often established in hard to reach areas, Appalachia has both benefited and been harmed by this isolation. The benefits include self-reliance and a community of family. Everyone knows and takes care of each other. The harm would be the lack of new ideas but to a greater extent the manipulation of natural resources and hollowing out of people, that have left the area more depleted and less able to be self-reliant (Carr \& Kefalas, 2009, 2010; Russ, 2010).

Peak County, has been affected by both isolation and exploitation. Very few major roads come into the county with only one major highway cutting through a quarter of the county, making that area of the county comparatively more economically independent. This Western part of the county also has the more modern schools, newly built or newly renovated. Many major industries in the Eastern sections of Peak County have closed or are slowly dying. With the economy lost, schools in the Western section have also suffered a loss of students and income via fundraising. Areas around the manmade lake have seen the building of "McMansions" and an abundance of seasonal visitors as well as an influx of seasonal income. Visitors are alienated by locals who use 
the term "touron" - a cross between tourist and a moron. This exacerbates the feelings of outsiders being harmful to this small Appalachian community.

Peak County has been a long-time vacation spot but it is also home to coal miners and farmers, and it has provided manufacturing jobs in the eyeglasses industry. As these workforces have either been reduced or moved out completely, the economics of the county have also taken a downturn. Groenke and Nespor (2010) describe the neoliberal and globalizing changes in rural areas as an economic shift from higher paying labor jobs such as manufacturing to service industry jobs such as Walmart. This effectively lowers the economic standards in the area and increases unemployment (Schafft \& Jackson, 2010). Shifts in economic conditions have also led to an increase in drug use and the breakdown in families (Groenke \& Nespor, 2010). The draw of the recreational area and the college continues to bring more citizens to Peak County from much broader and diverse backgrounds and ethnicities. These patterns might be an important factor in the county under study.

\section{Community Challenges}

Because of these influences, teachers in Appalachia are seeing changes in their school populations and communities. The decrease in population and tax base in Peak County has caused schools to close and communities to shift identities. As teachers retire, staff is downsized. At one time, the school population was over 5,000. It is now closer to 3,000 (Maryland Department of Planning, 2017). International adoption alone does not cause the racial changes in Peak County. Some families are returning after having lived away; they are like "boomerangs" as Carr and Kefalas (2010) say. Some of these families have become interracial prior to returning. The way of life, especially the availability of 
outdoor recreation activities, has pulled families to the area of Peak County. Finally, the ability to be more involved in community activities and part of a quieter community is a draw for many families (Cromartie, Von Reichert \& Arthun, 2015).

In Peak County, TRAAs are situated in a predominantly White racial setting (Table 1), which, as mentioned, is very gradually shifting over time to become just slightly more diverse in terms of race/ethnicity. Asian adoptees represent a small but significant population in Peak County. The Appalachian context poses challenges for them. 
Table 1. Peak County School Demographics

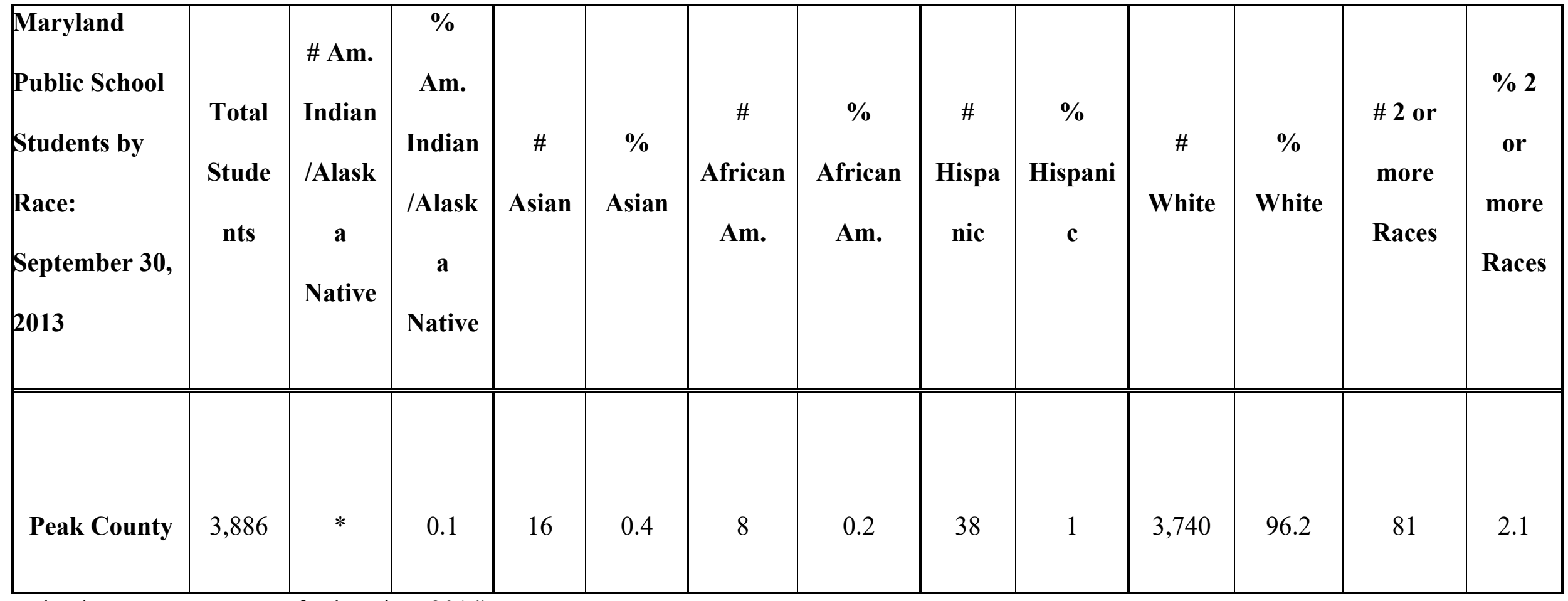

(Maryland State Department of Education, 2014). 


\section{Transracially Adopted Asian Students (TRAAs)}

Although the challenges that TRAAs face at school are many, there are also potential assets of rural and Appalachian schools that are supportive of TRAAs. A major strength is their ability to make a positive impact on their students' lives. As Schafft and Jackson (2010) suggest, rural schools have served key roles historically as centers of social and cultural meaning making. They have helped to maintain unique local traditions. Schools are, furthermore, the sites of civic consciousness and activity, and intergenerational identities and experiences. Along these lines, in a study completed in Arkansas by the Rural School and Community Trust in 2002, researchers found that not only are the small schools in rural areas important centers of social activity, their small size supports students well. Pedagogy, as well as the training and education of the teachers in the community, can become the driving force to enhance the lives of the diverse students.

\section{Adoptive Parents in Appalachia}

Being a parent in a rural Appalachia county has challenges attached. As mentioned, Peak County is a "transitional poor" county with a limited community of Asian residents. As such, parents are positioned to advocate for TRAAs' access to cultural and ethnic resources. Parents in general are a major contributor to the formation of children's identities and social and emotional development. For years, parents have been the educators about race, culture and ethnicity for their children (Baden, 2007; Bartholet, 2006; Selman \& Milbrandt, 2015). Historically, adoptive parents have had a unique role in this process. Initially, parents were told by agencies to "assimilate" the child into the family and that the child should forget birth culture and become 
"Americanized" (Adams, 2002). However, it is now becoming apparent that assimilation can be harmful to TRAAs development. For example, Callahan (2011) illustrates that when racial identity development is ignored, TRAAs feel as if they are "stumbling through a maze blindfolded" and "initiated into White society, shut off from birth culture."

Parents often do not understand the harm that an assimilationist stance can hold. More recently, adoptive parents must study children's rights and "best practices" in raising an international child (Hague Conference on Private International Law, n.d.), as well as post-adoption services. In this new framework, assimilation has been replaced with more balanced views of the importance of recognizing race, culture, ethnicity and adoption. Parents of transnational adoptees speak of learning how to code switch or code create in dealing with their new status as a multicultural family (Davenport, 2013). Code switching means recognizing the idea of the "White" language used in the home and becoming more culturally inclusive (Davenport, 2013; Fogle, 2012). This includes being aware of the dominant culture as reflected in the social arena of digital space, media and print materials; exploring issues of race and adoption; evaluating the local neighborhood, community and activities based on the needs of the multiracial family; learning to confront racism; helping the child learn more about their culture; creating genuine relationships with persons of color; and learning about racism, prejudice and White privilege (Callahan, 2011).

Prior to the advent of the internet, the agency within the U.S. that facilitates the adoption would often help parents explore the culture of their adoptive child through limited counseling, books and printed papers. As mentioned earlier, adoption agencies 
now must provide access to pre-adoption classes as well as show evidence that these have occurred before an adoption can take place. Within these classes, culture, race and identity, along with possible support and solutions, are topics of discussion. As waiting parents in Appalachia, my husband and I would travel four hours one way to these meetings, but most of our education came through the traveling social worker from our agency. Mentorship and building a supportive community of adoptive families is very important in the process, and receiving agencies will work with parents to help establish connections with experienced adoptive parents. Prospective parents in Appalachia struggle to form an adoption community because of their geographic location, but often rely on the Internet and participate in news groups, blogs, Facebook and other online resources, for education on international and transracial adoption. Finding adults who are racially matched mentors for TRAAs currently living in Appalachia can be challenging and often require travel outside of the local area. Parents are encouraged to educate teachers about the culture of their child, although it is unknown how often these relationships occur.

\section{Local Education Policy}

Within the state of Maryland, it is a requirement for each county/district to develop a five-year plan for educational outcomes. This document is called the Master Plan. When looking at Peak County Schools' Master Plan, it is clear that the county does not have a program that actually focuses on teacher or student diversity or interactions. The plan itself includes: (a) field trips to Amish cultural events in the county and region, (b) cultural events in the metropolitan areas, (c) Native American heritage, (d) traditions and history into their curriculum, appropriate activities during Black History Month, Hispanic 
Heritage Month, and Irish History Month, and (e) multicultural opportunities to students through dance or theatrical opportunities as they are available (Peak County Public Schools, 2015). The plan shows exposure to different cultures, but there is little indication in this framework that the county has a plan to teach in culturally sustaining ways that embrace the diversity of the students themselves, including TRAAs. Much of what is described is a "fun, foods and festivals" approach. Although being introduced to different cultures and ethnicities is a good thing, it can also lead to the construction of stereotypes that cause more harm to those who do not fit those stereotypes. Visiting, watching, and viewing others from the outside looking in cultivates an atmosphere of “other," "abnormal," "different," and "less than" (Gay, 2000). This approach also creates cultural homogenization, which means absorbing a culture into the dominant majority (Zulfikar, 2016). Cultural homogenization is problematic because it erases the voices of individuals who are not from the dominant culture.

\section{Teachers}

The teachers in Peak County are all White. A colleague recently told me, "I don't see color." Another staff member said, "We really don't have those [race] problems here." Although this might sound progressive in some ways, the colorblind ideology expressed at my school is actually dangerous because, "This is how whiteness works: the privilege and luxury of whiteness involves 'the option [for White people] to confront race or to avoid it"” (Flintoff, Dowling, \& Fitzgerald, 2015, p. 561). Teachers' abilities to identify with and discuss race with students in a classroom is similar to what White parents of TRAAs face when trying to speak to this same topic. From the movie “Adopted: We Can Do Better": 
As White people, nobody taught us how to talk about race. We're afraid.

I'm afraid ... I'm going to be seen as a racist... I'm going to make mistakes. I have very little experience ... I don't really know how to do this. (Greene, \& Parsons, 2008)

Race is not the only area in which rural and Appalachian communities experience discomfort. Becoming more common in schools as well are LBGTQ+, and immigrant families. Some teachers arrive in public schools from universities that required them to take coursework, perhaps one or two classes, in multicultural education. Yet multiculturalism in rural and Appalachian communities is an emergent field. Furthermore, specific diversity knowledge related to TRAAs is important for teachers in Appalachia, yet no education or professional development in that area has been available. Adoption agencies have developed resources for educators using a culturally relevant perspective (CHLSS, 2017; Holt International, 2016; Post Adoption Support Service at Relationships Australia (SA), 2009). These resources do not just arrive in teachers' hands and often just sit on websites on the internet unused.

\section{Summary}

This study specifically looks at the lived experiences of two TRAAs in Peak County. Within this chapter is outlined the historical geopolitical progress of adoption, its effect on present day TRAAs, and the roles that adoptive parents have played. Also shared is information on the teachers within Peak County and the state system that not only influences the local school system but the spaces that TRAAs occupy. Within the next chapter, Third Space and additional critical and socio-cultural educational theories, the contextual lens for this study, will be explored in depth. 


\section{Chapter 2: Conceptual Framework}

This chapter explains the conceptual framework for the dissertation. Many academic fields concerned with supporting the transracial adoption (TRA) experience have sought to explain how transracial adoptees have created a space of belonging within a broader culture that is not their birth culture (Hubinette, 2004, 2007, 2009; Witenstein \& Saito, 2015). The organizing concept for such studies is called third space theory.

\section{Third Space Theory}

Third space, as originally envisioned by Bhabha (1994), derived from his study of post-colonialism. In his published work The Location of Culture, he brought forth the idea of how cultural discourse was able to adapt and create a hybrid when two diverse cultures communicated although this was not always possible and quite complicated because of the role of the broader social structure. Third space theory idealizes the awareness of hybridity. It is a socially constructed space, not a physical space. Before addressing third space theory and its implications, I would like to take a step backwards to conceptions of neoliberalism and its influences on society because it presents significant challenges to this project.

\section{Challenges of the Neoliberal Society}

Third space is created within the constraints of the broader culture, which since the 1980s has increasingly moved towards a global neoliberal market economy; this system affects every aspect of daily life (Carter \& Davila, 2017; Hübinette \& Tigervall, 2009). A search of the term neoliberalism turns up a definition that it is an "economic and social idea that favors the free market" (Smith, 2019). In essence, less regulation of the 
market will take care of us all. In social arenas, this translates to a commodifying of the people and institutions that are within this free market. It is the wielding of power to keep control of these commodities and affect change for those in power. This reasoning has had a direct impact on the educational system in the U. S. and in turn the governing districts, schools, employees and the children within the country.

Neoliberalism has penetrated our schools with ideas of what "success" looks like. Students' academic proficiency or success is demonstrated through state and local tests. Those students and schools that are able to perform to the standards set by government, not educators, are judged to be successful. Those schools that are unable to meet expectations are put on probation and in some instances government take overs in the form of charter schools replace the public school. Vouchers, another form of commoditization, allows parents to remove their student and place them into a more successful location. This process takes money from the unsuccessful school and places it into the successful school by way of the formula of per student capital. Often these unsuccessful schools are in economically poor areas in which resources are historically low or nonexistent (De Lissovoy \& Cedillo, 2016).

Another effect of neoliberalism is its outlook on children of color and low-income children and families. It exposes a "blame game' of declaring a deficiency in children who from the onset do not have access to the same quality of materials, buildings and teachers (Gorski, 2013). Generally, these schools may be dilapidated, have few newer books, and are understaffed. People of color are looked at through a deficiency lens and seen as less capable than others. 
Because local administrators are charged with being the managers of these districts and schools they are influenced by a government-controlled bureaucracy of commerce and success. They need to control issues and have success commodified in order for it to be reflected in the data-driven atmosphere that neoliberalism runs on. This again leads to the focus on punishments, which disproportionately position these students as in need of punishment (De Lissovoy \& Cedillo, 2016). Teachers, as a result of these and other influences of neoliberalism, will consciously or subconsciously react in similar ways as their principals towards their students by also adopting a deficiency view of students and accept the commodification of their role in education. Students, as a result of these practices, will often fall into one of two roles. They will become either the "prize commodity" or the "undervalued product" viewed as defective.

Recognizing the challenges of neoliberalism to contemporary education, the main framework of the dissertation builds from Bhaba's (1994) notions of third space as described above to provide a practical framework for understanding the TRAA child. Figure 1 below shows how the chapter is organized toward its goal of explaining how TRAAs are situated in my work and the role of education in their development.

\section{Third Space}

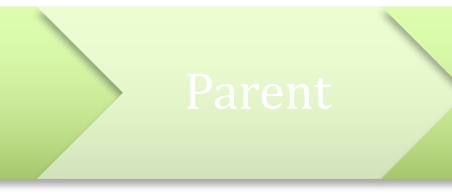

Figure 1. Organization of the chapter.

The content of Figure 1 is actually more fluid than it appears. It is difficult to represent these complex ideas in a diagram. Indeed, there are intersections among the 
four parts of the chapter that I must present sequentially, due to the two-dimensional space I have to work with.

Adding to my definition of third space thus presented, it is important to recognize that it also can be thought of as potential resistance and possibility for the child's transformation within the constraints of neoliberal schools and society. It has been used in popular studies of TRAAs (Hübinette, 2004; 2007; Hubinette \& Tigervall, 2009). According to this literature, in considering the transracial adoptee, the first space would be the native cultural home. The second space would be the imposed structures of the preeminent culture of the land. In the U. S., this preeminent culture exists through the postcolonial structures of school, politics, church, and businesses that are often White. The third space is the place where cultures meet and construct shared meaning, a hybrid of the two or more diverse discourses (Bhabha, 2012; Rutherford, 1990; Wilhelm, 2010; Witenstein, 2015).

\section{Third Space and the Child}

For TRAAs, third space is the place where they negotiate who they are culturally, racially, ethnically, and personally within a context. It is their identity. Third space is also where they live every day (Hübinette, 2004; 2007; Hubinette \& Tigervall, 2009). TRAAs' native first space is not truly their first space (Agustin, 2017; Hoffman \& Peña, 2013; Layborn, 2017; Wind, Brooks, \& Barth, 2007). They have been removed from their native first space and are thrust into negotiating it as well as the new first space of their adoptive home. Upon arrival in this space they are becoming acclimated to new sounds, sights, tastes and feelings all in one traumatic beginning (Frank, Hochman, \& Child Welfare Information Gateway U.S., 1990). These children often have gone through 
further trauma prior to adoption of being in more than one home. Some children have physical disabilities and others have emotional disabilities (de Haymes, \& Simon, 2003; Dole, 2005; Wind, Brooks, \& Barth, 2007). All TRAA children have acclimation issues whether seen or unseen (Agustin, 2017; de Haymes \& Simon 2003; Dole, 2005; Iyall, Smith \& Leavy, 2008; Langrehr, Yoon, Hacker, \& Caudill, 2015). Figure 2 below shows many of the complex ecologies discussed throughout this dissertation that TRAAs may be situated within. These add challenge yet also possibilities when considering how third space might be socially constructed.

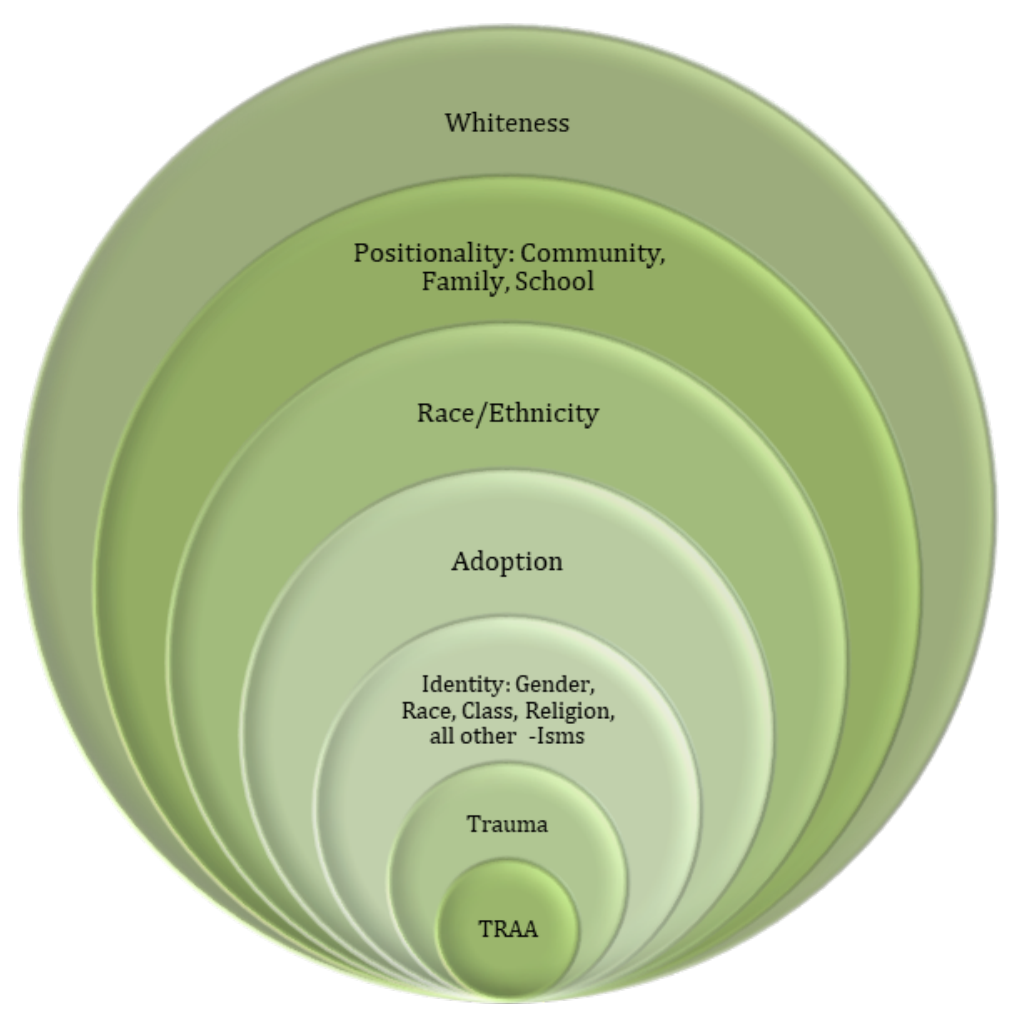

Figure 2. TRAA children's potential ecologies. 


\section{Third Space and the Family}

When a family adopts transracially, they automatically become a part of generated third space. This can be visualized in Figure 3 below.

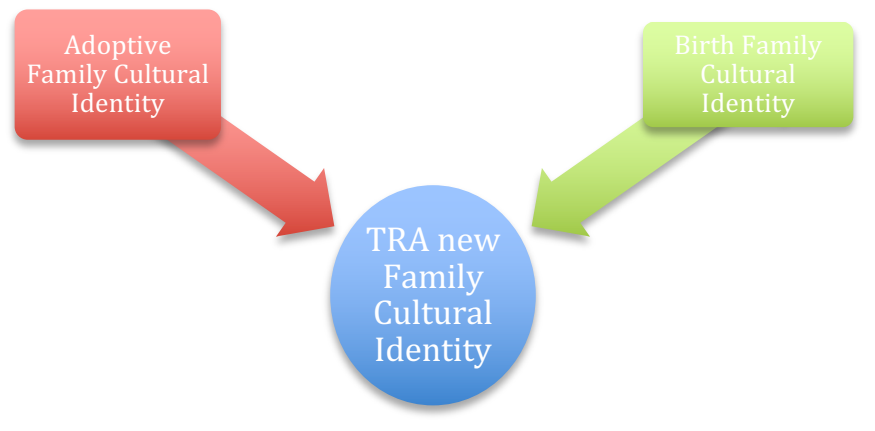

Figure 3. Family as a third space.

Adoptive families are comprised of their own homeland culture, their first space. The child comes with a birth culture, whether the child knows it intrinsically or not, the child's first space. The child usually "looks" like this culture. Adoptive families are normally directed to mix this culture with their own by the placing adoption agency creating a third space where discourse can be found (Callahan, 2011; Ferrari, et al., 2015). Generally, even in the most culturally aware families who have adopted transnationally, TRAAs are still not physically living with a family that is culturally, ethnically, or racially like their birth family. Families that adopt transracially that are not prepared for this new role as cultural liaison for their child could have detrimental effects on their child's identity, ethnically, racially and socially (Breuning, 2013; Ferrari, et al., 2015; Javier, et al., 2007). These effects include but are not limited to the emotional, physical, and psychological effects. These effects can manifest through a variety of ways including attachment disorders which can include depression, trust issues, suicide, social 
rejection, inability to assert themselves particularly in racially charged situations (both overt and covert), abandonment issues, and poor self-esteem (Callahan, 2011; Langrehr et al., 2015; Laybourn, 2017; Wood, 2009). Many of these can be carried over into adulthood and result in the inability to create stable, lasting relationships (Javier, et al., 2007; Schwartz, Luyckx, \& Vignoles, 2011; Kiang, Tseng, \& Yip, 2016). TRAAs are often the defendants of a culture they have had little interaction with, depending on the family dynamic (Breuning, 2013; Javier, et al., 2007).

Just as every person can be different in their perspective on TRAA, every family can also have differing viewpoints (Leslie, Smith, Hrapczynski, \& Riley, 2013; Reinoso, Juffer, \& Tieman, 2013). Some families leave ethnic/cultural identity totally up to the child (Leslie, et al., 2013). If the child wants to investigate their birth culture then the family will be open to it. Other families initiate discovery for their child, embracing all aspects of their child's birth culture. Some families fall in the middle of this spectrum of approaches to ethnic and cultural identity (Javier et al., 2007; Schwartz et al., 2011).

Moving through the years, TRAAs understand that they do not look like their parents, and that they do not originate in the now adopted first space (Baden, Treweeke, \& Ahluwalia, 2012; Hübinette, 2007). Their adopted first space is actually an acculturated first space (Baden, Treweeke, \& Ahluwalia, 2012; Ferrari, L., Ranieri, Barni, \& Rosnati, 2015; Wickes \& Slate, 1997). As children's interactions with the outside world increase through their imposed spaces of their parents and the communal spaces of their peers mix, a new hybrid cultural identity will be created (Dredger, Woods, Beach, \& Sagstetter, 2013; Pichardo, 2012). 
Until recently, TRAA adoptees who lived with their families in isolated areas did not have access to the same resources as those that lived in more populated areas. Now with the growth of technology and specifically social media, TRAAs can explore culture, race, and ethnicity in a variety of ways. Many TRAAs find and join groups that reflect themselves (Hübinette, 2004; 2007; Witenstein \& Saito, 2015).

\section{Third Space and the School}

Numerous articles, on creating a third space for students, in various academic subjects, have been written (Moje, Ciechanowski, Kramer, Ellis, Carrillo, \& Collazo, 2004; Phompun, Thongthew \& Zeichner, 2013; Wilhelm, 2010). Most often, third space theory in education is used to identify power struggles in classrooms leftover from postcolonial influences in schooling. In the educational context, first and second spaces are two different, and sometimes conflicting, spatial groupings where people interact physically and socially, such as the home and the school (Susan, 2009).

Third space theory has specific implications for education, and has much potential for informing TRAAs' education although this is an unexplored area at this time (Witenstein \& Saito, 2015). As they attend school even when faced with students who might look like them TRAAs still do not have shared cultural first space experiences since at many times these students have parents at home that do share a cultural first space (Kreider, \& Lofquist, 2014; U.S. Department of Health and Human Services, Administration for Children and Families, Administration on Children, Youth and Families, \& Children's Bureau, 2015). As they get to middle school, their bodies develop, and self-awareness is magnified, often they feel a tremendous disconnect from those around them (Farrell, Henry, Mays, \& Schoeny, 2011; Williford, Boulton, Forrest-Bank, 
Bender, Dieterich, \& Jenson, 2016). They question who they are culturally, ethnically and morally (Akos \& Ellis, 2009). With a disconnect from their original birth culture they can be recognized as both the harbinger of everything from their birth culture and expected to be hyper-aware of that status or the native immigrant who never belongs (Akos \& Ellis, 2009; Javier, et. al., 2007; Greene \& Parsons, 2008).

School can be a very confusing space, especially middle school (Wentzel, \& Caldwell, 1997). Students at this age are very "self" aware in that they are focused on where they belong, including race, culture, ethnicity, gender, sexuality and ability (García Coll \& Marks, 2009). They see difference and sometimes that difference can be a target for others (Akos \& Ellis, 2009; Farrell, Henry, Mays, \& Schoeny; 2011; Nishina \& Juvonen, 2005; García, Coll, \& Marks, 2009). Because no person is one designation, more facets of identity intersect with race and ethnicity. This intersectionality is explained as the convergence of race, class and gender but also includes disabilities, religion, etc. Intersectionality affects the experiences of all groups, including those on the "top" and "bottom" of the social hierarchy (Davis \& Brunn-Bevel, 2015). All of this impacts identity development and can be reflected in school relationships (Tigervall \& Hübinette, 2010).

The theory suggests that academic knowledge and power-laden discourses need not be in accord with an absolute and exclusive privilege, precisely because there is potential for the rearticulation of both academic and everyday knowledge as well as of the discourses constituted by the communities that produce such knowledge (Moje et al., 2004). Moje (2004) looks at third space in three different ways. She discusses it as: (a) bridge building between marginalized and conventional knowledge and discourses, (b) 
spaces of navigation that allow students to bring their funds of knowledge (Moll et al., 1992) from their homes to school to combine with school discourses to influence learning, and (c) a space where both home and school will produce new forms of learning (Cook, 2005). I will explain each of these in turn.

Bridge building. Millar and Warrican (2015) recognize that many teachers reside in second space, a postcolonial space where they are following historically developed ideas of education in line with neoliberalism. By stepping back from this ideology and opening up to accept other literacies from students, they can create bridges that can be part of the creation of a third space. By forming this bridge, TRAA students can use previous first space knowledge to aid in the construction of the classroom third space that allows equal discourse and aids in meaning making (Millar \& Warrican, 2015).

Education has always been a personal matter. Engaging students in conversations about their lives helps them to connect personally with students. Since students are not recognized as the same, it can be agreed that all TRAAs are also not the same as to how they construct meaning developmentally, emotionally, ethnically or racially. Conversations can lead to interactions within the classroom that enhance learning and create social justice learning, a.k.a. a third space.

This bridge consists of using students' funds of knowledge. According to Esteban-Guitart (2013), these funds of knowledge can be more clearly referred to as the students' funds of identity. As the name reflects, this goes beyond just what is learned in the home culture to include resources for curriculum and pedagogy that are also from the time period and lived experiences of the student. By time period, it is referring to the issues of the time of the child's life. For the TRAA the time period in which the child was 
adopted includes many factors such as age at adoption, length of stay in foster care, gender, physical or mental issues, age of parents adopting, age of birth parents, pre- and post-adoption courses for parents, and immigration status (Javier et al., 2007). Taken either individually or all together, these can create stress for the child that can be manifested in the classroom.

Also influenced by these time factors are the child's lived experiences. Prior to the 1990's, culture camps, though offered, may not have been accessible or of interest to parents. Influenced by the Hague Convention and supported by many adoption agencies, the idea of cultural preservation was promoted through culture camps and parent education. Culture camps are places that transnationally adopted children meet other children who have been adopted from the same country or area. They serve to not only introduce transracially adopted children to birth culture but to create a space where these youth can associate with children from families that resemble their own (Delale-

O'Connor, 2011). Certainly, whole family culture camps were not promoted. Today some families take advantage of these experiences while other do not (Baden, 2015; Baden, et al., 2012). One example of how this affects the lived experiences of the individual child would be the lack of knowledge of birth culture that a native of that birth culture would have even as a non-adopted immigrant.

Navigation through funds of knowledge. As a navigational space, third space is fluid in the classroom and allows students to feel respected. It allows students to bring their "first space" perspectives, in this case the knowledge they have gained as a TRAA, into the classroom. Another bonus of bringing home culture into the classroom is the foundation of mutual respect and value. Students see the value of the learning as it 
pertains to their own lives (Gliner, 2016). In this way, various viewpoints are used to understand and navigate concepts being learned (Levy, 2008).

González, Moll, and Amanti (2005) feel that the educational process is enhanced when teachers learn about their students' everyday lives. TRAA students arrive in classrooms as cultural hybrids of diverging degrees. One way to navigate the existing hybridity of culture is to get to know the students through ethnographic processes. These created spaces of navigations can be simple pictures from home that may touch on this hybridity by showing where the student embraces their racial, ethnic and cultural space with interactions with their birth land (Allen, 2007). These experiences may also show how integration within the home occurs. One example might be cooking a meal that is from their birth country but now a regular family meal in this country. This would be an example of the borderland that Bhabba (1994) discusses. For TRAAs these funds of knowledge are their cultural first space (González et al., 2005). This knowledge may be brought into the home through social media (Facebook, Instagram, YouTube, etc.) when the TRAA explores their birth culture (Millar \& Warrican, 2015).

Linguistic third spaces occur in the discourse humans conduct with others. In the classroom these interactions occur when students are able to understand a new concept. Teachers start with what they know, the funds of knowledge/identity, which the students bring to school, and incorporate it into new hybrid knowledge (Cook, 2015; Gutiérrez, Baquedano-López, \& Tejeda, 1999; Stevenson, 2015). An example would be the conversation between teachers and students when first teaching reading in Kindergarten. Teachers at this level will ask children to tell stories about the events in their home lives and put those to paper with the student. They construct meaning using student knowledge 
from their first space. Herrera (2016) suggests in the book Biography-Driven Culturally Responsive Teaching, to have students complete a Student Biography Card. On this card, students would share knowledge about themselves that would hit upon those life events and experiences that make up their funds of knowledge/identity. In this way, teachers can draw on these experiences to work towards creating third spaces in the classroom (Allen, 2007; González, et al., 2005; Millar \& Warrican, 2015).

Home-school relations. Third space can also be constructed between homes and schools. There are many ways to do this that may be useful to my interests in supporting TRAAs and all students through this dissertation study. In the article Fostering Collaboration Between Home and School Through Curriculum Development: Perspectives of Three Appalachian Children Lalik, Dellinger, and Druggish (2003) describe their investigations about bringing Appalachian life into an Appalachian school to not only enhance literacy but to enrich the lives of the students. They used the stories of the children themselves to make this happen. Within Appalachian culture, storytelling is a dynamic part of home literacy, which is these children's first space. Allen (2007) also uses these home-school relationships to foster relationships that enhance learning in the classroom that create a third space for learning.

Not only are the students in my study TRAAs, they are also culturally Appalachian. By getting to know families and forging connections from personal exchanges with families and not just assuming all families are alike, teachers can help build curriculum and assignments that enhance student learning by incorporating family knowledge. Both Herrera (2016) and Allen (2007) also concur with these strategies. Allen suggests the use of photography with students to showcase their home culture and 
to enhance not only reading and writing but engage the whole child and make use of their funds of knowledge. Herrera suggests working from the biography of the child to also create this welcoming space of learning for the student.

Culturally sustaining education. Cultural sustaining education stems from prior work in both cultural relevant (Ladson-Billings, 1995) and culturally responsive (Gay, 2000) education. Both of these pedagogies have asked teachers to learn about their students in the classroom, to relate to them and ask them to fit their culture into what is taught in the classroom. Culturally sustaining education asks for that too but just a bit more. Culturally sustaining education asks teachers to prioritize and make student culture the leading force in the classroom (Ferlazzo, 2017). This allows for sustaining minority cultures and the elevation of worth of those cultures. It is a way to uplift communities so they are not looked upon as a deficit to be fixed but as add-ons to enhance. It seeks to sustain a social justice platform. It also finds some roots in third space (Algava, 2016; Ferlazzo, 2017; Gay, 2000, 2008, 2013; Ladson-Billings, 1995, 2000; Novelli \& Sayed, 2016).

All third spaces deal with intersections of two different viewpoints or peoples and the creation of a space, a negotiated hybrid space that allows communication and exchange to happen. By working together and using funds of knowledge and culturally responsive teaching, a new third space might be developed that will allow TRAA students to thrive along with their peers. However, this may be challenging work. Third space in the rural and Appalachian context is easier to imagine from my experience as a teacher, mother, and longtime community member than it is to glean from the literature, as third space literature in the rural and Appalachian context seems nonexistent. 


\section{Additional Tools for Navigation}

Social positioning and border pedagogies are two additional theoretical tools that might be culled. While third space theory provides the broad conceptualization and constructionist possibilities for this work, additional tools may help educators understand everyday challenges that may "normalize" rather than transform the space of TRAAs.

Positioning. Poststructuralist theories of power show the relationship between power and knowledge, and how the former is used to control and define the latter. Because this context is understudied, I anticipated that I may need theoretical tools that examine constructionist possibilities within third space. What if there were examples of discursive or spatial positioning that challenged the formation of third space at home, at school or in the community? I wanted to have possibilities for challenging it.

Positioning is a poststructuralist tool that shows how language can be used to support identity formation through shifts in power dynamics in which one individual constructs themselves as "higher" or more privileged than another. Harre and Van Langenhoeve are social-constructionists that believe communication shapes identity. Intentional positioning speaks to the direction of the speaker to exude power over another. The idea of intentional positioning such as through the use of microaggression and stereotypes helps to understand the power of the words that shape TRAAs' perspectives of themselves and their position in the community and world writ large (Harré \& Van Langenhove, 1991, Van Langenhove \& Harré, 1994, 2010). This idea of intentional positioning also gives clarity to how school systems (including teachers, administrators and school boards local and state) use words through policies and practices to either aid and abet or dismiss the positioning of their students, particularly TRAAs 
(Harré \& Van Langenhove, 1991; Moghaddam \& Harré, 2010; Van Langenhove \& Harré, 2010). How groups and individuals see themselves within the community and educational institutions, the influence of cultural experiences, family and the world at large have important effects on students that may be hidden from view.

Specifically, a form of positioning called slippage fits with the literature on TRAAs' development and everyday experiences. In school policy and practice creation, often policies, guidelines, and practices are created with middle class White children in mind. Children of color, low income children, children with disabilities, non-English speaking children, etc. are not considered in the creation. This causes a "slippage" in the intent of the policies and how they might be received if these policies and the intent is unmet (Ellsworth, 1997). Another example of slippage is when the central administration of the state creates policies and programs far away from the local county, with different communities in mind. The end result is not what is expected or often needed in a rural vs. urban setting. TRAAs while they mostly live in White middle class families grow up in that culture, but are not phenotypically White and have their own birth culture as well as trauma and other unique challenges.

Border pedagogies. The final tool I present in this chapter is border pedagogy. Border pedagogy is "attentive to developing a democratic public philosophy that respects the notion of difference as part of a common struggle to extend the quality of public life. The notion of border pedagogy... links the notions of schooling and education to a more substantive struggle for a radical democratic society" (Giroux, 1991, p. 51). Such boundaries in education would include the recognition of what is safe and what is not to students of color. The same could apply to teachers and administrators as to the lines 
either presumed or imagined when talking about and acting on racial issues. For the purpose of this study, by recognizing these borders and their implications, positive changes could be made for not only TRAAs, but all students of color. These borders can generate a new third space for discourse between all members of the child's educational team.

\section{Summary}

"Third space" occupancy can influence middle/high school culture, the educators within it, and the students who lie outside predominant cultural norms. By considering how the third space operates from the perspectives of the stakeholders involved, how the teachers, the school, and the district support the social identity of TRAAs, and how they create spaces for these children to share their experiences, the faculty and others in similar contexts can gain insights to improve their educational practices to support all learners. This chapter has focused on the epistemological background of the third space and related theories used to view the data. In the next chapter, I present the methodology for this study. 


\section{Chapter 3: Methodology}

In this chapter, I explain the rationale for using qualitative methodology to research the lives of TRAAs in both home and school. I will discuss my specific positionality on the methodology I chose and the challenges I faced when approaching this study both personally and professionally. I will discuss the case study method used to address the research questions. Included will be a description of the methods of research, my positionality, and ethical considerations. This inquiry should add to the general body of knowledge and encourage future research in this understudied area.

In previous chapters, I explained how my background influenced my choice of dissertation topic. When approaching my methodology and collecting data, I felt an even greater pull of that positionality. As Anais Nin once said, "We don't see things as they are; we see them as we are.” Being mindful of this idea, as a researcher I have looked back to the past and my experiences as they have brought me to - and through — this research. I am the mother of a TRAA who, along with my husband, faces the brunt of the decision to live in this majority White area. This is due to responsibilities we took on such as taking care of our elderly parents. We are part of the "sandwich generation." I am an individual who researches everywhere to see what I need to know to take on the next challenge. Prior to adopting, I started reading about the best practices of bringing a TRAA to the United States. Although I was well-meaning and filled with good intentions, I feel my research was not thorough enough. What I mean is that after the adoption, and partly through this study, I have realized that the White privilege that I enjoy has forced me to ignore the Whiteness that surrounded my child. I have taken an even harder look at the implications that I now have to prepare my child to face. This 
means I have to gone to extreme lengths to not only embrace my daughter's heritage but to find cultural mirrors for her. This often involves four hour drives to cultural and adoption driven activities. When we drive to these activities or others, it means stops at Korean Markets to purchase specific Korean ingredients to cook Korean food. It also means searching for those recipes and watching Korean film, listening to Korean music, reading stories by Korean adoptees, and joining groups where I am the outsider and need to just listen. One such group is Transracial Adoption Perspective where one of the moderators, Mark Hagland, an early Korean adoptee himself, has allowed me to ask him questions and quote him directly here in this paper. All of this has shaped and driven me in the pursuit of this study.

My responsibilities have sometimes been impediments to progress at times. I mentioned above that I am part of the "sandwich" generation. I am raising my own kids and taking care of my husband's dad and my own mom who lives with us. I have worked full time as a teacher for 33 years. My mom is a first generation graduate of college in nursing. She is almost 93 years old. I take her to all her appointments. My father-in-law just recently passed away as I finished this study and worked on the last two chapters of my dissertation. He was living in a nursing home for about three months and slowly slipped away from us, so I was also visiting him regularly. These parents and my position in their lives have forced me to focus on finishing because, among other things, my mother's greatest wish is to see me graduate with my doctorate before she dies.

From the start, the process has not been an easy one to juggle. When starting my prospectus, I found out I needed thyroid surgery. I used this time to read and read and read. I needed the background before I started to write. Later, while beginning my 
interviews, it was knee replacement surgery due to a car accident with a drunk driver, so I could walk without pain. Again, I did a lot of reading related to different parts of my dissertation. Time - work time, parent time, children time and husband time, have played into how to accomplish this goal and also how to frame this study. I started to regularly get up at five o'clock in the morning to work on all parts of this dissertation and still be able to be there for the other parts of my life. I also squeezed in time as I sat at different sports, theater and music events in my children's lives and was supported by fellow parents as I read and wrote between children's soccer goals and music solos.

I have mentioned teaching throughout this process and this has shaped me too. I have changed teaching positions and schools four times from the start of the classwork for my doctorate to dissertation writing. I have shared my journey with my students throughout this time. I have used my experiences writing to explain that the first time you write something doesn't mean it is done, red doesn't mean it was bad but is a help. The elementary students I had when I first started this journey are now in ninth grade. I have gotten to teach many of them twice, once in third or first grade and again in seventh. Many of these students are the children of students in my first classes I taught in Peak County 33 years ago.

Because of my daughter, I started to pay closer attention to what was actually going on in the classroom with people of color. It started with my daughter and her experiences but branched out as I watched informally other Asian, Black, Latino and biracial students. The children in my classes and schools have always impacted me. Some, because I have seen myself in them but others because they suffer more than necessary and can bring me to tears as I think of them. In my latest placement as a 
seventh grade language arts teacher, I have seen some of the greatest impact of the words spoken from hurt, by children. This too has helped to focus my attention on the continual problem of race relations and its impacts on all students.

Hoping to be able to understand what was going on, I realized I needed to understand many of these issues theoretically. I needed to think of questions, to not only frame my dissertation but I needed to think of how I would create the questions to ask the students, my peers, and friends in an interview process.

The people directly involved in this study, the students, parents, teachers and administrators I have worked with are in many cases dear friends. I also had deep connections with adult members of the Asian adoption community who had shared stories of childhood and being the lone Asian in the room. I had a responsibility to understand my positions and respect theirs. When realizing I needed to frame the questions for my interviews in the most respectful ways, I asked them for suggestions of what information would they like to know about TRAA's in Appalachia today. Their questions were deep and I realized for many of those questions I was not the person to conduct that research, those needed a TRAA researcher. I was coming from a privileged voice of Whiteness and not the experiences of a TRAA. Instead, I used their information to form a basis of what I could ask and learn from as a teacher: That is, I could find out through my position what current TRAA students think about the community and the schools they attend. I could get a glimpse of that and combine it with information from parents, teachers and administrators. I feel it is this information that will make the most impact for change in the lives of TRAAs in school. 
I have strong personal viewpoints on the topics of race, education and change. Perhaps the greatest challenge has been to keep those viewpoints to myself during the interview process. I couldn't not bring myself into this process. Using the theories and methodologies mentioned in this chapter I tried to limit the impact of my viewpoints and allowed the research to speak for itself.

The advantage of my position allowed an entry point to information that under other circumstances I may not have access. For example, the teachers with whom I work viewed me as an insider and graciously spoke with openness and honesty because they view me as "one of them." Several times during the focus groups and some interviews, teachers would relay personal experiences with adoption such as having family members who were transracially adopted. They also asked me questions about issues my daughter might have faced at our school or another school. We would share as what we were, friends.

The disadvantage of being overconfident in my abilities to obtain private information also affected outcomes. When I went to interview the girls and their families, I thought that they would openly speak to the issues of racism and adoption. I asked specifically if they had any issues with feeling out of place or comments made toward them. Both girls seemed to brush it off and just said that no, everything was great. This, in part, I feel was due to my position. I am an adult and a teacher, I am not another teenage girl. Frankly, I also am not young anymore. During the analysis of the girls' data, it took more from me. After I looked at the interviews of the teachers and administrators, I then returned again to the girls' data. At first I thought I had nothing; after multiple rounds of reading, discussions and analysis I then saw more of what I had missed. My 
first shock came when revisiting Geneva's interview. I saw during the second read that she believed that racist comments were attached only to people from out of town, that locals would not say those things. Also, when asking her about issues that her sister had had with racism in middle school she referred to the racial comments as "drama." According to boyd (2014), the term "drama" is teen code for bullying.

Teens regularly used that word to describe various forms of interpersonal conflict that ranged from insignificant joking around to serious jealousydriven relational aggression. (p. 137)

When asked about how she dealt with drama she responded, "I'm nice to everyone, be my friend". What I had missed the first time through was what the girls didn't say about themselves, the avoidance of "all things drama." I will reflect on this in my findings.

From these vantage points and biases, I conducted my baseline research, data collection, examined my data, and dissected my findings. It has been a journey of learning, reviewed constantly based on life as I have experienced it especially throughout these past three years of the actual dissertation process.

As a reminder to readers, these are the research questions that I studied in this research.

\section{Research Questions}

The primary question to be answered by this study is:

How do Transracially Adopted Asian (TRAA) youth see themselves within the contexts they negotiate in rural Appalachia?

Speaking to the nature of qualitative research in education, Small and Uttal (2005) address the inclusion of the "insider's perspective" in educational research. These 
researchers point out that the more rigor and control in research, the more artificial the research and research findings become. In contrast, the more researchers observe social situations and people, taking the time to develop deep description of a phenomena, the more an "insider's perspective" will be developed (Small \& Uttal, 2005). The best way to pursue this outcome was by gleaning the experiences of the participants themselves.

How the TRAAs interacted socially at home and in other situations was used to clarify interpreted experiences of the TRAAs and school staff in this study. Based on this goal, a secondary question of the study was:

How do teachers and administrators position TRAAs?

\section{Epistemology and Theory}

Piaget believed that we construct meaning and learning through our ongoing lived experiences and activities within the world "based on previously acquired categories, concepts and experiences" (Jardine, 2006, p. 21). I believe that interactions with the lived world shape humans socially and culturally, and create knowledge. These interactions are unique to each individual as are the situations that surround them as they grow. No two people live the same exact life with the same exact stimulations, rejections, homes, parents, schools, etc. This is in turn called a constructivist epistemology. To explain further:

[The] constructivist view, is that knowledge is established through the meanings attached to the phenomena studied; researchers interact with the subjects of study to obtain data; inquiry changes both researcher and subject; and knowledge is context and time dependent (Coll \& Chapman, 2000; Cousins, 2002). (Krauss, 2005, p. 759) 
From this viewpoint, I qualitatively analyzed my data using the lens of Third Space Theory. Using this theory in conjunction with constructivism allowed me to look for those spaces that were both conducive and averse to learning and growth for TRAAs. This position assumed several possibilities. It recognized that the participants in this study were and are constant learners, including the researcher. It also assumed that the knowledge gained from this research will be applicable to question two in this study: How might educators support transnationally adopted children and their families in the K-12 setting? I expected that my own viewpoints would be altered, even though my daughter is a TRAA. This is because new knowledge of other TRAAs was added to my own. By examining the experiences of transracial adoptees in an educational setting, the gradations of understanding, interactions and knowledge with their lived worlds could be added to the general body of knowledge of experiences within this group of marginalized individuals (Merriam, 2002).

This was a qualitative study. Qualitative research is comprised from the interpretation of events, as individuals perceive them. This approach fits very well into the ideals of constructivist epistemology and Third Space Theory because these too are perceived spaces. By using a qualitative research design, it allowed the researcher to capture "the complexity of human behaviors in ways that are not possible when studies are based on prediction and randomized controls" (Koro-Ljungberg \& Douglas, 2008, p.163). As a qualitative researcher, I worked to understand the phenomenon of the context of TRAAs from an insider's perspective. I needed to work directly with participants to denote the significance of their daily exchanges and interactions. Explained in more detail later, for this study, the researcher used interviews, 
observations, and personal recordings for data collecting. Later, facial expression, venue, artifacts and mood, were noted to infer meaning in analytic memos made by the researcher (Merriam, 2002).

The fluidity of a qualitative study allows for redirection in questioning and the unexpected answers that may come from participants in the study. This accounted for the diversity of the human element under study. Using an inductive form of research, qualitative researchers build on the data derived from participants to create hypotheses and a descriptive ideal of the phenomenon (Merriam, 2002). This enquiry generated a picture of the lives of the participants and those that directly impacted them—parents and teachers, primarily from the participants' viewpoint. Schofield and Blum recognize the importance for educators to be aware of their students' lives and what better way to do that but through qualitative research? (Blum, 2002).

\section{Method}

\section{Case Study}

Case study was the method that best fit my goals as a researcher. The case study provides rich insight into the phenomenon studied. When looking at case study the process revolves around the case. The definition for case that is chosen for this study is from Gillham's book, Case Study Research Methods (2000). He defines a case as:

[A] unit of human activity embedded in the real world; which can only be studied or understood in context; which exists in the here and now; that merges in with its context so that precise boundaries are difficult to draw. (Gillham, 2000, p. 1) 
Merriam (2002) describes a case study as "an intensive description and analysis of a phenomenon or social unit such as an individual, group or institution, or community" (p. 8). Yin (2003) lists three prominent reasons to use case study for research: “(1) when the main research questions are "how" and "why" questions; (2) a researcher has little or no control over behavioral events; and (3) the focus of the study is a contemporary (as opposed to entirely historical) phenomenon" (p. 2). This is a study of two "how" questions of a developing phenomenon in contemporary Appalachia. The case study method provided the voices that I thought needed to be heard. The voices in this case were the TRAAs, of which little has been written about. Once those voices are heard, the ability to use the voices of the voiceless to guide instruction provides the change or action I wish to see. It is hoped that by observing and talking with participants, the information shared will be able to support teachers and guide instruction.

As a teacher, I am constantly evaluating interactions in my classroom, my curriculum, and my school to provoke change within my practice, school, students and myself. I do not feel that this is unique to myself, but that other teachers do the same based on the information to which they have access. This case study has allowed for selfreflection initially by myself, and when results are shared with other professionals, they too will be able to reflect on their practice. Steeples (2004) optimistically states that this level of closeness to the topic, in educational practices, is beneficial:

This close linking between teaching and the research practices enables me to make sense of research ideas generated directly through my own practices and my experiences within the teaching and learning content. (p 
In case study research, there needs to be a clear and bounded case identified (Stake, 2006; Stake, 1995; Yin, 2003). This means that there are specific boundaries placed on the case. It is one group or one person that fits a particular set of criteria. The criterion for this study was the lives of two TRAA's and their learning communities. These learning communities have been identified as home/family, school, and the activities (i.e., sports, dance, clubs) in which the TRAAs participate.

\section{Study Design}

No two families are the same. This is also true for families of international adoption. They may share certain characteristics that help or stymie identity growth in their children. I have explored to the degree possible, the diversity amongst adoptive parents. In this study, I was afforded the opportunity to see what these family knowledge might be brought into the research to be used for teachers to support learning in the classroom.

\section{Participants and Study Context}

I used purposeful sampling to select my participants. Purposeful sampling is used for "identification and selection of information-rich cases for the most effective use of limited resources" (Palinkas, Horwitz, Green, Wisdom, Duan, \& Hoagwood, 2016). My sample started with two female students chosen from within the Peak County community from a local Asian adoption group to participant in case study. This could be recognized as a convenience sample. "Convenience sampling (sometimes called accidental sampling) is the selection of a sample of participants from a population based on how convenient and readily available that group of participants is" (Salkind, 2010, p. 254). This type of sample for this study was both purposeful and convenient since the study 
was about TRAAs in the Appalachian school setting, and represented the intended research goals. It was also a sample that was readily at hand within the community I work, making the scheduling of interviews and observations accessible. Although the sample was small, I view this sample as one that meets the guidelines that researchers) would refer to as "information rich" (Merriam, 2002; Palinkas, et al., 2016). An information rich case would be one that would allow the researcher to gain a significant amount of information that is important to the purpose of the study (Merriam, 2002). The sample size also allowed for a more thorough investigation of the phenomenon. From this sample, parents, and teachers were also included with the TRAA youth.

\section{Youth}

This case was bounded by several conditions. The first consideration, as mentioned prior, was access. The number of Asian transnational adoptees in all Appalachia is not well known, as shown previously in chapter one. In Peak County in the past 10 years, TRAA's have been a constant in classrooms and have been representative as 1-6 students spread over 12 schools per year (Maryland State Department of Education, 2014; 2017). Case members were drawn from TRAA students who were of middle/high school age (11-18), currently in public school. I personally know the parents from the local Asian adoptee family group. Predominately, this group resides within Peak County, Maryland and up to 15-30 miles in any direction across the county lines. Access and personal connection made this group a valuable resource for the selection of case members. This group is comprised of children of East Asian descent, primarily individuals that have been adopted either from Korea or China. Another reason for selection from this group, in addition to convenience, was that these students are among 
the newest generation of adoptees to be of school age. This group would have been adopted during the era of cultural preservation as opposed to cultural assimilation promoted originally by the Hague Convention. Both TRAAs attend public school in Peak County.

The participants in this study were in eighth and twelfth grade at the time of the study and are TRAAs. These are key developmental periods related to lived experiences that are influenced by culture, space, and adoption. According to Bernstein (2002), middle school is a time of confusion and change. It is a period of self-discovery and identity forming. Students arrive in middle school in late childhood and leave in early adolescence. Come high school, students are continuing on their journey to adulthood. For girls, their bodies have stopped growing but their friendships and self-discovery have not. Continuing changes in brain activity can both taint judgments and boost confidence (Mercer, 2013; Rodriguez, De La Sierra, \& Schachter, 2013). These periods of flux are also significant times in adolescents' emotional and identity development.

This particular study group has been identified by their unique position of being Asian and also being adopted transnationally and transracially. They have also been adopted into an understudied community of Appalachia. The unique position that TRAAs have been adopted into is one that has previously separated them from biological ties, cultural routes, and social connections to Asian-ness (Hübinette, 2004).

As adoptive parents and agencies have changed, many have recognized that assimilation is not the best way to address issues of identity—emotional, cultural and ethnic. Current TRAA's in Appalachia need to develop ways to navigate both the space 
in which they are fostered and their position in the larger world. As mentioned in the previous chapter, this is the world they will grow into as Asian Americans.

\section{Parents}

The U.S. Department of Health \& Human Services (2017) has indicated that nationally $73 \%$ of parents that adopt transnationally are White. From the local Asian transracial adoption group, $100 \%$ of the parents are White and middle class. They reflect a historical moment related to assimilation versus the new cultural preservation stance.

I interviewed parents on their perspectives about education, adoption, and particularly their views on their children's perspectives. Parents were contacted prior to contacting students in order to establish their willingness to participate in the study and also to ascertain if they felt their child was interested. Parent perceptions on education are an important facet of this study. They allowed comparisons and generalities to be deduced to form an image of what education, both inside and out, looks like from a parent's viewpoint. Although parents added their views to this body of research they were not the primary knowledge source of the phenomenon, that role was left for their children.

\section{Teachers/Administrators}

According to educational statistics, $80 \%$ of teachers in the U.S. are White women (IES National Center for Educational Statistics, 2017; Office Of Planning, Evaluation And Policy Development U.S. Department Of Education, 2017). That is reflected in the teaching staff of Peak County. Those that are not White females are White males. The diversity within these groups includes marital status, religion, sexual orientation, original residency (born within the county) and transplants (not born in the county). 
Teachers in the study were chosen for two different purposes. First, two sets of teachers (group sizes of five to eight) were from the schools that the students presently attend. These two groups formed the focus groups. Next, six teachers were selected from the classes in which the observations of each student occurred. The teachers that were chosen were willing to be both interviewed and observed during a class period. This allowed the student participants to be observed during a class period with those teachers. The two school administrators from the two participants' schools were asked to discuss, on a school building level, similar questions as those asked to the teachers. Administrators also gave insight into the broader scope of implementation and acceptance of the racial changes in the school. I did capture teacher insight of "othering" and its influence in the classroom. I also asked about the strategies, methods, and processes that the teacher and the school have used.

\section{Data Collection}

To help form ideas of the case under study I used several techniques that are advantageous in data collection in the qualitative method: surveys, interviews, observation, field notes, reflexive field notes and analytic memos, artifact collecting, transcribing, fact checking, and coding. Analysis was ongoing throughout the process through coding and analytic memoing which will be described in more detail shortly.

\section{Surveys/Interviews}

Initially I set up appointments and completed my consent forms with parents and their children. My first plan of inquiry was to create and share questionnaires, one for the TRAAs and one for parents to complete after their consent forms (Cico, Vogeley, \& Doyle, 2011). These questionnaires covered basic questions (Appendix A) such as 
country of birth, age at adoption, gender, etc. (Hancock \& Algozzine, 2011). Survey questions of this genre were in a yes/no format so that answers might be quantified and compared. My questionnaire provided both a starting point and a framework for elaborating on my in-depth, semi-structured interviews. I was able to pinpoint probes that need to be explored more fully in an interview by using the questionnaires as a basis (Cico, Vogeley, \& Doyle, 2011; Kvale \& Brinkmann, 2015). Besides general demographic information these surveys helped isolate areas I addressed more intensely in the semi-structured interview. This was the same process for student-identified teachers; I used consent forms and then a basic questionnaire with yes/no response questions that led to the formulation of probes to support the semi-structured interview process.

Interview question probes were developed and created in such a way that they could be personalized based on information from the surveys (Appendix B). As mentioned previously in my positioning statement, an effort was made to place the voice of the interviews in the voice of TRAAs. A brief question was put out to adult TRAAs asking what they would like to know about TRAAs' lives in Appalachia today. These questions were first placed in generalized categories (Parent involvement/Home, Bullying, Role Models, Teachers/School, and Activities) and examined as to their importance to the study and appropriateness for the age of interviewees. Some of the questions the adult adoptees answered:

"Are your parents supportive?"

"Have you ever been teased because of your looks?"

"Who is your role model?" 
Upon reflection, I revisited the questions and reworded the questions for appropriateness and respectfulness for the intended interviewee and also suitableness to inform the present dissertation study questions. These questions reflected the following groupings: (a) family/community relationships and school relationships and support and (b) peer relationships and support. Next, I cultivated questions for the parents. The parents' questions addressed similar topics but from the parent perspectives. I also created a set of questions to ask teacher and administrator participants. These include references to experiences with TRAA's in their classrooms and school (Flick, 2014; Hancock, \& Algozzine) (Appendix B). Finally, I developed a set of questions for the focus groups I interviewed. All interviews lasted approximately 30 minutes to 1 hour. Focus group interviews lasted approximately the same amount of time even though there were more voices.

After the questionnaire was returned, the semi-structured interview probes were further planned based on this new information. I scheduled semi-structured interviews with students and parents at their convenience at their homes, to allow for the best story generation and flexibility. For one family, they chose to be interviewed at my home for its convenience to their place of work. Semi-structured interviews allowed for the same types of questions to be asked to each interviewee but also allowed for adjustments such as when they are asked and how they were asked. Open-ended questions were employed to allow participants to divulge their own perspectives and not those of the interviewer. These interviews were audio recorded for later transcription, examination and evaluation through coding and thematic analysis. Recording interviews allowed me to concentrate on the topic and the dynamics of the interview. While transcribing, I was able to make 
reflexive notes about the words and their tone, pauses, etc. This also made it possible to return again and again to the recording, and to listen and clarify ideas (Kvale \& Brinkmann, 2015).

According to Kvale and Brinkmann (2015) the "qualitative interview attempts to understand the world from the subjects' points of view, to unfold the meaning of their experiences, to uncover their lived world prior to scientific explanations” (p. 3). This approach fits into my constructivist viewpoint that knowledge is constructed and with this process of interview, I was co-creating meaning with my participants such as the traveler who moves alongside participants and participates with the subjects in the production of knowledge (Flick, 2014). Also, because of this stance, as mentioned briefly before, I chose to use a semi-structured interview process. This process allowed me to know what my participants know, but also provided a structure to guide my interview. There were no set answers to each question and they were open-ended in nature. They also allowed me to have the opportunity to ask probing questions (Hancock \& Algozzine, 2011). This allowed for interviews that were more personal and more informative about the lived experiences of my participants.

Focus Groups. A benefit of focus groups is the ability of the moderator (researcher) to gather a great amount of information in a shorter period of time. Another benefit is to the participants. In this instance the ability to discuss with colleagues and negotiate difficult subjects with support from peers benefited teachers in their practice by adapting their methods and strategies to the advantage of all students (Barbour, 2014; Bloor, Frankland, Thomas, M. \& Robson, 2001; Freitas, Oliveira, Jenkins, \& Popjoy, 1998; Moje \& Wade, 1997; Williams \& Katz, 2001). 
Field notes. During interviews, field notes were taken. The first purpose of field notes is to get down on paper the first impressions of the interview, observation or experience (Emerson, Fretz, \& Shaw, 2011). The nuances of these experiences cannot be strictly told from a transcript. These notes became part of the data itself (Emerson, Fretz, \& Shaw, 2011; Stake, 1995; Saldaña, 2013).

Analytic memos. Throughout the process I wrote analytic memos to record my thought process and the connections I made between the interview and the research. This process of reflection on these experiences and my connections to the data helped with the movement from the data to meaning making. This allowed me to gain insight into the data included in my final analysis (Flick, 2014). It also was a strategy that helped me to compare and triangulate data across individuals and groups (Merriam, 2002).

\section{Observation and Artifacts}

I shadowed each student for one day, in one-hour segments, to observe interactions within each classroom as they changed classes. This required permissions from not only the classroom teachers, but also the school principal and the school superintendent. During these direct observations, I took field notes recording details that occurred in the room about the teacher/student interactions (Van Manen, 1990).

During the research process, I gathered artifacts as additional sources of evidence of the lived educational experiences of adoptees, parents and the teachers in the classrooms. These included but were not limited to photos, classwork, lessons, lesson related items and a variety of other documents (Yin, 2003). Permission from the school staff was necessary for those items. The usefulness of these artifacts was to connect the students to varied learning experiences. Learning experiences inside the classroom are 
important, but since these students also have learning experiences outside the classroom, documentation of those events was also important. This included clubs or activities they participated in but also could have included ethnic activities such as culture camps or other special festivities related to their culture.

\section{Data Analysis}

\section{Analytic Memos}

Memos were a part of my analysis as I drew conclusions from the data. The purpose of the memoing while completing my transcripts and field notes was to help me develop analytic leads and insights early on in the fieldwork process (Emerson et al., 2011). This included stepping back from my notes and teachers, parents and other vested interests. While stepping back I wrote what I witnessed during the interview process or classroom/community observations. I noted significant interpretations that I arrived at along with any notes that contributed to reconstructing the exchanges and patterns of note within these activities (Flick, 2014). Memos were the first step of constructing initial suppositions.

\section{Coding}

Auerbach and Silverstein (2003) have identified coding as the procedure used to look for patterns within a group of data, such as transcripts of interviews, observations or field notes. It is the first step in making meaning of the conducted research. I had planned to use word-processing software to aid in the development of interview coding sheets. The software was to serve as my investigating tool. I had done this for previous interviews in classwork. Instead of this I transcribed and hand-coded all of the data. I 
was later able to physically sort the data by cutting it apart and hand sorting. This was possible because the number of interviews was relatively small.

Coding itself was conducted procedurally. The first step after transcription was to conduct initial coding. Initial coding allowed a free form base for gathering and evaluating the information in the transcript. It was a time to gather first impressions of the interview and group general observations (Saldaña. 2013). After this initial coding I conducted InVivo coding. The strength of this method of coding is to be able to capture the interviewees' actual voices, what they actually say. This is a particularly important strategy when working with the "marginalized voices of children" (Saldaña. 2013, p. 91). The coding used the words of the participants as the code. An example could have been, "I get teased about my eyes." In the case of the student participants in this study this was harder than expected. At first I saw no real categories and patterns in the codes related to the students. I decided to move on to the teachers and administrators to see patterns first. Next, I took coded strips of the interviews from each part of the triad and actually cut them apart from the paper transcription and regrouped all of the interviews by group and overarching themes. One actual repetitive phrase that came up among staff interviews and focus groups was that their schools were filled with "nice kids." Physically manipulating the data really helped with my meaning making process. I was able to look at the process in reverse order starting with administrators, then teachers, and then students. I was able to cross check the meanings of participant groups through this process and consider the relationships between the various groups by consulting additional data, particularly my notes. 
Themes. The final step of analysis of all the data (interviews, observations, field notes, memos, artifacts) was the interpretation of themes that occurred throughout the data. The word-processing software lent itself to this by being able to search for repeating words and phrases. Saldaña (2013) thinks of themes as "an extended phrase or sentence that identified what a unit of data is about and/or what it means" (p. 175). Themes are the connections made through the coding. I looked for the repetitiveness of ideas within the codes, field notes and memos. I then used the coding and subsequent themes to interpret the data. By comparing my participants' information with my own deductions, I was provided a type of triangulation.

\section{Research Ethics/Trustworthiness}

I followed strict ethical guidelines. As mentioned previously, prior to surveying, I had parents, student and teacher participants sign consent forms that had been fully explained in compliance with the Institutional Review Board (IRB) policy of West Virginia University. I explained to participants that this was a consent form but that the consent form does not obligate them to remain in the study. Consent was recognized as ongoing. The participants were informed that if they chose to leave at any time they could, without any penalty. Participants also were made aware of the fact that all information is confidential. All identifying information has been changed in this dissertation and will be in any future publication. It is important to protect the identity of the participants, the schools and the community. In considering these groups, the following will be done to maintain the privacy of subjects: All interviews were conducted in private locations for which the subject has agreed. For the focus groups, I included in the cover letter the necessity of not discussing the research outside the focus 
group to respect the confidentiality of all participants.

Regarding trustworthiness, I explained how they and I are an active part of the research process, as I sought clarification through member checks. I made known to them that I would share my ongoing reflections with them throughout the research (Cico, et al., 2011; Merriam, 2002; Paris \& Winn, 2014). Whenever appropriate I also shared my field notes and analytic memos. This was especially important for clarification of points that, at first, may not appear straightforward for the researcher. Although in reality I was able to do member checking on a limited basis with one teacher, I found other ways to bolster the trustworthiness of the study as well.

I used several additional strategies recommended by Merriam (2002) to support the trustworthiness of the study. Peer reviews were an important part of understanding and validating participants' responses. I was able to share emerging analysis confidentially with teachers and TRAAs who were not a part of the study as a way to better understand the data and confirm the analysis. I also kept careful notes of each part of the study and constructed an audit trail to the best of my ability in my records and throughout this document. Finally, I compared multiple data sources with one another in a process of triangulation in an attempt to understand the meanings of individuals and groups. Triangulation is important for validity, rigor and reliability. According to the authors of the article "The Use of Triangulation Methods in Qualitative Educational Research", by collecting data from different perspectives and comparing it, data will be more accurate and valid (Oliver-Hoyo, \& Allen, 2006). Writing up the data was a time for another type of triangulation protocol that Stake (1995) refers to as Theory Triangulation. This was when others looked at my evidence and conclusions to see if 
perhaps there was another way to look at the data from alternative theoretical viewpoints and also, to ask if my conclusions stood firm. This was first, the job of my chairperson and then my doctoral committee.

I have spoken to my involvement in the community of TRAAs. Separating out my preconceptions of this phenomenon from the actuality of the lived lives of these student participants was important for me to separate. One aspect of that was the questions I choose to ask my student participants. I asked questions that were devoid of leading to the answers I wanted but toward the participants' voices.

During this write-up I needed to consider other factors. The most pressing was the intended audience. Although my initial audience was my doctoral committee, there were others to consider. I will present to the academic community but also the teachers, parents and adult adoptees that my phenomenon represents. Foremost in my mind is the protection of the adoptees and other participants, but also the area that they are from, Peak County. As a small community it is important to guard the identities of the participants. As mentioned previously, I used pseudonyms for people and places and I also used masking techniques when necessary. I created an audit trail of data in appendices as well, that others might exam. An audit trail will allow fellow researchers to analyze the procedures used and determine the trustworthiness of the findings based on the presumed ability to replicate the findings (Carcary 2009).

\section{Timeline of Research}

April 23, 2018: Defend Prospectus

April 2018: Submit IRB Protocol

May 2018: Once IRB Approval is granted begin surveys and initial interviews 
Summer 2018: Community and family observation with students, additional interviews

Fall 2018-Winter 2019: School observation, focus groups and curriculum development / workshop based on the data collected

Summer 2019: Transcribe, analyze data, write chapters 4 and 5

Fall 2019-Spring 2020: Edit and rewrite chapters 1-5

Spring 2020: Defend dissertation

Fall 2020: Present teacher training based on research

\section{Conclusion}

From the start of this research, I have approached it as a constructivist. I have built on prior knowledge that has been shaped by my experiences as a teacher, and an adoptive mother of a TRAA living in Appalachia. These experiences have provoked me to find out more. I have formed my research questions searching for answers to better understand educational process for Asian American adoptees and also to make known what many do not know about this phenomenon.

The current chapter has focused on the methodology that was followed for this research. I have shared the plan for the procedures of interviews and observations. In the next chapter I will examine the findings and their connections to my research questions. 


\section{Chapter 4: Findings}

\section{Three Perspectives on TRAAs' Lives in School}

Data analysis has as much to do with the data and the people interviewed as it does with the researcher. I questioned myself continuously from start to finish in the process of coming to these findings. When I first imagined my interviews with the two TRAA students, I believed they would open me up to a new view of the lives of TRAA teenagers in Appalachia. I was anxious to hear how they spoke about racism in the schools and other challenges of race/ethnicity they faced in the curriculum and in the third spaces of middle and high school. Through this study, I was anxious to see how families and schools had used third space to create a new space for their TRAA children. How could students be both Asian and Appalachian? How might they embrace their birth culture and new home's culture and how might that, in turn, help teachers and administrators provide new insights to make teaching better for all students, but particularly those of color who were living in Appalachia?

As mentioned earlier in this dissertation, the idea of studying TRAAs' third spaces sprung from conversations with my daughter and her openness to talk with me. She has shared over the years how racism and race are expressed in her schools both overtly and covertly. She has spoken of teachers and students alike having stilted viewpoints about adoption, culture and race. Most importantly, she has shared how that has affected her directly. We have practiced over the years how to identify racism, sexism and "isms" in general. We also have spoken on how to have "comebacks" to react to these scenarios, how to be in charge of her own story and be proud of who she is. How to be proactive in the third space she embodies with others. 
In this Chapter 4, I present the findings in three sections. First, I discuss what was learned through studying two teenage female TRAAs, Sarah and Geneva, through several months of their daily activities, seeking to know them better and know a bit about their own lives as well as about the experiences of their families. Then I describe the school context, middle and high school, respectively that the girls attended. I discuss the leadership structures that the principals put in place in each of their schools and examine the degrees to which these schools created a third space for TRAAs and other students who may be different from the White and low income to middle income norm. Then I unpack the interviews with the teachers at these two schools, considering more broadly how education in Peak County serves TRAAs and why. 
Table 2. Student Demographics

\begin{tabular}{|c|c|c|c|c|c|c|c|c|c|c|}
\hline Pseudonym & Data Collected & $\begin{array}{l}\text { Grade/ } \\
\text { school }\end{array}$ & Gender & Race & Age & $\begin{array}{c}\text { Age at } \\
\text { Adoption }\end{array}$ & $\begin{array}{l}\text { Favorite } \\
\text { Subjects }\end{array}$ & Activities & $\begin{array}{c}\text { Family } \\
\text { Activities }\end{array}$ & $\begin{array}{l}\text { Cultural } \\
\text { Activities }\end{array}$ \\
\hline Geneva & $\begin{array}{l}\text { Interview, } \\
\text { Observation, } \\
\text { Survey }\end{array}$ & $\begin{array}{l}\text { 12/East } \\
\text { Peak High }\end{array}$ & Female & Asian & 17 & 12 months & $\begin{array}{l}\text { Theatre, } \\
\text { Financial } \\
\text { Management, } \\
\text { Government }\end{array}$ & $\begin{array}{l}\text { Cheerleading, } \\
\text { track, Girl } \\
\text { Scouts, cross } \\
\text { country, school } \\
\text { plays, student } \\
\text { council, } \\
\text { journalism, Tae } \\
\text { Kwon Do, 4-H }\end{array}$ & $\begin{array}{l}\text { Hiking, taking } \\
\text { care of animals, } \\
\text { holiday visits } \\
\text { with family }\end{array}$ & $\begin{array}{l}\text { Lunar New } \\
\text { Year, plays and } \\
\text { concerts at the } \\
\text { college, 4-H } \\
\text { camps }\end{array}$ \\
\hline Sarah & $\begin{array}{l}\text { Interview, } \\
\text { Observation, } \\
\text { Survey }\end{array}$ & $\begin{array}{l}\text { 8/East } \\
\text { Peak } \\
\text { Middle }\end{array}$ & Female & Asian & 13 & 10 months & $\begin{array}{l}\text { Math, } \\
\text { Science, } \\
\text { Computers }\end{array}$ & $\begin{array}{c}\text { Gymnastics, } \\
\text { cheer, volleyball, } \\
\text { dance }\end{array}$ & $\begin{array}{c}\text { Going on } \\
\text { vacation } \\
\text { together, theme } \\
\text { parks/amusement } \\
\text { parks, hanging } \\
\text { out as a family }\end{array}$ & $\begin{array}{l}\text { Lunar New } \\
\text { Year, concerts, } \\
\text { meeting with } \\
\text { adoption group }\end{array}$ \\
\hline
\end{tabular}


Table 3. Parent Demographics

\begin{tabular}{|c|c|c|c|c|c|c|c|c|c|c|c|c|c|}
\hline Pseudonym & $\begin{array}{l}\text { Kind of } \\
\text { interaction }\end{array}$ & $\begin{array}{l}\text { Parent } \\
\text { of }\end{array}$ & Gender & Race & $\begin{array}{l}\text { Present } \\
\text { Age }\end{array}$ & $\begin{array}{l}\text { Age at } \\
\text { Adoption }\end{array}$ & $\begin{array}{l}\text { Age of } \\
\text { other } \\
\text { parent } \\
\text { at } \\
\text { adoption }\end{array}$ & $\begin{array}{l}\text { Marital } \\
\text { status }\end{array}$ & $\begin{array}{l}\text { \# of } \\
\text { TRAA's } \\
\text { in } \\
\text { family }\end{array}$ & $\begin{array}{l}\text { Level of } \\
\text { Education }\end{array}$ & $\begin{array}{l}\text { Income } \\
\text { (custodial } \\
\text { parent) }\end{array}$ & $\begin{array}{l}\text { Family } \\
\text { Activities }\end{array}$ & $\begin{array}{l}\text { Cultural } \\
\text { Activities }\end{array}$ \\
\hline Lois & Interview & $\begin{array}{l}\text { Mother } \\
\text { of } \\
\text { Geneva }\end{array}$ & Female & White & 64 & 47 & 50 & Single & 2 & Master's & $\begin{array}{l}\$ 30,000- \\
\$ 60,000\end{array}$ & $\begin{array}{l}\text { Gardening, } \\
\text { hiking, } \\
\text { taking care } \\
\text { of pets }\end{array}$ & $\begin{array}{l}\text { Plays, } \\
\text { concerts, } \\
\text { Chinese } \\
\text { New Year } \\
\text { party, } \\
\text { Moon } \\
\text { Festival }\end{array}$ \\
\hline John & Interview & $\begin{array}{l}\text { Father } \\
\text { of } \\
\text { Sarah }\end{array}$ & Male & White & 61 & 48 & & Married & 1 & $\begin{array}{l}\text { Some } \\
\text { College }\end{array}$ & $\begin{array}{l}\$ 60,000- \\
\$ 90,000\end{array}$ & $\begin{array}{l}\text { Movies, } \\
\text { shopping, } \\
\text { eating out, } \\
\text { cheer events }\end{array}$ & $\begin{array}{l}\text { New } \\
\text { Year's, } \\
\text { Gotcha Day }\end{array}$ \\
\hline Carol & interview & $\begin{array}{l}\text { Mother } \\
\text { of } \\
\text { Sarah }\end{array}$ & Female & White & 52 & 40 & & Married & 1 & $\begin{array}{l}\text { Some } \\
\text { College }\end{array}$ & N/A & $\begin{array}{l}\text { Vacationing, } \\
\text { attending } \\
\text { cheer and } \\
\text { dance } \\
\text { competitions, } \\
\text { playing } \\
\text { volleyball, } \\
\text { spending } \\
\text { time with } \\
\text { family and } \\
\text { friends }\end{array}$ & $\begin{array}{l}\text { Attended } \\
\text { concerts, } \\
\text { attended } \\
\text { Lunar New } \\
\text { Year } \\
\text { activities } \\
\text { with } \\
\text { adoptees in } \\
\text { our } \\
\text { surrounding } \\
\text { areas, } \\
\text { Lunar New } \\
\text { Year, } \\
\text { events with } \\
\text { local } \\
\text { adoptees }\end{array}$ \\
\hline
\end{tabular}




\section{The Students}

A major assumption of mine going into this research had been that most adoptive parents recognize the need to have conversations about race/ethnicity with their children, to help them interpret the world around them and make meaning, as well as to have coping strategies for dealing with the challenges of being a person of color in rural Appalachia. These are thoughts that have been cultivated throughout the local adoption community, at least from my experience. Entire Facebook groups are dedicated to making understandings of identities and agency stronger for this generation of adoptees by and for other adult adoptees.

I have known Sarah (age 14, an eighth grader in middle school) and Geneva (age 18 , a senior in high school) and their families for over 15 years, since the time my daughter came home in early February 2005. I enjoyed relationships with them through social events and school. We had formed a group of transracial/transnational families that had bonded over group events like Hayrides, Christmas Parties, and Maple Syrup Runs. Originally, about 10-12 local area families of 18-20 Asian children, Sarah's parents, Carol and John, as well as Geneva's mother, Lois, were a part. Sarah and Geneva were chosen from this group because they met the age criteria of the study, I was familiar with both families, all resided in Peak County and both attended public school, another focus of this study.

Each family had slightly different configurations that added to the study.

Geneva's mother and father were divorced. Lois had moved to Peak County for a full time teaching position at the local college and a more outdoors lifestyle that Peak County 
provided. When asked, she specifically spoke of the "safety of the communities" that drew her here. Sarah's parent were both born and raised in Peak County. They met at the local hamburger hangout and as John says, "the rest is history." Geneva has one sibling, Kate, also adopted from China, who is about five years older than her. Her older sister actually traveled with her mother, Lois, when she went to pick up Geneva in China.

Sarah is a shy but active eighth grader. She is involved in many activities such as dance and volleyball outside the school day and student council at school. From both observation and conversations with Sarah, she has a few close friends that she "hangs out" with. These friends are mostly from the activities that she is a part of. She is shy around strangers and will not actively seek to engage with others until it is necessary or she knows them well. Once she knows people and is comfortable with them she has no issues. She admits that she had bad experiences with other girls that were once her friends but are no longer. She is both excited and anxious to go to the high school. She enjoys her family and spends a great deal of time with her family. Sarah was adopted as part of a second family for her mother and father. Sarah has two much older siblings, a brother (age 40) and a sister (age 36) who have families of their own. Sarah will occasionally babysit her nieces and nephews. So although she has siblings, Sarah has been raised virtually as an only child. Sarah is determined to be a physician. She has always been fascinated with science and it is her favorite subject. She speaks of moving away for a little while but thinks coming back to a small area and living near her parent is also a real option for her.

Geneva is an outgoing "go-getter". She too is involved in both school and community activities. Some of her activities include theater, dance, student council, 
model United Nations and Girl Scouts. More than once, she was described as having a "bubbly" personality. She is open in her friendships and seems to have friends in every group she encounters. She is definitely not shy and seems to draw people towards her. As mentioned she has an older sister who, upon graduation, went to the local college, graduated, and now lives out West, working in adventure sports. Geneva would like to be an accountant and will also attend a nearby college but has visions of living in a far different area. She does love living in this small community.

Being in a small close-knit community, everyone knows everyone, but especially the Asian adoption community recognizes each other. Our children had grown to be friends all over Peak County, where neighbors are spaced long distances apart and a 3040 minute drive is considered a short drive to meet with your friends. So when it came time to have conversations with Sarah and Geneva I felt comfortable but also mindful of the relationships I had with these families. I didn't feel exactly nervous, but aware. I wanted to be respectful and able to continue the relationships I have had through the years. I was anxious to hear their perspectives, feeling confident that I would see similar stories to my own transracially/transnationally adoptive family. I also felt I would be a trusted figure with whom to talk about sensitive issues such as racism. However, the research taught me some important lessons about my own biases related to TRAAs' experiences.

Throughout my analysis I looked for evidence of the social construction of a third space that Bhabha and many others suggest can support the identities of transracially and transnationally adopted Asian students (Bhabha, 2012; Hübinette, 2004; Witenstein, et al., 2015). I have looked for evidence of social construction of knowledge and support 
between Sarah's and Geneva's birth cultures and their transplanted culture with their adoptive parents, schools and community. However, I have not seen much evidence of constructing third spaces by bridge building (Miller, Latham, \& Cahill, 2016) nor by using the students' funds of identity gained through their journey from their birth culture to their home culture in their rural Appalachian community. In the following vignettes, I show how Sarah's and Geneva's parents work to construct the "second" or home space that positions their daughters as blending into the woodwork of Peak County.

\section{Blending into the Home Community}

At sporting events and in their honors classes, Sarah and Geneva are typically the only students of color. It may not seem surprising that the parents of these teenagers described them as "blending into" local community life. Normality is a goal that most families seem to want for their children and the teenagers wanted for themselves. Typically, parents and teens attributed fitting in to personal characteristics, such as "easygoing" personality with "not a lot of drama" (Geneva) or "not that outgoing" so that other teens did not likely have the opportunity to "judge" or "treat her different" because "she simply didn't put herself out there" (Sarah). The teens themselves seemed to like the small town feel that was relatively easy to navigate and liked certain teachers who "don't exclude or like they don't have a... they don't have an opinion of that sort of ... like your ethnicity or something like that" (Sarah, Interview 3, April 18, 2019). For Geneva, her friends even “...think it's cool, like being adopted and they don't mind really that I'm adopted. They don't see any difference" (Geneva, Interview 3, 4-10-2019). The fear of differences is paradoxical because we often view youth as "the change." 
Passing as phenotypically White was another way that TRAAs and their families constructed a discourse of blending into rural Appalachia. Hearing this discourse multiple times during the research caught me off guard at first, so much so that I needed to confirm my thinking about how we perceived our daughter's appearance with my husband. Whitewashing TRAAs' appearance goes against the advice from experts on transnational adoption that I had read since before EunAe's homecoming (e.g., Baden, 2015; Callahan, 2011, Kim, \& Hall, 2016). But on reflection, colorblindness is common in the U.S. (Burke, Jayakumar, \& Adamian, 2017; Logan, 2017; Mueller, 2017). In mainly White communities in particular, race is not a topic that people want to talk about, and sometimes may pretend they do not even "see" (Pollock, 2004). This happens in the adoptive community as well, as shown by these examples from my interviews:

Geneva: I don't really look very Asian...

Me: Oh, (surprised) so you don't think you look Asian?

Geneva: I mean, I think a little with like my eyes but uh, I mean, no, not really. (Geneva, Interview 3, 4-10-2019)

Geneva's mom also spoke about the fact that, as her daughter grew up, the adults around her compared her to her mother, a White woman, as a way of diminishing her ethnicity:

$[\mathrm{H}] \mathrm{e}$ said, "Lois you know she really doesn't look that Chinese. She kinda looks like you." And I said, "Yea, she's much fairer and her eyes are more round and her natural hair color is lighter than what my natural...” And at that point in time when Dan Horner is his name, made that comment to 
me. I still dyed my hair, so my hair was real, real, real dark. (Lois, Geneva's Mom, 6-25-2018)

This phenomenon also occurred in Sarah's family, as noted in a conversation with her father:

John: ...The kids that she was playing with, didn't know she was Chinese. Me: Yeah? They didn't? Why not? I...

John: I mentioned it. They said, "She's Chinese?"

Me: She had mentioned that a lot of people thought she looked like her mom. So that she didn't look Chinese to them. (John, Sarah's Dad, 7-102018)

Through our conversations and time together, Sarah and Geneva gave the impression that they did not want to seek out more information about their birth country. It is not that they are opposed to such information or activities but it is generally not their interest at this time. They seemed to enjoy being like everyone else to the greatest extent possible. Interestingly, the observations of the girls' school and community activities bore witness to the fact that these girls are not outwardly recognized in local conversations as being Asian. No one appears to look at them or treat them differently from the White students around them. Geneva states that any racism in the community or school is normally not aimed at her, but others. In this instance, a visiting friend was the target of racism:

Me: Have you come across, in the community any racism even if it is from people visiting in the community? ... 
Geneva: I haven't but sometimes, in like at Fall Festival, my friend's brother's girlfriend, I heard a story that um, she got racial comments at her and the brother was surprised that people were like this in here. And mom was like, "Yeah." ... Me: She's not from around here? She had just come in visiting?

Geneva: Yeah, she is Vietnamese.

Me: She's Vietnamese? But you haven't heard anything [racist] like that?

Geneva: No, not toward me, no. (Geneva, Interview 1, 6-25-2018)

As evidenced in Geneva's characterizations of racism projected towards outsiders but not herself as a longtime resident of Peak County, the girls' position is one of being protected and whitewashed. For example, they state that they are not affected but they seem to pay little attention to the racism around them unless it is brought to their attention specifically. Geneva's mom, Lois, believed that Geneva did not receive much bullying because of her phenotype, that was her mechanism for "deflecting" any potential racism. Racism is not a part of the girls' and families' vision of Peak County. Instead, it comes in from "outside."

\section{Context and Naming the Location of Culture}

I spoke to Lois, Geneva's mom, about choices of culture camps and culture schools and how they affected her and her children, if at all. When first becoming a blended cultural family Lois had sought out information about concerns and her choices as a mother of a TRAA. She spoke to another mother with adopted Asian children about her concerns and her experiences with adoption and also about culture camps. At this time Lois was living near Washington, DC. Her friend lived in Brooklyn. Lois explained the cultural context there: 
Darlene just laughed at me and said, "What are you kidding? I'm from Brooklyn. My neighborhood is culture camp. My daughter is exposed to the children next door, they're biracial. Up the street it's, ah, a lesbian couple with lovely children, so no, she's an American. She lives in Brooklyn, so I'm not really interested in that because we're a melting pot." [Darlene] was...and when she said that I kinda thought well yeah, that is a different perspective. Instead of being so worried about "Oh my kids are from China don't they need to know about that?" Well, they're Chinese Americans. They just happen to be adopted rather than having been born here. (Lois, Geneva's Mom, 6-25-18)

This melting pot idea is an old one, one not supported in the adoption community at large, at least in my experience and in the literature I am familiar with (Baden, 2007; Grotevant, Dunbar, Kohler, \& Lash Esau, 2007; Javier, 2007). This makes it interesting and somewhat surprising to hear how Lois learned how to reframe and define her children's identities as Chinese American rather than TRAAs who have a need to connect with their birth cultures. Lois, who was originally from a racially and culturally diverse area, moved to this rural Appalachian community and established an adoption group but did not believe in networking more broadly to celebrate her children's birth cultures with the exception of Lunar New Year. The group that Lois had established locally was originally to bring together families with like family cultures, transnationally adopted children (specifically Asian) and their white parents in the area that surrounded Peak County. Events did not focus on birth culture but more to establish that normalization of White 
parents and TRAA's as family units. It provided support to parents and recognition among families in the area. The one holiday celebrated annually was Lunar New Year. Lois did often bring in information and resources at this time depending on the year. In the Year of the Snake, participants got to learn more about snakes from a herpetologist. Another year they performed a dragon dance with help from a local artist. More often than not, it was a social activity for parents and children to meet and chat.

\section{Birth Culture: Asset or Add-on?}

Both families have had limited exposure to Asian culture since living in Peak County. They seem to have limited contact with mentors from the Asian community and do not see the necessity of doing what they consider "going overboard" towards their children's birth culture as if they are hesitant to embrace and remember the Chinese part of Chinese American. Sarah's father, John, explained his reasoning related to this issue:

John: We don't go overboard with the culture.

Me: ...What do you mean?

John: I mean doing everything. You know like the red envelope. [These are traditionally filled with money and given out on Lunar New Year to children in China.] We never done that. We just celebrate New Year's and Gotcha Day. [Gotcha Day refers to the day that transracial children arrive in the United States. This name is disputed among adult TRAA's as to its appropriateness]. We usually end up going to a Chinese restaurant because that's what she likes. (John, Sarah's Dad, 7-10-2018) 
Geneva's family echoed a similar tradition on her Gotcha Day. While her mother, Lois, spoke of the challenges of less opportunity to engage with Chinese culture in Peak County than their prior urban home. Like John, Sarah's father, Lois spoke a lot about Chinese food and festivals in her interview, and much less about the challenges of drawing on cultural assets and bridging cultural knowledge. The multicultural literature has long pointed out that food, fashion and festivals are the "go-to" resources of topical approaches (Au, 2014; Davis, 2007; 2014; Herrera, 2016; Schniedewind \& Davidson, 2014). Sarah's and Geneva's families seemed to replicate the same approach that has long been common in schools. More specifically, families focused on "post card" cultural approaches, which highlighted engagement with fun yet stereotypical "Small World" cultural activities. From the girls' perspective, Geneva explained in her third interview that she did not speak Chinese, but that she had a "China-themed" room in her home, where cultural artifacts were displayed. Likewise, in Sarah's home, her dance solo photograph was prominently displayed; the dance school had cast her as the South Pacific Islander Disney Princess, Moana.

\section{Rural "Idyll"- Racism Viewed as Exception, Not the Rule}

The safety of their children was a top priority for Sarah's and Geneva's parents. They stressed the safety of the local area as a good place to raise their children. Fears of the city or outsiders coming from the city disturbing local tranquility was a theme repeated by both parents and students. Problems always seemed to arrive from the outside, not the inside. Problems came from the city, 
not the rural area of Peak County. John, Sarah's dad, commented on an incident involving outsiders and racism:

John: Well the only thing we came across one time was down at Uno's [restaurant]. [Sarah] was playing on the outside equipment. And one of the "touron" [local name given to tourists by combining the words tourist and moron] kids just looked at her said, "What do you speak?" That was about it.

Me: So it wasn't even kids around here?

John: No, it wasn't no kids around here. I just told her, I said, "You know, when you get people out of the area, that's how they act.” (John, Sarah's Dad, 7-10-2018)

The mother of Geneva revealed issues with her older TRAA daughter as an example of out-of-towners being the racists:

So, this had to do with a Schwann truck driver calling her a derogatory name at her Sally's Restaurant place of work. [Me: “This is Kate?”] Kate, yea, and she saw me call Schwann's toll free international number and a few hours later having a conversation with a supervisor out of Valleyview and getting him fired. He eventually got fired because there had been other issues with this truck driver also. (Lois, Geneva's Mother, 6-25-2018) Geneva's mother shared in another story that Geneva's older sister had a problem while working at a restaurant with a couple from out-of-town who didn't want a "foreigner" waiting on them: 
Lois: [T]hen as the young adult working at Sally's Restaurant. And this is very political but again this is confidential. I'm a very liberal person and at this point in time, I am ashamed to be an American because of our current president. So when he was running for president, this was right before he was elected, Kate at her job was waiting on people, and she, whatever, she had heard them talking about Trump and then the other couple came in, whatever, and they basically told the manager... in front of Kate, "I'm not being waited on by any foreigner!" Now did that manager of this restaurant defend, ask the people to leave? No, they simply apologized to Kate that she had to hear something like that. (Lois, Geneva's Mother, 625-2018)

The families speculated about why the racism was starting to creep into Peak County on these few occasions, but were hard-pressed to name answers: "I don't know if it's ignorance, maybe that is too strong, it's just because people here haven't been exposed. They've grown up here and that is just the way it is. I don't know" (Lois, Geneva's Mother, 6-25-2018). Although he did see some racism "creeping in" to the county, John thought that "probably if anything is going to happen it is probably when she goes to college and she's out of the area" (John, Sarah's Dad, 7-10- 2018). Besides Geneva's example of her Vietnamese friend being targeted, the girls were hard-pressed to discuss race and racism in their community. In the next section, the participants elaborate on their dreams and aspirations for the future. 


\section{Where do You Picture You?}

Both the parents and the girls discussed the future in their interviews.

Although while in middle school and high school the teens did not seem affected by the lack of racial diversity, part of them still seemed to crave it. The students appeared to want to experience more multiplicity by seeking higher education experiences that included cultural and racial diversity. For the students themselves, it was a chance to see and operate in the "outside world" as demonstrated in this data.

Sarah on the future. In the following quote, Sarah expands on how she sees herself moving into the future:

Me: Where do you picture you? What type of place do you picture yourself living in the future... and why?

Sarah: I'm trying... I don't know... because I like rural now, but then I kinda want to go to urban. Maybe they like well, I know that North Carolina is not really... urban. I'll probably go somewhere urban and then like move back to rural. But I'm not really sure like where exactly I would go... Like bigger areas just like to get out of like small areas just to explore other places. (Sarah, Interview 3, 4-18-2019)

While Sarah was interested in trying out new places yet unsure of the possibilities, her mother Carol commented on how difficult it would be to let her go because she is "a girl" and her first child. She hoped that it would be a good adjustment if Sarah would attend a racially diverse campus like WVU, and not sure what it would be like to go to a new locale for college that was more racially homogenous, whether Sarah would be accepted 
or not. Ultimately, she believed that was up to Sarah to a large extent, and she worried how "friendly" she was and how able to make friends she might be (Carol, Sarah's Mom, 7-10-2018).

Geneva, who has had more experience in cities than Sarah, may have been influenced by that experience. When speaking of her desire to live in a more diverse area, she put a unique spin on her experience.

Geneva and her the future. Geneva said after living in a small town, "I definitely want like more diversity more things to do" (Geneva, Interview 3, 4-10-2019). When I probed for the reasons she considered moving to DC or Morgantown, as Geneva suggested she may, she framed the racial context of other places in relation to what she knew from Peak County. Instead of saying that she craved diversity, she said that she did not dislike heterogeneity: "I don't dislike not having a community of all one race" (Geneva, Interview 3, 4-10-2019). When I asked directly if she wished she had more people who looked like her, she said, "Yeah. Yeah more related to my looks. Um, I mean, I guess more fitting in. I mean I fit in here too more 'cause I mean, it's not, but it's just like more common. There's more diversity... and more, I don't know, just options. (Geneva, Interview 3, 4-10-2019).

Although both girls and their families had suggested that fitting in was not a problem in Peak County, and indeed, they even looked "White," they were more unsure about where their future would lead and why, as is common among teenagers, and especially middle-schoolers. Yet when asked to compare where they would best "fit in" from a racial perspective, people seemed to agree that it might be in a more racially diverse area, although they also saw that more than race mattered in assimilating to new 
contexts and places. Even at an unconscious level these girls are seemingly looking for that third space where they are able to communicate and express their Asian selves and their adoptive selves and reconcile it into a wholeness of identity. They have incomplete identities (Hübinette, 2007). This matches adoptive stories of awareness and searching that many adult TRAAs have, in my discussions with community experts, expressed.

In the next sections, I demonstrate that these ideas of otherness, Whitewashing, the downplaying of race, and cultural tourism, are reflected in administrators' interviews too. I show how the administrators react to race, culture and ethnicity in their schools and what they feel are the real issues surrounding diversity and education in Peak County 
Table 4. Teacher/Administrator Demographics - Middle School

\begin{tabular}{|c|c|c|c|c|c|c|c|}
\hline Pseudonym & Position/grade & $\begin{array}{c}\text { Kind of } \\
\text { interaction }\end{array}$ & Age & Gender & Race & Highest Degree & $\begin{array}{c}\text { Years' } \\
\text { Experience }\end{array}$ \\
\hline \multicolumn{8}{|c|}{$\begin{array}{c}\text { East Peak Middle } \\
\text { School }\end{array}$} \\
\hline Ben & $\begin{array}{l}\text { World history } \\
\text { teacher/ } 7\end{array}$ & $\begin{array}{c}\text { Focus Group } \\
(\mathrm{FG})\end{array}$ & 45 & Male & White & Master's & 15 \\
\hline Steve & $\begin{array}{l}\text { Computer teacher/ 6- } \\
8\end{array}$ & $\mathrm{FG}$ & 44 & Male & White & Master's & 23 \\
\hline Maggie & $\begin{array}{l}\text { World history } \\
\text { teacher/ } 7\end{array}$ & $\mathrm{FG}$ & 50 & Female & White & Master's & 27 \\
\hline Stormy & Science teacher $/ 8$ & $\begin{array}{l}\text { FG and } \\
\text { Interview }\end{array}$ & 51 & Female & White & Master's & 15 \\
\hline Grace & Librarian/6-8 & $\mathrm{FG}$ & 51 & Female & White & Master's & 29 \\
\hline Helen & Math teacher/8 & $\mathrm{FG}$ & 70 & Female & White & $\begin{array}{c}\text { Master's/National } \\
\text { Board Certified } \\
\end{array}$ & 30 \\
\hline Christie & Math teacher/7 & $\mathrm{FG}$ & 38 & Female & White & Master's & 6 \\
\hline Mel & $\begin{array}{l}\text { Language arts } \\
\text { teacher/ } 8\end{array}$ & $\mathrm{FG}$ & 48 & $\begin{array}{c}\text { Cis- } \\
\text { female }\end{array}$ & White & Master's & 6 \\
\hline Ellie & History teacher $/ 8$ & Interview & & Female & White & Master's & 25 \\
\hline Addie & ELA teacher/8 & Interview & & Female & White & Master's +30 & 16 \\
\hline Cheryl & $\begin{array}{l}\text { Principal/East Peak } \\
\text { Middle }\end{array}$ & Interview & 41 & Female & White & $\begin{array}{c}\text { Master's +30 Admin } \\
\text { II }\end{array}$ & 24 \\
\hline
\end{tabular}


Table 5. Teacher/Administrator Demographics- High School

\begin{tabular}{|c|c|c|c|c|c|c|c|}
\hline Pseudonym & Position/grade & $\begin{array}{c}\text { Interview } \\
\text { Type }\end{array}$ & Age & Gender & Race & $\begin{array}{l}\text { Highest } \\
\text { Degree }\end{array}$ & $\begin{array}{c}\text { Years' } \\
\text { Experience }\end{array}$ \\
\hline \multicolumn{8}{|l|}{$\begin{array}{c}\text { East Peak } \\
\text { High School } \\
\end{array}$} \\
\hline James & $\begin{array}{l}\text { Media/9-12, } \\
\text { English/ } 9\end{array}$ & $\begin{array}{c}\text { Focus } \\
\text { Group } \\
\text { (FG) }\end{array}$ & 42 & Male & White & Master's & 20 \\
\hline Kelly & Counselor/9-12 & FG & 64 & Female & White & 2 Master's & 25 \\
\hline Tammy & World History/11 & $\begin{array}{c}\text { FG and } \\
\text { interview }\end{array}$ & 50 & Female & White & Master's & 28 \\
\hline Fanny & $\begin{array}{l}\text { Theater I/9-12, } \\
\text { Theater II/10-12, } \\
\text { Set } \\
\text { Construction/9-12, } \\
\text { Spanish I/9-12 }\end{array}$ & Interview & 46 & Female & White & Master's & 21 \\
\hline Jesse & Unavailable & Interview & $\begin{array}{c}\text { Early } \\
30 \mathrm{~s}\end{array}$ & Male & White & $\begin{array}{r}\text { Teaching } \\
\text { certificate }\end{array}$ & 3 \\
\hline Morgan & $\begin{array}{l}\text { Algebra I B, } \\
\text { Geometry, } \\
\text { Algebra II/9-12 }\end{array}$ & $\mathrm{FG}$ & 36 & Female & White & $\begin{array}{c}\text { Master's } \\
+30 \\
\end{array}$ & 12 \\
\hline
\end{tabular}




\section{Administrators}

I interviewed the principal of East Peak Middle School, Cheryl. I also interviewed the principal of East Peaks High School, Noel. These experienced administrators provided a broad perspective on the community of Peak County as well as the schools the girls attended. While I sought to learn more specifically about the context of TRAAs' lives at secondary school from the principals, they were not certain of specific issues or examples related to these high-performing students who, consistent with the parents' and girls' own perceptions, seemed to mostly blend in with the other students socially, culturally, and racially.

The middle school principal, Cheryl, lives in the county next door to Peak, Pespco County, where she grew up. It is a 50-minute drive each way to and from East Peak daily. As such, she is much closer to a university community and has everyday experience with more diversity than what is in Peak County. In Pespco County, the schools are more diverse as opposed to Peak County. It is closer to a larger city associated with a college. She has previously taught in that county before coming to Peak County as a special education teacher. Then she became a vice principal at East Peak High School and then moved to her current position as principal at East Peak Middle School. She holds a Master's degree in Special Education and certification in Administration and Supervision. She seems to have blended these experiences into her administrative style. She is more teacher and student-centric than administrative, meaning she looks to find what she can do for the teachers and students before administration.

Noel, the principal at East Peak High School arrived in the county much differently. She would be considered more of an "outsider." She and her husband often 
camp and participate in outdoor activities. That is what initially brought them to the county. Originally from rural northern Pennsylvania and later moving to the Virginia area for her first teaching job, she was a music teacher first then a vice principal at a diverse school which had a Black principal. During the interview she mentioned how she learned a lot from this colleague and recognized those same opportunities for diversity were not available for students of color in Peak County. She first became a principal of an elementary school in the west side of Peak County. Noel holds both her Master's and doctoral degrees in Educational Leadership K-12. She follows the laws of the state quite closely. When working with teachers she is very mindful that staff follow the policies and procedures and seems to hold staff accountable equally.

In this section, I build on the discussion of TRAA students' and families' experiences by highlighting the perceptions of their administrators, discussing the themes of colorblindness in the secondary schools. I also explore the phenomenon of "transplants" to the community and their potential impact on TRAAs' racial identities. Finally, I discuss how school board policies, procedures, and the national education context influenced their abilities to promote a culturally sustaining education for TRAAs.

\section{Normative Understandings of Race}

The principals did not talk about race as being an important type of diversity in Peak County. Reflecting on the test and accountability culture of the county, they saw fewer honors students being produced in recent years, and thus a decline in test scores. Administrators were forced to strategize around student achievement. High performing Asian students blurred into this lens on management and organization. Although there are some culturally diverse students and families within the county, both principals regarded 
this as a small minority of children and instead described the economic and intellectual divides facing children and families:

I've really not seen a great population [of students of color] in school... Basically I've seen a greater division among the breakdown in the different sections that we have... now we have less honors level kids, less merit level kids and an increase in the general level... a more wider pot (sic) in the general numbers. (Cheryl, MS principal, 1-22-2019) We've kept a pretty decent socio-economic diversity as far as we generally have a pretty high proportion of students that are socially economically diverse. (Noel, HS principal, 2-27-2019)

Principals often situated themselves between the students and their own state and local supervisors, and the regulations with which they must comply. Another perspective that one administrator gave was the influence of state government on their school decisions:

...I have my own beliefs... but I have to filter that through the federal lenses of what my job is. And my job is to protect all students, and my job is to make sure that they all have a safe learning environment. If they're not feeling that way, that's problematic. (Noel, HS principal, 2-27-2019)

In this example, the principal foregrounds safety and protection of the students, as per the policies, but not necessarily to actively create an environment in which the students feel comfortable and welcomed.

The principals said that while they were uncertain about how TRAAs and other students perceived living in the county, children craved more cultural experiences. There 
was a sense that this was a "conservative" place in which residents "struggle with diversity" because it is overwhelmingly White. For TRAAs and other students, that meant that there was not "access or exposure" to people in their peer group that are of the same culture. Administrators thought that this lack of exposure to diversity would create future challenges for the TRAAs. They saw the generally homogeneous cultural context of Peak County as "difficult to navigate" at times because "there's insensitive people." Without specific strategies for understanding the social and cultural aspects of diverse communities, the onus is put on the students to be the peacekeepers and change agents. It appears from the principals' viewpoint that in order to maintain harmony, TRAAs and other students of color might first need to blend in:

[School is] the perfect opportunity to also be challenged and to grow and understand that there are challenges in life and you can learn from them and grow... (Noel, HS principal, 2-27-2019)

Noel, however, also explained that students of color should also serve as ambassadors for their race:

... and hopefully educate, would be my goal, the rest of the population to understand that. We're all human and we come from different backgrounds, and it's okay, and we have the unique fingerprints. (Noel, HS principal, 2-27-2019)

But underneath the project of creating peaceful schools there was an acknowledgement that tensions might bubble up:

But I think that obviously, you know, there's going to be some challenges inherently just because of the populations. (Noel, HS principal, 2-27-2019) 
In the next section, I discuss further principals' thinking related to the idea of a "rural idyll" that TRAAs and their families grappled with as well.

\section{Rural Idyll}

Race and racism were major challenges for the people of the area. The biggest problem mentioned by the middle school principal was drug use:

Drugs... that has been the major shift I've seen probably in the past four or five years...That's been the biggest, more than divorce, more than culture, more than employment, more than anything. Yep, I mean I think it is the root of all evil. (Cheryl, MS principal, 1-22-2019)

Drug use was not associated with a particular race at any time during the conversation. Instead, it seemed to be seen as a universal problem in the area.

Urban and rural spaces were discussed often by the principals, with principals characterizing the rural spaces as having more positive attributes. These administrators hinted at how this rural county tries to rediscover and keep its rural White roots by hiring into positions of authority those from inside the county those whose views reflect the local majority and not the local minority:

Cheryl: A lot of them are from here. Even our head of administration, straight from here. Now prior to Dr. Martin wasn't. She was from York County...I mean change can be good, but I think everybody should be open to new ideas. Just because it's been the same way for the same time, it doesn't mean that's just the way it needs to be all the time.

Me: That's an issue sometimes?

Cheryl: Sometimes, yeah! 
Me: Because we've always done it that way?

Cheryl: Yes, you know what I'm saying! Yeah.

Me: And that's the way it works?

Cheryl: Yeah. (Cheryl, MS principal, 1-22-2019)

\section{What is the Role of the School Relative to the Rural Idyll?}

Although the administrators saw the community as conflicted and drug use as a major problem, schools were also seen as a "shelter" from the storms that might occur, again from the outside world:

I think from my perspective the benefit is that our county and our community is so sheltered that there's a lot of wonderful things that occur. We have really great behavior. We have really great, you know, students and teachers and we have this level of camaraderie because everybody, that you know, if you take race out of it, there's that advantageous nature of just being in our county for that reason if that makes sense...there's that inclusiveness that you know, we're all in the EAGLES family. We're all EAGLES, you know. We have strong sports programs from academic programs. So they gain, all students, regardless of race, gain from being in our community for that reason. (Noel, HS principal, 2-27-2019)

Cheryl, the middle school principal, agreed with the high school principal about the camaraderie, and shifted the challenges to the natural, individualized nature of child development:

I like to say that Peak County kids are kind kids. For the most part they just like one another, get along with each other. Most of the time in the middle school the root of all evil is between a boy and a girl because they 
don't want to date each other and someone else is dating him or her!

(Cheryl, MS principal, 1-22-2019)

And although the high school principal foregrounded team spirit, she acknowledged challenges:

We're very sheltered, I know when I was working at the elementary school there were students who had never seen someone that was from like the African American culture or different culture. Like they had never experienced an interaction with someone from a different culture. (Noel, HS principal, 2-27-2019)

Children arriving in the county from outside Peak were seen as a problem specifically if they were from the city and clung to "ideas from the city." For example, when speaking about the racial mix in their schools, the principals agreed that the slight increase in racial diversity over the years has been from increased foster care placements of students from Baltimore. These students are associated with services and needs that require time and resources from schools and administrators:

I've had a few more students over the course of the last seven years that are joining our population from different backgrounds, diverse backgrounds....Most of the ones that we do have here have been a transfer through foster placement of DJS [Department of Juvenile Services]... I know directly over the past 11 year they have been through those agencies. (Cheryl, MS principal, 1-22-2019) 
The administrators explained in their interviews that the demographic shift affected relations. Children sometimes contributed to an insensitive environment at school, according to the administrators:

It's really a small portion of people, in my opinion, that just have their mindset of a certain way and they are in a rural location and they don't have a lot of diversity around them. And for whatever reason they have insensitive mindsets relative to that but, I mean, I have had students that have been insensitive to students. It's not a lot and it's not on a regular basis, but there's, and those same insensitive people are in the city too. It's just I haven’t experienced that. (Noel, HS principal, 2-27-2019)

Throughout these conversations about demographic shifts and race relations, TRAAs are not seen to require this amount of labor and care as the new students, often Black students, who entered Peak County in recent years. In the racial equation, TRAAs seemed to become displaced to a degree in the minds of administrators because they simply were not discussed or thought of in the context of racial changes and challenges.

\section{Deflecting Race}

Race and racism were mentioned occasionally by principals as they discussed the community, but much less when talking about their schools. In schools, race and racism was constantly downplayed. Principals deflected discussions of race by demoting it to "name-calling," "a love triangle," "a problem," or "joking." This is the so-called "drama" that is often not identified as bullying by teens: 
[W] hat most teens consider bullying is not the same as adults. For teenagers, it is not bullying if rumors circle online and both parties are contributing and fighting back. This is called drama... this definition is that there must be a difference of power and it must be repetitive and ongoing. (Deogracias, 2015)

Teens negate the importance of these situations and in direct reference, so do teachers and administrators (Dennen et al., 2018). These issues also can point to outside social media or television as the ultimate problem causing conflict:

We had an incident where a student flew off the handle on social media. (It) had nothing to do with some of East Peak High School, but it happened outside in our community, and it bled into our school. This individual was in our office before the bell rang because she knew she said something that she should not have said and the wrath of the people, both cultures, because we have a large population that obviously we have Caucasian and then we have minorities and that's a lower population. (Cheryl, MS principal, 1-22-2019) "Bleeding into the school" and provoking a "wrath" at school was one example of racism coming in from the outside. Another was a conflict in which a student of color was positioned by the principal as both perpetrator and outsider:

Back at West Peak High School we had a student who was... transplanted, who was into an issue with a student on a bus... I think the ultimate was they were arguing over whose boyfriend belonged to who... Then you have the conversation with the African-American girl, who's the 
transplant here and she goes, "Well if I'm saying that among my own kind it's fine, but what I'm saying to a White girl, she's trash!"... So it's a very interesting dynamic talking to the two, the girls. (Cheryl, MS principal, 122-2019)

In this case, the problem was that the administrator viewed the important dynamic as understanding the differences between the students more so than advocating for an anti-racist learning environment. In carefully considering the patterns in my data, it seems that those in power did not want change from the outside that might create conflict and misunderstandings. There is no space for social justice when the focus is on surveilling or stopping bullying for the short term rather than a deep and long-term focus on social justice. Humans typically see no need to change when things are good and perceived as even better than the outside world. In middle and high school, students will interact with a wide variety of adults. Most of these adults are their teachers. Teachers hold great influence in the areas of students' perspectives about themselves, their capabilities, and their future. Administrators guide TRAAs and other students and in some important ways serve to shape school with the policies they make and the tone they set. But teachers have significant influence in the classroom.

\section{Teachers}

In this section, I consider how the teachers saw themselves and their students, particularly TRAAs, within the negotiated spaces of race and class in rural Appalachia. I had the privilege of talking with Sarah's and Geneva's middle and high school teachers, respectively. I met with them individually as well as in focus group interviews. Throughout the months I spent interviewing them the adage, "People show you who they 
are" continually came to mind because the teachers used many rich examples and metaphors to show the complexities and tensions in their thinking about race in a rural Appalachian community. During the interview process, I noticed how the teachers were constantly evaluating, reflecting and trying to work out how what I asked reflected on their practice and how what they said would be taken and used. They seemed to be very open in their answers although they also appeared to think they really didn't have much to say. The truth was they had very much to say.

In this section, I discuss the middle and high school teachers' themes of how they viewed TRAAs in the context of the community, how they perceived middle and high school students generally to perceive TRAAs, and why.

\section{The Blessing of TRAAs}

For teachers, the idea of adoption is a vague one, as they rarely have been active participants in the triad of birth family, child, and adopted family, especially at the middle and high school levels. To further complicate this concept is the addition of both transracial and transnational children into the mix. Teachers in this study have made several assumptions about TRAAs and adoption in their schools. The literature on adoption shows that every child of adoption suffers from the trauma of loss and separation, even in adolescence (Bartholet, 2006; Debiec, 2018; Javier, 2007). In this data, however, students were viewed as a blessing to their families because the children were chosen by parents and therefore likely only to have positive experiences in their homes, which may transfer to school. 
I'm thinking are you referring to average intelligence, well adjusted, for whatever reason you were adopted and you were brought here by a sane, stable family... (Grace, MS Focus Group, 3-20-2019)

This teacher, Grace, contrasted the blessing of TRAAs' adoption to the "other" way that teachers could receive students of color in their classes, which made the "blessing" relative:

...as opposed to, we just pulled you out of Baltimore because your parents are somewhere or nowhere anymore. And we're going to put you up here. (Grace, MS Focus Group, 3-20- 2019)

In just one case in the study, a teacher discussed that a TRAA might incur some distress through the adoption questions asked to them by other students. In my data, this was not viewed as a real issue to be concerned about:

Ellie: Every once in a while [another student] maybe, you know, they might bring up [adoption]. Well, "Do you know your background?" "Do you know where, you know, your biological parents are from?" Once in a while. Not too much, just out of curiosity. (Ellie, MS teacher, 1-16- 2019) Adoption itself, at whatever age, is a trauma. It does not matter to what extent the child can have "good" adoptive parents and still have issues that spring from adoption. Older children are known to have trauma of separation but infants can also suffer attachment issues (Javier et. al. 2007; Jerng, 2010; Tigervall, \& Hübinette, 2010). Transracial adoption adds another layer to this complicated issue because trauma can manifest itself through other possible issues like attachment disorders, or anxiety that often does not appear until teen years. (Javier 
et. al., 2007). Children of transracial adoption can face racism or not, but even just looking different affects perceptions about themselves socially and culturally. The need to reconcile the different parts of themselves and their positionality amongst others in their peer group is a trauma while often deemed "blessed." (Schwartz, Luyckx, \& Vignoles, 2011; Tigervall, \& Hübinette, 2010). Being "blessed" promotes a negative view of self in that obviously America was the better place to be so their birth country becomes part of a deficit view of the child and xenophobia is reinforced.

\section{Blending In}

The ability to blend in socially and phenotypically was brought up by teachers as a positive for adoptees and children of color overall. Based on the teachers' data that follows and as seen in the students' and families' perceptions earlier, becoming one of us was an important factor for success in the community. Once that was broken in any form, entrance into the community could be lost. TRAAs had an advantage in some sense because they typically grew up in Peak County. But for other adopted students in the county, identity was different in some ways, as teachers noticed:

She was adopted. She was part Black but she looked White. The kids all through elementary school and all through the middle school thought she was White. Well, somehow it came out when she got into high school that she was part Black and it was then kind of the, "Well, who do I date now?" kind of thing that she ran into. (Helen, MS Focus Group, 3-202019) 
This misunderstanding about identity was confusing and difficult for the child, yet something the teachers felt uncomfortable with yet unequipped to support. Again, this need for students to be homogeneous, part of the sameness of neoliberalism, is used as protection. The teachers continued their conversation by discussing another child who was White, yet adopted internationally. He also experienced challenges:

Grace: Todd Smith was adopted from Russia when he was probably five. And, I remember in seventh grade him saying one day, "My mother didn't want me so they sent me here." And I thought, "No, they don't just pick a number. Someone wanted you." Maggie: ...chooses you.

Grace: And for the longest time, and I honestly think that has affected his behavior and that he feels unwanted and that was something you didn't want to talk about, didn't want to deal with you just knew that his mother hated him and she had sent him away. And I always think, "Wow, that is not something I'm going to want to talk about. I think adopting is such a personal... maybe you wouldn't want to talk about maybe you wouldn't want people to know any more than they... (MS Focus Group, 3-20-2019) At this point in the focus group, teachers had some sudden realizations. First, they saw that transnational adoptions can come with unknown complications and secondly, it became apparent that teachers are ill prepared to talk about those complications. Both teachers, Grace and Maggie, wanted to look at adoption as a "blessing" rather than the losses that the child was actually feeling. Talking about feelings felt like they might be 
intruding because "adopting is such a personal [thing]." This deflection, is rooted in the topics and feelings brought up in the discussion. In this next section, a teacher brings up that Todd can get away with not talking because he is White, which is confusing too. Helen starts to process the complexities of being adopted internationally, the knowns and unknowns are part of the puzzle:

Helen: But he can get away with it because he doesn't look different than the rest of the kids here.

Grace: Right.

Helen: Where an Asian kid...

Grace: Right, you're right. (MS Focus Group, 3-20-2019)

In reality, there is no choosing a child, children are placed with a family in transnational adoptions. In a transnational adoptive family, the children can often "blend" into White families because for many years, as mentioned in Chapter Two Russia and other European countries were the birthplaces of transnational children; therefore, many transnationally adopted children are White. When a teacher states, "But he [a White transnationally adopted boy] can "get away with it" because he doesn't look different than the rest of the kids here" she also suggests that on the flip side, transracially adopted children cannot blend into White America because of their skin color. But Grace goes on to share how Todd still has effects of international adoption trauma, yet then dismisses them:

Grace: In seventh grade [Todd, a Russian adoptee] said one day, "My mother didn't want me so they sent me here" and I thought, "No, they don't 
just pick a number. Someone wanted you.” ((MS Focus Group, 3-202019)

I interpret this quote to show how blending in can be used to dismiss the effects of transnational adoption trauma even when the child is White.

\section{Model Minorities-Plus}

The TRAAs in this study were constantly referred to by the teachers as "exemplary students". This fits with the model minority stereotype. But, they were not immigrants and they had not often moved to Peak County from other places. They had grown up in Peak County and they were considered to be "well established" in the community. One teacher alluded to assets, such as blending in and being stellar students, as skills that should be acquired in to order to succeed at school, skills that Sarah and Geneva exhibited:

The [TRAA] students... who weather [adoption] well, are the students who are well socialized, who have supportive parents, who are involved in the school, and have good social skills. (Kelly, HS Focus Group, 3-262019)

Some teachers stated that the TRAA students they worked with blended into the community so well they were "one of us" or part of the "White club". Perhaps they are the "other White people" in the crowd, as Asians in general are often characterized to be in the U.S. The following data shows additional teachers' perspectives on the two girls studied. Sarah was portrayed as a model: 
I think she's [Sarah] been brought up to...she's very confident. The kids are very accepting... I guess because they've known her from such an early age. (Ellie, MS Focus Group, 3-20-2019)

As was Geneva:

I think she's [Geneva] had amazing support not only from home, but from community. That never once has she been thought of as adopted. Never once has she been thought of as anything less than at home and belonging. So, I think, I think she's very, very, fortunate in that. (Jesse, HS Focus Group, 3-26-2019) Referencing how "fortunate" she is replicates how blessed and gifted she is, fitting in and being "whitewashed" to be one of us. To be whitewashed in this instance is like the fence in Tom Sawyer, but metaphorically painted over with a wide brush to become more White in both action and thought. But in this case, the extreme of whitewashing is to negate Asian features to say they look White too (Chevalier, 2016; Norris, n.d.; Pyke \& Dang, 2003). A hallmark of the model minority status is growing up in a two parent home. However, being told you belong is very different from actually belonging.

That particular child, [Geneva]... She carries no accent that I can perceive. She's a beautiful child to look at. She's a talented child, gymnastically talented and her skills, like you can see, she's super optimistic and upbeat, so I think that she has put some skills in her own corner that's made it easier for her here and easier socially. (Fanny, HS teacher, 1-24-2019) 
The "skills" she has acquired seem to resemble some of those represented as a model minority: smart, hard-working, self-reliant, obedient, uncomplaining and never in need of assistance (University of Texas Austin, Counseling and Mental Health Center, 2020). This negates the possibilities that these skills are representative of all races, not just whites. These expectations and skills can also mask many hidden problems, the least of these being problems when a TRAA does not match the model minority or is indeed not having educational needs met because they are assumed to be doing fine.

I don't think she [Geneva] sees herself, I personally don't think she sees herself as a minority. ...I don't see it. (Tammy, HS teacher, 1-8-2019) This ability to not "see", to be colorblind, is a gift only to White people (Burke, Jayakumar \& Adamian, 2017). Not seeing color seems like a positive, but actually color is a negative. One wouldn't want to have a child looked upon as less than White because White is the norm.

The teachers in this study used particular discursive practices to construct TRAAs as White. Teachers would connect back to other TRAA's with whom they had experiences. Using this information seemed to also justify and establish their points of acceptance and lay the groundwork for erasing negativity towards Asian adoption and any effects of racism:

She's [Geneva] very similar to the student [Rachel, an older TRAA who has graduated and is now in college] that I have mentored... Neither one of them [Geneva or Rachel] know limitation from diversity. Which I so admire... Never once has that young lady [Geneva] said, "I'm different than anybody" or I've never heard her say anything about, no comments 
about race, or about challenges or even about being adopted. ...I just, I'm amazed that never once... have I verbally seen or emotionally seen, "Hey, I'm different," or “I'm, I don't get equal opportunity because I'm different... or people think less of me because I'm different." (Jesse, HS teacher, 3-5-2019)

Jesse uses this ideal to not only portray these students, Rachel and Geneva, as perfect students but also negates the rights of other minorities to have problems with race. By invoking the myth of the meritocracy—that if TRAAs can "do it" anyone can — the teacher takes up Whiteness and its fragility. She denies the effects of structural and institutional racism on students of color and their families. Although Geneva and Sarah were discussed by their teachers as model minorities-plus because they were beyond ideal. But, as I have experienced as the mother of a TRAA and as the following data hints at, the assumption that all is well internally or externally can be deceiving, as one teacher realized in an inconsistency through personal experience:

My niece, my sister's niece and nephew are adopted from Asia and they seemed popular, what I could see, but they said they were bullied in school for their ethnicity. (Maggie, MS Focus Group, 3-20-2019) Teachers may assume that because a student blends so well into the classroom their race has no effect on them. Teachers' thoughts on the identity of their community, themselves, their students and specifically the TRAAs was revealing of how their positioning in the community supported this super-normalizing racial discourse, reinforcing the one also constructed in families. 


\section{Rural "Idyll"-Contextualizing Racism}

Like the other participant groups, the teachers spoke about various threats to the peaceful bucolic nature of Peak County coming in from the outside. The seasonal residents in the resort areas and the college students that came to the county to work in these resorts changed the demographics for three months of the year. As middle school teacher Ellie said, "You know you can't keep the outside world from coming in." Having the outsiders each summer, however, meant that students and community members were exposed to diverse individuals in a cyclical fashion. Teachers also recognized, "I think of Peak County as being about very White conservative people who don't venture out a lot" (Stormy, MS teacher, 1-14-2019). Following on this idea, teachers believed that there was an ignorance towards people of color ignorance that "starts in the home a lot of times" (Addie, MS Focus Group, 3-20-2019). Several teachers made comments similar to this one:

I would say we have a large population of ignorance as well. So, I think as a disadvantage for a child of color, they would probably be prone to getting some misuse not just in school, but in all areas of their lives. (Mel, MS Focus Group, 3-20-2019)

The ignorance from some of the White families that the teachers identified seemed to stem from stereotypes that were reinforced by examples within the community. Specifically, teachers "blamed the victim". They stated that TRAAs galvanized the stereotypes that others had about them because they actually did (in the teachers' minds) fit the model minority stereotype to a tee. 
Blame the victim. Blaming TRAAs as the victims of their positioning was one strategy that the teachers mentioned:

They're so smart. Okay. I do hear that, about the family in our, the Chinese family in our community and those kids are smart, you know. And so, because they may fit that stereotype, they helped propel it without meaning to maybe? I also think that generally our Caucasian students are a little bit more ignorant about what are the stereotypes because they just don't have exposure to these other cultural groups. (Fanny, HS teacher, 124-2019)

The results of this ignorance in the community can have harsh consequences.

Demonizing difference. As I explained in the sections about the students, families, and administrators, alienating and ostracizing differences were not uncommon in Peak County. Although Geneva and Sarah seemed to experience little overt bullying directed at themselves, dysconscious as well as targeted racism seemed to be on the increase. One of the teachers explained why she thought this was:

Some of those folks are just being plain out afraid. You know, "Oh the gangs are coming!" and anyone Mexican has to be a part of it... that whole South of the United States culture. And, so, I think it's a lot of paranoia. And of course we know that transfers from parents to children. And, so, when you are afraid of something it's easier to make fun of it. (Stormy, MS teacher, 1-14-2019)

Not only were outsiders a perceived threat to the rural "idyll" but so were insider groups that historically have organized against difference. 
And there's, there's a group, there's a group brewing in Peak County. That's under, they're not brewing. They've been here for a long time, that are White supremacist. They just are. And the children of those people come here. And then you know, I've heard it said in the lunchroom, "We hang Niggers here." And that's, I'm sorry (starting to cry). That's like real, that poor child [black/biracial student in cafeteria] you know and I just feel like it's got to be super hard. I don't see those children [minorities in the school including black/biracial and TRAA's] get dates to homecoming, honestly. I think it would be miserable. (Fanny, HS teacher, 1-24-2019) These teachers' comments recounting the tensions and challenges in what seemed to be such a peaceful and protected community are similar to those of the families and the administrators. These ideas disrupt the myth that Peak County is a protected space for all children and families. In the next section, I will discuss the diverse viewpoints of the teachers related to how they saw their students' racial identities.

\section{Teachers' Perspectives of the Students' Racial Identities}

The teachers spoke often in their interviews about youths' socialization in the rural context. Several themes suggested processes that the teachers saw as shaping youths' racial identities.

"Small world". Teachers on several occasions referred to the rural idyll as a "small world". This phrase has Disneyesque connotations. The teachers expressed that the "small world" they live in was not just a physically small town or small community, but rather the fact that many students never leave that community for most of their lives, 
“...their world is very small. For a lot of our students their worlds are very small. They don't get out of the county very often" (Ben, MS Focus Group, 3-20-2019). Following the literature on the rural brain drain in which teachers' mission is to push the best and brightest students out of the local community for more opportunity (Carr \& Kefalas, 2009, 2010), several teachers made comments like this one:

Some of them, they don't even know that you know, our neighboring county is a different county. Like, "Oh, I just thought that city was still part of my county and like it just kind of opens their eyes a little bit... It's sad, some of them... (Addie, MS Focus Group, 3-20-2019) Speaking from experiences from when I taught fourth grade I witnessed this firsthand. I had a student who lived with his parents and brother in a home that had a dirt floor. I had the opportunity to take him to Baltimore along with his mother. He had never seen the bay or ridden on a boat. The best part of his day was riding the water taxi. Another student on a different trip to Baltimore commented, "There are certainly a lot of Black people here, Miss Wilson [my maiden name].” These experiences have always reminded me how small the students' world is in Peak County.

Qualified acceptance. According to teachers, their students seemed to become more open to differences amongst their peers even though, as stated throughout this section on teachers' perspectives, there were certainly racial challenges within the county. This was a hopeful observation within the research.

I noticed kids in my opinion today are more... welcoming of, just with the different ...the change in the whole United States. It just seems our society is changing and I feel like I'm seeing it here. Changes where people are 
more accepting of those who are a little different from them.... Special ed kids, the ones I have now nobody ever points out that they receive extra. Or that their test might have to be read to them. ...And they don't say, in the past when we regarded inclusion, it was a much bigger deal. Like "Why did they get this read to them ?" (Tammy, HS teacher, 1-8-2019) However, this example was limited to disability rather than an acceptance of racial differences. In that sense, it was qualified:

The one advantage I think in Peak County is that we still have relatively nice kids here. So, I mean when I talk to counselors and some other schools, and they are daily putting out fires because it is constant battles going on in the school.... our problems are not at the scale that I've heard of from some schools in urban areas. (Kelly, HS Focus Group, 3-26-2019) This example seems to qualify that disruptions in this county were few compared to urban areas. This seems to parallel literature that links notions of chaos and danger to conceptual Blackness and notions of innocence to Whiteness (Goff, Jackson, Di Leone, Culotta, \& DiTomasso, 2014).

Developmental levels. Middle school and high school teachers viewed their students' attitudes towards race and social inclusion differently. The middle school teachers believed that the age level leant itself towards problematic thinking due to immaturity. The high school teachers stated that their students grouped themselves by different categories, yet race was not one of the categories mentioned:

Students separate themselves by all kinds of labels... "That's the prep group" and, "This is the this group, and this is that group, and that's the 
redneck group"... and there's a certain amount of association and belonging to doing that I think, but there's also some... students who are more accepting than others and some are not. They're going to run into kids who are not accepting of their differences." (Kelly, HS Focus Group, 3-26-2019)

The small world realities of students, their qualified acceptance of differences, and unique developmental levels revealed that there were no clear patterns or processes through which teachers viewed their students' perspectives on race. From these questions, it was difficult to tease out answers as to how typical students viewed TRAAs and other students of color. As we saw in the discussion of students' and families' treatment of race, the teachers also seemed to deflect discussions of race related to their students, yet in a different way.

\section{Classroom Challenges}

The individual and focus group interviews with the teachers brought up five unique challenges for the classroom that, if addressed, would support TRAAs' identities and learning, and indeed these challenges impact all students such that addressing them might better support all learners.

Challenge 1. Assuming assimilation of TRAAs. The first challenge was a deep and pervasive understanding that because TRAAs have grown up in Peak County since they were very young, they and the community has had sufficient time for "total assimilation" (Tammy, HS teacher, 1-8-2019), such that they are "typical" students and community members. A teacher named Jesse put it humorously: 
It's like a dog thinking it's a cow. You know, or a duck thinking it's a dog. You hear those stories and it's not that I'm equating children to animals. But it's the dog doesn't know any different and the duck doesn't know any different. Just how they were raised. (Jesse, HS teacher, 3-5-2019) Jesse's metaphor reveals the double-consciousness of teachers - that they are aware to a degree that the context of "assimilation" affects the ways in which they view TRAAs as "White". It is a challenge for teachers to know how to act on the knowledge that assimilation may distort children's identities and realities. It also supports the need for teachers and schools to support heterogeneity of students and ideas instead of homogeneity.

Challenge 2. Deflecting race talk affects TRAAs. Race talk has been a major theme in the teacher's data, as it also was for the students/families and administrators. I found that the challenge for teachers around race talk was balancing how to respect all ideas and opinions, to remain a focus on academic learning, and to bound the teacher's role (to teach academics as efficiently as possible) and the administrator role (to deal with race talk). In the context of an intensified emphasis on testing and accountability for academic knowledge. There were three processes that teachers used to deflect race talk that I will explain next. "Americanism". Identifying as "American" rather than a particular racial or ethnic background has been a common political strategy in Appalachia related to Whiteness and instantiating cultural homogeneity in a region that has long been oppressed due to the extractive industries and positioning of poor and working class individuals, mainly White, related to these industries (Anglin, 2016). 
Homogenizing students was common amongst teachers in Peak County, as in the data below:

[TRAAs]... they have American values. They have American mindsets. They don't... think any different... Culturally, they're not... too different. So... a lot of students just either don't care to notice or have chosen not to notice. (Jesse, HS teacher, 3-5-2019)

Jesse's explanation that students have not chosen to notice race is provocative in that, as teachers like Jesse talk about race, they begin to realize that they hadn't noticed race or culture and its effects on them and on students.

Tangled up in "diversity". Another mechanism for deflecting the conversation away from race was to grapple with meanings of diversity, asking, "What is diversity?" When I mentioned that in the context of TRAAs I was primarily interested in race, but the teachers would often unconsciously switch to other "safer" identity markers, for example: "[Diversity] is being different but in my eyes academically and emotionally and psychologically there's no such thing as diversity" (Jesse, HS teacher, 3-5-2019). By doing this, I felt they were avoiding discussing racial differences and thus making race itself an unacceptable topic. The challenge is supporting teachers to understand the intersectional nature of diversity while still understanding how race matters in the lives of TRAAs and their families, as well as for rural Appalachian schools and communities-it is both/and thinking as opposed to one way or the other, but the analysis needs to be understood in context. 
Trading culture talk for race talk. The final mechanism that teachers used for deflecting race talk was to trade it with culture talk as a means of deflection. For example, in a discussion with a teacher about race, she shifted the conversation to highlight how great TRAAs sharing their birth language and culture could be:

I had one website that a student made... completely in Chinese. I had no idea what it says. She got a hundred percent on her website. ... But you know other students got to see her make that and ask questions. So that was really good for people physically directly around her and I was excited about it as a teacher, you know. (Jesse, HS teacher, 3-5-2019) Some teachers have tried but given up on lessons about different cultures or related to culture:

So, I feel it's kind of double-edged when we say we should do cultural lessons because you can teach kids about other cultures and you can talk about tolerance and acceptance, but you can't change the attitude [of prejudiced students]. ... So ... you deal with it straight.... I think... that's how we address it. (Grace, MS Focus Group, 3-20-2019) Grace's example is that the approach has shifted to not actively teaching about cultural knowledge in the classroom because it may bring on a wave of microaggressions afterwards.

Challenge 3. Exoticizing particular differences affects TRAAs.

Interestingly, while TRAAs were seen as assimilated into the community and thus beyond the fray of teasing and bullying, as we have seen in Challenge 2 above 
and other data, this is not the case. There was a parallel identity process for students who were immigrants new to Peak County, for example some new immigrants and foreign exchange students. Their entrance was seen as novel and they were unique and worldly, thus they were not teased by other students according to the teachers. Instead, they were seen as "cool" like Brian, a student who travels to visit extended family in Peru each year, as multiple teachers mentioned:

Isn't it interesting that students who come from other countries as exchange students are seen as exotic and interesting? And students who are here all the time are discriminated against. (Fanny, HS teacher, 1-242019)

If we have someone who is... from a different culture, sometimes they're the cool kid, because everybody wants to learn or hear them speak their native language. (Tammy, HS Focus Group, 3-26-2019).

In the data that follows, the influence of the news media on white fragility have also impacted the area, according to teachers. They have noticed that some of President Trump's policy agenda items such as building the wall between the U.S. and Mexico, and the separation of children and families at the U. S. /Mexican border have shaped how students view, and unfortunately bully, the small Mexican immigrant population in the county:

The name-calling and the racial slurs towards the Mexicans, seem to be more prominent. And I believe those children actually dropped out of several activities because of that situation. And I really think a lot of that 
had to do with... the news stories, the media. (Stormy, MS teacher, 1-142019)

Another participant, Fanny (HS teacher, 1-24-2019), mentioned that media and news stories also influence the ways in which Black students are treated by other students. In this, it seems that TRAAs seem to be forgotten at times when it comes to potential bullying and harassment as they are positioned between the "cool" newcomers and those that are demonized in the media. Challenge 4, presented below, addresses specifically how bullying takes place for TRAAs in "the middle."

Challenge 4. Bullying TRAAs is minimized. Many teachers in the study looked at racial name-calling as a small offense and often dismissed it as such instead of labeling it the "microaggression" that is a driving force behind racial tensions in US society today. The following examples from teachers' interviews illustrate their thinking that racial name-calling towards TRAAs is a normal behavior for secondary students:

...I have children who make an inappropriate false Chinese type language and say things like "ching chong" and that kind of stuff. So that's a norm in my opinion that I've seen in just two years. (Mel, MS Focus Group, 320-2019)

All I've really seen is name calling, but that's not something that I had to speak to kids about. It's also not something that happens frequently and it's not necessarily something, it's not like I'm disciplining over that more than anything else. (Morgan, HS Focus Group, 3-26-2019) 
Unfortunately, because TRAAs "get lost" in the middle of new immigrant students and exchange students who are "cool" and the African American students who are often demonized in the media and society, when bullying occurs towards TRAAs, it seems to be minimized by teachers.

Challenge 5. Teachers do teaching, administrators do race. As we saw in challenge three above, teachers have several strategies for deflecting race talk at school. Deflecting race talk generally seemed to position teachers as "innocent" regarding the responsibility to teach for social justice around race and to insist that all students respect each other. Indeed, from the interviews I found that the teachers at the secondary level were overwhelmingly opposed to teaching about race and racism in class. When the idea of facing racism and talking about it in class occurred, a reverberating "no" rang out. The teachers strongly believed that teaching about race and racism directly in middle and high school made the students think about race and racism, which then stirred them to use racist language towards their peers. There was one teacher, James, who was at first hesitant to do a civil discourse lesson in his class, but when he did he found that the students responded very well. By and large, however, the teachers were opposed to teaching about race and racism:

In the middle school, you teach a lesson, they walk out of the room, and they start making fun of them. I think you actually point the spotlight, as one of you said. (Steve, MS Focus Group, 3-20-2019) Why would we draw attention to something we don't want the students to draw attention to? (Stormy, MS Focus Group, 3-20-2019) 
Studies continue to show that talking about race and social justice lessons are what are needed in schools to promote students' knowledge of social context and to promote thoughtful, peaceable social change within society (Chubbuck \& Zembylas, 2016; Dell'Angelo, 2014; Gonzalez, 2017). It is ironic, then, that teachers in general completely removed race from the classroom as much as possible, shifting the burden of dealing with extreme racial slurs and aggressive behaviors to the administration, as stated in this quote:

Because we have no training on how to deal with a problem like that.

What do you do? If a student says, "We hang Niggers here" we send them to the office. (Fanny, HS Teacher, 1-24-2019)

Because teachers don't seem to address this racism in the classroom either directly or through socially just education it is often left to the office to handle. However, Fanny pointed out that something more is needed to be done here for the students, beyond sending them to the administration for discipline:

That's what we do and that's not enough. That's not enough. That didn't help that child. I mean if anything that made it worse. (Fanny, HS Teacher, 1-24-2019)

Fanny, like James, saw the need for learning how to bring discussions and teaching on race and racism into the secondary classroom; in their eyes, it was not only about discipline, but about a lifelong learning opportunity. These teachers' insights show an opportunity for developing race talk in Peak County. 


\section{Summary}

Throughout this chapter I have told of three perspectives; families' (TRAAs' and parents'), administrators', and teachers' perspectives. The TRAAs and their families spoke of the normal American lives their daughters lived. The girls themselves spoke of blending in and having few challenges outside of typically teenage issues. The administrators in this chapter were recognized as the peacekeepers and negotiators of their buildings. As the leaders they too seemed to view TRAAs' challenges as nonissues. Indeed, there were bigger problems such as drugs. Administrators were also the guardians of policy and conveyed that policy down from state and local officials to students and staff. They viewed their students as overall "nice kids." Teachers, by far, had the most to say in this study. Teachers often viewed race as challenging, both discussing it and dealing with issues that come up in school and particularly the classroom. Teachers often viewed TRAAs as doing well in the school. When asked directly about race issues they would deflect the conversation to other more problematic issues. When dealing with race it was expressed that those issues were handled by the office and school policy. Again, we have "nice kids." Race issues are few and far between, until they're not.

In my final chapter I will discuss the findings, implications and conclusions that I look forward to sharing with my teaching community in Peak County. It is my hope that we can work together to support children, families, and each other through additional education, dialogue, and learning about race in the context of TRAAs and more generally. 


\section{Chapter 5: Discussion, Implications, and Conclusion}

This final chapter of the dissertation seeks to "tie together" to the greatest extent possible what was learned in this project through a discussion of the findings that were presented in Chapter Four connecting these with the broader literature. Then, I provide insights on the implications of this work for theory, methodology, policy and most importantly practice with local educators in the community. My hope is that some of these implications may have generative value for similar communities seeking to support TRAAs, and all students. Finally, I share my conclusion with my readers.

\section{Discussion of the Findings}

I started this study thinking that my participants would think similarly to me and that together we might figure out a way to support TRAAs at school and in our community. As the mother of a TRAA, I assumed that the parents of other TRAAs would think similarly to me, and have similar ideas about raising a TRAA in rural Appalachia. As a teacher, I assumed that administrators and teachers would more easily acknowledge racism in the community as TRAAs were affected by it. I was unprepared for the work of constantly confronting Whiteness through this study. Although I thought of myself as an insider - to the community, to the local schools, and to TRAAs - I realized that in many ways I was an outsider to TRAA's beyond my own daughter, EunAe. Perhaps all of this should not have been surprising to me as my impressions were cultivated from nearly 16 years of being EunAe's mom. Without literature addressing TRAAs in rural Appalachia, the lived realities of our family naturally generalized to my participants and beyond. What I learned in this study, then, is a beginning point for me to step beyond my own 
field of vision and an invitation for others to use this data as a starting place for their own.

Two research questions were addressed in this qualitative case study. The first question asked how Transracially Adopted Asian (TRAA) youth see themselves within the contexts they negotiate in rural Appalachia, and the second question asked how educators in this context support transnationally adopted children and their families. These questions produced robust yet complicated answers that were in many ways unexpected. Through field research and work with four participant groups (students, parents, administrators, and teachers) I believe that I was able to answer these questions.

\section{How Did Students See Themselves?}

The two adolescent girls who were central to this study taught me a lot about their experiences with race in rural Appalachia. I discussed their experiences at length in the previous chapter. However, the most important finding was that they seemed to discount and ignore race and ethnicity. They did not appear to be comfortable talking about race and deferred racial issues as what happens to "others" but not them. The two TRAAs studied were surrounded by White rural and Appalachian culture in their hometown, although there occasionally surfaced reminders that they came to rural Appalachia from Asia, through symbols and celebrations in their homes. The challenges of race seemed outside their daily concerns although ironically there were disturbing, racial incidents occurring in their lives in the community and school as well. Despite this, the lives of TRAAs were framed positively by all participants, with little acknowledgement of challenges or possible futures. The data characterized the TRAAs protected within the rural idyll and cast urban areas as the source of problems and challenges, even when the 
TRAAs were directly or indirectly affected by racism in their own backyards. All their lives they have been told, "You are one of us." Being viewed as White had many benefits locally. These benefits, based on other TRAAs' experiences, will not bear out in the future. Many rurally raised TRAAs counter this idea once they leave the confines of their rural community (Kilgore, 2014, 2015).

The families I studied loved their children and were proud that they were in honors classes. Parents spoke of few negative interactions about race and when they did occur, they often happened to other people's children, yet prolonged conversations revealed racism towards their daughters, often seen as an outside force from urban areas pushing into the protected community space. The parents seemed to think that college would be a springboard into the wider world for their daughters; because they would likely be surrounded by diversity at college that would be their opportunity to transition away from their more homogenous rural and Appalachian settings. In turn, at least one of the daughters seemed to tolerate rather than resist their families' framings of race and community; they mentioned leaving the community for college yet likely returning

\section{How Did Educators Support TRAAs?}

TRAAs seemed to disappear within the larger racial narrative within the community; in other words, they generally were not uniquely supported as TRAAs yet educators spoke highly of them as individuals. Their socially constructed "White" identities were reinforced and their birth cultures deferred and neglected as educators focused all of their strengths and energies on the "deficits" of "outsider" students. These outsiders were students who arrived in the mountains from Baltimore or other cities and were referred to as "the outside coming in." In this community "outside" was coded 
language for African American and Latino/a students. Those teachers who see racism originating in this small community and not from the outside as an issue are also at a loss for decisive action other than reporting it to administration for comments such as, "We burn niggers here." When I mentioned that it was a person from the area that was the root of unwanted racism, it was dismissed as their ignorance for not being colorblind. This ignorance perspective is not specific to rural Appalachia:

Geye Hamby, superintendent of Buford City Schools in Georgia, was caught on tape talking about killing 'niggers"...School districts' spokesperson and President Trump portray these incidents as isolated events, the work of a few overzealous, culturally insensitive but 'good' teachers, students, and community members. Mainstream society uses the 'few bad apples' argument, which misdiagnoses the systemic and ideological production of race itself which is squarely centered in White Supremacy. (p. 38)

Why is it that good people, good adults, and good kids are committing these hateful acts? If conquering ignorance is the job of education, then why is this still an issue? The answer is the infiltration and ongoing support of a White Supremacy culture. White Supremacy culture is the dominance of White power and White positioning in schools, even Black schools because crucially, at this time period, social justice policies and procedures are limited, neglected or not existent, nor are they being propagated in teacher preparation as necessary (Ladson-Billings,1995, 2000; Juárez \& Hayes, 2010). The flipside of this story isn't that these teachers are all racists wanting to harm their students of color. These are kind teachers, who want the best for their students, all 
students. Institutionalized racism affects them too, for most without their knowledge. How to bring about this realization is a question, but a bigger question is how to bring that change to benefit not only TRAAs but all students.

\section{Whiteness All Around}

Several effects related to Whiteness appeared in my study. The most prominent two were first the positioning of White supremacy in schools and secondly, the silencing or lack of construction of a third space in which TRAAs have voice. White supremacy, according to researchers (Love, 2019; Tanner 2018), permeates society and ergo education. It is rooted in its systems and blinds the overwhelming majority of White teachers in schools. It surrounds their beings. Being raised in such a system, it has become an invisible influence in White culture to the point that some Whites view themselves as the victims of invisible prejudice when race or White privilege is brought up. Harsher yet, as a result of this influence and their position of dominance, teachers do not speak of race in the classroom including their own race and its effect on their students of color. This was shown through my interviews with teachers. Again, I believe this is not because of intent but blinders of this system covering White culture's eyes.

For all members of this study there seemed to be opportunities for growth around racial awareness and change so that all community members might come together and face racial challenges. Yet teachers and administrators continue to hold on to Whiteness as "an invisible shield" that blocks the realities of what they are doing in their classrooms. Without talking with students of color, they really never know what is happening in students' lives. This recognition and promotion of students' heterogeneity is a precedent for third space. Actively and intentionally co-constructing a third space to 
listen allows concerns to be recognized, but also gives voice to people of color (Bertrand, 2014). Educational policies continue to minimize issues that are occurring in rural, Appalachian areas. Examples previously shared include cultural events such as festivals or food, that still place difference as exotic and other. State policies have been written in a blanket manner and some local policies ignore the small, growing populations of students of color in Appalachia. In January 2019, the state of Maryland made a change in policy from "Education that is Multicultural" to "Educational Equity." This is a significant change as it both promotes equity in education but also states the promotion of social/emotional well-being, along with characteristics to be addressed but not limited to the following: Ability (cognitive, social/emotional, and physical); Ethnicity; Family structure; Gender identity and expression; Language; National origin; Nationality; Race; Religion; Sexual orientation; and Socio-economic status (Maryland State Board of Education, 2020). At the current time, there has been no significant change in local board policy that I have been able to find in Peak County documents in response to state policy.

In Chapter Four, I unpacked the key findings of the study based on my fieldwork in Peak County. To summarize, the loss of identity for students of color and TRAAs in particular can cause confusion for them. TRAAs within the community benefit in some ways due to their position in White families. They don't stand out and they conformed to the dominant White culture in this study. Challenges from outside the community seem to force these students to recognize realities about themselves and the world around them. TRAAs in the study were Asian American with no tie to their Asian Culture other than the "postcard culture" they have been surrounded with. They have few, if any, racial mirrors to support them and of those racial mirrors, most are also TRAAs. They have 
become "invisible Asians" (Park Nelson, 2016). The rural and Appalachian community seems to provide them support while other students of color seemed to be objects of direct racism. Microaggressions were viewed by TRAAs as harmless or beneath their dignity to address. Third space in this community seemed to be silenced because the space of Whiteness was being constructed instead of a hybrid space that sought to meld TRAAs' birth culture with the rural and Appalachian culture and other complex cultural contexts of the community and adoptive families.

Conversely, the inability to see color or recognize their culture also stunted teachers' perspectives and their abilities to join in the creation of a third space for growth for TRAAs. This, along with viewing TRAAs as being "saved" or "blessed" by adoption promotes a deficit view of these students as a whole because it positions their birth culture as deficient in relation to the American "way of life." The inability to see color in front of them is distinctly racist and a mark of the world of White fragility that surrounds them (Burke, et al., 2017; DiAngelo, 2018). Thinking it is a good thing not to see race only perpetuates the notion that Brown/Black is bad and White is good (DiAngelo, 2018). This disrupts the ability of these teachers to make true connections with students (Hines, 2016). I would argue that both of these ideas contribute to an educational system that does not promote recognizing Funds of Knowledge and the opportunities to bridge cultures as described in Chapter Two of this dissertation (Esteban-Guitart, 2014; González, et al. 2005; Levy, 2008, Moll, 1992).

Constantly throughout this dissertation research, I was told about the "nice kids" from Peak County. These "nice kids" who are predominantly White and middle class are victims in an undeclared race, as are TRAAs and students of color. The inability—of both 
nice kids and the adults in this study — to talk about race or recognize their own racialization put them at odds with the "outside world" even when that outside world pushed into the wealthier lake region of the county each summer, or transferred from Baltimore to the residential treatment facility before transitioning to Peak County Schools.

\section{Implications}

\section{Theoretical Implications}

The findings from this project pointed to the need for a more contextualized understanding of third space theory, one that is not only constructed by students, families, and teachers. Instead, time, memory, and embodied trauma are aspects of TRAAs' lives that contribute to opportunities for constructing and bridging between multiple worlds. Thus, these elements should be included when conceptualizing third space production. When considering the role of the rural and Appalachian place, additional layers of social constructionism such as summer populations shifting in and out, the positioning of the rural community in relation to dangerous "urban" places, and outsiders were aspects that influenced and ultimately seemed to limit opportunities for creating hybrid spaces in practice. Therefore, this dissertation speaks to the need for more nuanced examples, discussions and ultimately conceptual models that take into account more particularized understandings of these processes for TRAAs in rural Appalachia.

Another important conceptual idea addressed in this dissertation was the model minority stereotype common in communities and thought to affect people with Asian phenotypes and names, specifically that they are inherently high performers, musically gifted, and mathematically astute (Chai \& Weseley, 2017; O’Connor, Hill, \& Robinson, 
2009). Before starting the research, I expected to see how racism impacted the lives and education of TRAAs and in turn how their families were affected by Whiteness in the surrounding community and how they suffered, resisted and perhaps even fought back against these harmful stereotypes. I expected to see a "third space" of students' and families' dialogue established in the home where racism and inequality was specifically addressed. Instead, I saw and heard from parents, the students themselves and their educators about how unaffected they were by the fact of being TRAAs. Indeed, they were positioned as White to the extreme that they were said to "look White" and "not look Asian". The two girls studied were examples of how the model minority stereotype was performed a bit differently by TRAAs and their families and communities in rural Appalachia. Indeed, it seemed as if they had been "whitewashed" (Chevalier, 2016; Norris, n.d.; Pyke \& Dang 2003). The girls live very "White" lives knowing very little about their birth culture or how being Asian American has affected or might affect them. In the goal of fitting into rural and Appalachian America, they seemed to lack knowledge of the cultural and historical context of being Asian American. Therefore, this study brought forward a deeper understanding of the strength of the model minority stereotype and adds to the literature on this phenomenon. Indeed, the findings indicate that model minority stereotypes can become deeply embodied by birth families and TRAAs such that they used the stereotype when naming themselves and seemed unable to step back and reflect critically on their positioning relative to the stereotype. This finding has important implications for educational practices, which I discuss a bit later in this chapter. 
Another important implication related to the model minority stereotype is the ways in which it was taken to a new level to include understandings not only of cognitive and artistic prowess, but also a hierarchical positioning of phenotype such that the TRAAs in one case did not "look Asian" but rather blended in with the birth families' looks. The practice and positions of adoption having a Whitening effect are complicated to unpack. Did the participants mean that adoption was "meant to be" in a religious sense, such that God chose an Asian child for the family who ironically would not have fit well in Asia with their White looks? Or did the participants believe that their daughter looked White because they saw that as a kind of added value not unlike the Asian caricatures in Mulan, or even the performance makeup of the Japanese geisha; in other words was there a gendered component to the Whitening effect? Was "looking White" a protective, psychological move socialized in families to protect them from the pain of stares and racial insults in a community not used to racial diversity? This process found in the study calls for additional research to examine whether this is a more common phenomenon as well as the meanings behind it, and what they might reveal to help us better understand the model minority stereotype and its effects on TRAAs and other Asian people.

\section{Methodological Implications}

I expected that my interviews and meetings with the two TRAA students would reveal a world similar to that which my daughter has shared with me; although continually changing and growing, we work together to create - as much as possible - a "third space" for her as a TRAA. The two students I interviewed did not seem to have this space and conceptualized their identities differently than EunAe seems to. However, I am not certain even though I spent a good amount of time with the girls, met with their 
families, did a thorough review of the literature and collected and analyzed multiple data sources, that there is not something that I missed.

At this point, I wonder if perhaps my line of questioning about their identities and particularly the roles of race and birth culture needed to be more direct and sustained. Perhaps the ages of my selected students were too young - perhaps it was too difficult for them to process what has going on in their lives. Were they too comfortable where they were, did they feel too accepted relative to other students of color in their community to address instances of being rejected because of race and/or adoption? Was it true that they were just "light" enough in skin color to blend in compared to students from White racial backgrounds? Did the combination of being Asian and adopted by White parents mark them as less than Asian and more than adopted; in other words, more "normal?" Qualitative research methodologies and particularly interviewing techniques have been used over many years to help support understandings of identities and differences (Freitas, Oliveira, Jenkins \& Popjoy, 1998; Harf, Skandrani, Sibeoni, Pontvert, RevahLevy \& Moro, 2003). In future research on TRAAs, it might be important to further develop interview techniques and other methods such as autobiography, photovoice, filmmaking, etc. to probe into these types of questions more deeply and with a broader group of TRAAs in Appalachia as well as other cultural contexts.

The complexities of identity and the challenges they entail for TRAAs, their families, other students of color and the educators who try their best to educate them within a challenging context are often exacerbated by policies that lack a complex, intersectional approach to the issues that students face. 


\section{Policy Implications}

Love (2019) has stated that, "Policy agendas devoid of intersectionality do not allow questions and dialogues that reflect the lives of the people who will be impacted by policy" (p. 6). Intersectionality, as defined in Chapter Two of this dissertation, is the interconnected nature of social categorizations such as race, class, and gender as they apply to a given individual or group, regarded as creating overlapping and interdependent systems of discrimination or disadvantage. When investigating school policies on race both locally and statewide, I found that very little was written about race other than the edict to not discriminate. For example, Peak County Schools seek to "sustain a culture of excellence" and "prepare students for an ever-changing world" as well as to pay "particular attention" to families with "limited English proficiency" or those who are of "any racial or ethnic minority background." None of the state nor local school policy documents, however, identifies race as an area for which practices need to change. There are statements about racial equity but no plans nor trends to acknowledge the complexities of racial identities such as TRAAs and their families, nor to deal with the ability to talk about race in schools.

In the world of TRAAs, suicide and physical/verbal abuse are far too common (Akos \& Ellis, 2009; Lee, 2003) but they are nowhere addressed in policy. By limiting our policies to isolated, singular viewpoints such as a booklet on LGBTQ+ and a separate booklet on conduct, for example, policies divide children and families into groups rather than view children and adults as multifaceted, complex individuals. Policy "chunking" also creates the inability to address students' and families' intersecting realities and compartmentalizes 
concerns into check off boxes. All of this prohibits possibilities for collaboratively creating third spaces for TRAAs and for disrupting stereotypes such as the model minority. For TRAAs in Peak County, their intersectionality occurs in some obvious ways and some not so obvious ways. First, they are both adopted and Asian. They have come from trauma whether it is recognized or not. Other adoptees may be low income, students of color, and/or gender nonconforming. But the "boxing" of adoptees into categories allows policy to say it is addressing the whole child while actually only "fixing" one issue. This directly affects all students and creates complex challenges for the community and for schooling.

\section{Implications for Practice}

Becoming stronger schools. The second research question of this dissertation is about how I, as a teacher-scholar in this district, might address the challenges that educators may face related to supporting TRAAs at school. After spending nearly two years working on this dissertation project and digging more deeply than I ever thought I might around what makes this district tick, I have generated a plan for supporting change and growth towards more racially just knowledge, attitudes, and practices in schools.

Peak County Schools are situated in a very giving community. It a community that has challenges of classism and racism. All of the study participants, including myself, are members of the community and I believe that we all seek to have a strong community. Given the findings presented in Chapter Four of this dissertation, an important conceptual move for educators is to step away from status quo strategies such as putting TRAAs on a pedestal, silencing their differences, or even "saving" them. Instead, based on my framework of moving towards third space construction and 
troubling the model minority stereotype, I reflected on ways in which to actualize the ideal, "There is only a village, a community, and a goal: protecting children's potential" (Love, 2019, pp. 82-83).

Making schools stronger in the face of racism is a critical idea. How that is to be done is rooted in the caring and relationships that occur within the school system. As evidenced by the number of years staff is retained, Peak County teachers know not only the current students but the families that these students come from. Many have taught multiple generations of students from the same family. What hasn't changed is the necessity of providing a better education to support the acceptance and thriving for all students. Love (2019) calls this an abolitionist approach. Many other writers describe the same process of change without giving it a name (Dell'Angelo, 2014; Gay, 2000, 2008, 2013; Gonzalez, 2017; Gorski, \& Swalwell, 2015; Herrera, 2016; Landsman, Salcedo, R\& Gorski, 2015). All seem to agree that the most important step to be made is within White teachers themselves.

When the Brown vs. Board of Education (1954) decision introduced desegregation into the American lexicon, deep losses occurred for African American communities. Formerly attending schools where the teachers were Black and understood the families' culture, Black students were then thrust into new formerly all-White schools. This generated further misunderstanding and distrust. This case, for the most part, took away Black students' connections and pride in themselves by taking some of the very people away from them that instilled values, their Black teachers. A similar occurrence happened with Native Americans in the Indian Schools. Neither of these new places valued their students nor brought their funds of knowledge into the classroom; 
White knowledge was valued as best. Unfortunately, this has continued today, but not because White teachers intentionally propagate this idea. Instead, they fail to recognize its existence. So the first step in making better schools for all children is to recognize this issue and talk of the history and issues surrounding our students about race. The next step is to find the value in all our students based on the funds of knowledge they bring to school every day.

My research has provided insights from both the experiences of students, families, teachers and administrators in Peak County, my own reflections, and a steady review of the literature to develop a set of ideas related to how we might better support TRAAs and other students of color. One of the first steps is for White teachers to learn to speak of color without fear. We might identify White Supremacy and the affordances it gives us as a community despite the poverty that encompasses the area. Not being able to speak with conviction and knowledge maintains the bonds that hold all children back from reaching their potential. By creating these blankets of "model minorities," an opposite effect of anti-Blackness occurs: we judge and order skin shades from light to dark. Thoughts of how to do this in practice with real colleagues have confounded my thoughts. How does one get the people who most need to talk about race and specifically Whiteness into a position to be willing to talk race in a White-dominant area? How do you make teachers want to know more? They need to understand the importance and intricacies of race and racism and how they affect us all. This includes how our concepts of "White" unfairly give Whites advantages and take the souls of our students. Offering professional development to current teachers is one way to start. 
Starting with the volunteers who gave such open answers as to what was going on in their schools may be one answer. Small groups of White teachers might be led in thought-provoking conversations based on the results of this study. Questions such as "Does sending students to the office solve the issue of name calling?" or "Do we have a responsibility to address race in the classroom?" need to be addressed. But before these questions are unpacked, perhaps a basic question of "How comfortable do you feel talking about race in the classroom?" should be asked. Discussions of TRAAs and their issues of identity, race and gender could be included. Most important would be the discussion of White culture. By taking away the word "privilege" from the conversation, Whites from this poor area may be more open to the conversation itself. I know from other previous conversations about race in my district that one simple word can stop all meaningful progress. Whites in poor areas can have a very difficult time relating to how they have privilege when they are trying to survive day to day, which is often witnessed of the students and families in our area. Unpacking Whiteness could be a slow process with many bumps in the road. By using the funds of knowledge from the group, the same practice we should be using with our students, this knowledge will be easier to construct together. Gorski (2012) provided, an unexpected example of unpacking Whiteness from my area in his article "Complicating 'White Privilege': Race, Poverty, and the Nature of the Knapsack." In this article he spoke of his grandmother growing up in a town that lies about twelve miles from my home. His grandmother grew up during time of coal mining and racism in this area. Gorski also spoke of how poverty was never discussed as part of the problem when talking of racism. Many of our teachers are the children of coal miners who became teachers to move out of that industry. We have had teachers in Peak County 
that have tried to incorporate this history in their classroom. One elementary school has embraced it as a fund of knowledge and has built curriculum on it. Other elementary schools are following that example, although it is less widespread at the secondary level.

We know that poverty continues to have impact on the lives of our students and the power that wealthier visitors and residents have in the area. In teacher focus group discussions we spoke of the behavior curriculum that is used in Peak County Schools, called Second Step. It, along with many of our literature books, are missing images of kids that are like the children in Peak County. The characters tend to be all Black or all White depending on the resource. There are not books depicting White rural Appalachian kids and there are not materials depicting TRAAs, nor are there resources that depict the mix of students in our schools. This shuts the students down. It is not culturally responsive. They don't see kids like themselves, they see "others." Teachers grapple with how to incorporate culturally responsive teaching in their classrooms by individually searching for racial, demographic mirrors but they are unsuccessful. At a recent book selection meeting for English/Language Arts, I spoke with the publisher's representative. I informed them that the textbooks and novels cover much diversity but our students see nothing that represent them. The representative asked, "And what would that be?" My response was, "Poor, White, Appalachian kids". She had never heard of that demographic. I bring up this example and Gorski's (2012) example to make it clear that to reach my demographic we may need to unpack our Appalachian Whiteness as we bring in our TRAAs' concerns. Empathy for self could led to empathy for others. It also would give credence to the value of social justice and restorative education. 
I hope that this same process might be completed with administrators as well. By healing the administrators it is hoped that they also might support teachers so the teachers can support and grow with students. Administrators and teachers need to use their positionality as well as their discourse to promote positive change. By meeting in small groups, recognizing our own intersectionality of race, religion, gender, etc. we can more fully recognize the inherent funds of knowledge in our students. We can work to change policies that focus on singularities to address the whole person and not just a part.

This approach is different than what it might be in urban areas. It is different specifically because we are small, we are rural, and we have low racial diversity. Just because we are small does not mean we do not have to address bias. Our TRAAs and all of our students have funds of knowledge that we can use to help with these changes. We need the skills to develop third spaces that promote racial and intersectional justice.

Changing practices. Teaching has been increasingly difficult in the current context of pressure from policies centering standards based education and the inherent testing regimes. However, education is not only a science as standards based proponents would hold. It is both a science and an art. Teachers' minds are for more than instrumental tasks and checklists. They are, as Love (2019) states, an act of heart for students bound in deep listening and care; this is not about specific strategies or techniques often taught in professional development workshops, but rather a shift in consciousness, philosophy, and practice. It is about weaving together students, selves, and subjects.

Perhaps the most basic ways to address these issues come down to two. The first is getting teachers to know themselves, their strengths, their biases and their views. The 
second is getting teachers to know their students (Cantrell \& Cantrell, 2003; Scherer, 2003). These seem like a clichés but are crucial for change in classrooms. I see the classroom as a crucial space for the construction of third space that also can bridge to homes and communities in support of intersectional identity development. TRAAs come to class with a multitude of hidden strengths, as do all students. By maximizing and valuing those strengths, all students' potential may be realized.

Initiating a sea change in thinking requires starting with teachers' strengths rather than their knowledge gaps so that they feel a sense of efficacy and hope related to these changes. They also must see how the changes are necessary and how they affect them personally. Creating opportunities for deep and ongoing professional development that allows teachers to talk about their benefits as White teachers and how to use those strengths to also find the strengths and promote access to all students of color could be one way. Helping teachers to realize that this is a lifelong journey that they have the skills to accomplish and become an ally to TRAAs and other marginalized groups within the school system. Finally, allowing teachers in the schools develop the curricular ideas to support all students in their classroom with their current curriculums by identifying what are the important areas that need to change specifically at their school and how to make students active participants.

Professional development. Establishing professional development that is focused on White privilege is often not beneficial to change and action. Often a turn off for White participants and not a call to action, it can result in little or no change in the environments of students or participants, even with good intentions. Instead, a more fruitful approach would be a race-visible approach. Race-visible approaches presume complicated 
understandings of race-evasive and race-visible White identities and call on educators to "openly embrace the promise and pitfalls in the complex relationship between raceevasion and race-visibility when designing teaching and learning about Whiteness" (Tanner, 2018, p. 4).

This is how I would like to approach professional development with teachers. First, I would like to have conversations with small cohorts of White teachers on being White. I would like to use some of the videos available from the Whiteness Project website (Dow, 2016) to spark these conversations and recognitions of what it means to be White in America. I would next like to expand their knowledge of American history through writers and media producers who are people of color and/or TRAAs. Some of these include writers such as Geneva Gay and Tobias Hübinette as well as media produced by Shelby Redfield Kilgore. This would allow the participants to hear multiracial voices, yet not make these minorities responsible for all the knowledge in the room. This would bring out more conversations about race and the importance of talking about race. In small groups, teachers will feel less vulnerable and willing to speak up about their feelings on the topic of Whiteness. "Teachers need to be taught how to question Whiteness and White Supremacy, how to check and deal with their White emotions of guilt and anger, and how these all impact their classrooms" (Love, 2019, p. 75). Use of video from the whitenessproject.org would extend the conversation and encourage participants to share their feelings. All teachers would be able to bring their own experiences and suggestions for change into the classroom. By making teachers more comfortable talking about race it would also be projected into the classroom. If teachers are more comfortable in the classroom with race, then there will be more conversations 
with students and less reliance on the administration to solve these problems. As with students of any age, when teachers take ownership of their learning it leads to greater understanding of the issues and a willingness to learn and change to occur.

I think it is also worthwhile to revisit and discuss the diversity of families that are now in our schools with faculty. Perhaps having panels of willing parents from diverse backgrounds to come and talk to teachers about their families and answer questions would be useful (Norris, 2010). By conducting these informational presentations, teachers and parents can become more aware of how the voices of families might add to their classrooms. Teachers in this study tended to agree with this approach too and see only benefits. For example, James who was a participant in the high school focus group believed in the power of listening as a way to "reach that student" who may need extra support. Morgan, another high school teacher who participated in the focus group, said that, "The more information that we have as educators either about a specific student or group of students can never hurt us. It's only going to benefit us." Yet another high school focus group member, Kelly, said that it would be "very proactive" for parents to contribute ideas about the needs of their children. Because the teachers do have thoughtful ideas that might be brought together and actualized in order to contribute to third space development, their partnership would be crucial to promoting positive changes. The same opportunities might be cultivated amongst the middle school teachers, who might meet together with the high school teachers to hear their ideas and perhaps gain inspiration.

I would also like to work with the local high school theater teacher to construct a workshop for White high school students. This was something that was discussed by 
Turner (2018) who himself worked to replicate parts of the Whiteness Project with White high school students. His students evaluated their school's mission statement and this critical evaluation helped them to become more aware of their race and its position in learning. Then they worked to engage the community in this discussion through theater. The connections with theater makes this a safe space, a third space, for student voices on race to be heard also.

\section{Limitations}

A major limitation of this study is the small number of TRAAs participating. Only two representatives were available since in this small rural and Appalachian community, these were only these TRAAs attending in addition to my daughter. It is not appropriate to make generalizations to a broader group based solely on their responses. But this does not mean that it was not worthwhile to attempt the study, as the findings point to processes that may transfer to similar settings or may provide readers with the opportunity to reflect more deeply on their own settings. This is true especially because it was found that the narratives of TRAAs are intertwined in certain respects not only with the rural and Appalachian community, but with their peers of color even when these peers have had very different trajectories than the TRAAs.

\section{Future Research}

This study was initiated in part because there was no research on TRAAs in rural and Appalachian communities. To my knowledge, it is the first study of its kind and there is much opportunity to expand on this study. Future research might branch out to more nearby rural and Appalachian schools to see if the results and interpretations are similar. Specifically looking for how space and positionality work or don't work together to 
benefit TRAAs and other students of color is likely an important issue across Appalachia, given the changing demographics noted in this study.

Another future direction of research would be to follow up with these two specific TRAAs in young adulthood. This would allow me to track their accomplishments, challenges, and lived realities in the future as they reflect back on their middle and high school years. Looking at the general population of TRAAs in colleges and universities in rural Appalachia would also be an important area of study, as these students might better be able to articulate their experiences and the roles of K-12 education in their journeys.

One final direction of study would be to address families with TRAAs in this community that have chosen to homeschool their students and how that affects identity, education and whiteness in those students' lives. This might be an important area of study because through experience, I have noted that is a popular school form amongst TRAAs specifically and it stands to reason given the homeschooling literature that diversity is an important component shaping these choices (Apple, 2006; Sherfinski, 2014; Sherfinski \& Chesanko, 2016).

More research is also needed on teacher education. Broadening the interview base of teachers in the area study to those who have taught TRAAs throughout the years could add to the base of knowledge. Specific studies that relate to the context of Whiteness in rural Appalachia could result in better teacher practices and support better student outcomes; this might have a positive effect on the communities. The ability for teachers to talk about race and its effects on themselves, their students, and the surrounding community is vital for this success. 
The final focus that could be beneficial for expanding upon this topic would be how policy and power in Appalachia affect minorities in rural and Appalachian schools. Throughout the research, it was reflected back to me that those in charge of local and/or state policies don't seem to deal with the realities in the classroom. "Down state"otherwise known as the State Department of Education—-designed policies with urban schools in mind. As shown in this study, these policies did not always transfer well to the rural and Appalachian context of the part of the state in which Peak County was located. Therefore, it is important to continue to research the relationships between policies and practices in order to better understand how to fashion policies that align with the needs and realities of all communities.

\section{Conclusion}

In conclusion, this study has exposed a gap between secondary education and the realities of racism specifically in the lives of TRAAs living in rural Appalachia. It has revealed that Whiteness and the inherent and related privileges, power, and positions influence the thinking of students, parents, teachers and administrators in this rural and Appalachian community. It has also found that developing third spaces that support all students' funds of knowledge and the uniqueness of TRAAs and all students of color is an important goal. Furthermore, this topic is multifaceted and as such must continue to be addressed not only through confronting race and privilege but through understanding from an intersectional perspective multiple identities including the roles of transnational and transracial adoption and trauma and the impacts that these have on TRAAs. It also supports the need to create third spaces that recognize this intersectionality. 


\section{Reference List}

Adams, M. (2002). Our son, a stranger: Adoption breakdown and its effects on parents. Montreal: McGill-Queen's University Press.

Administration for Children \& Families. (n.d.). Children's Bureau Timeline. Retrieved July 14, 2016, from https://cb100.acf.hhs.gov/childrens-bureau-timeline

Agustin, M. S. (2017, August 3). As an international adoptee, I know the dark side of adoption. Retrieved August 04, 2017, from http://www.huffingtonpost.com/entry/dear-adoption-i-am-finally-ready-to-faceyou-the_us_59836703e4b0f2c7d93f542f

Akos, P. \& Ellis, C. M. (2009, March 8). Racial identity development in middle school: A case for school counselor individual and systemic intervention. Journal of Counseling and Development, 86(1), 26-33.

Algava, A. (2016). Beyond child-centered constructivism: A call for culturally sustaining progressive pedagogy. Bank Street Occasional Paper Series, 35. Retrieved February 29, 2020, https://educate.bankstreet.edu/occasional-paperseries/vol2016/iss35/5/

Allen, J. (2007). Creating welcoming schools: A practical guide to home-school partnerships with diverse families. New York: Teachers College Press. Amherst College (2008). The third space: Cultural identity today. Retrieved June 30, 2017, from https://www.amherst.edu/museums/mead/exhibitions/2008/thirdspace Amoamo, M. (2011). Tourism and hybridity: Re-visiting Bhabha's third space. Annals of Tourism Research, 38(4), 1254-1273. 
Anglin, M. (2002). Lessons from Appalachia in the 20th Century: Poverty, power, and the "Grassroots". American Anthropologist, 104(2), 565-582. doi:10.1525/aa.2002.104.2.565

Anglin, M. (2016). Toward a new politics of outrage and transformation: Placing Appalachia within the global political economy. Journal of Appalachian Studies, 22(1), 51-51. doi:10.5406/jappastud.22.1.0051

Appalachian Regional Commission. (n.d.). The Appalachian region. Retrieved September 24, 2017, from https://www.arc.gov/appalachian_region/TheAppalachianRegion.asp Appalachian Regional Commission. (2016). County Economic Status in Appalachia, FY 2017 - Appalachian Regional Commission. Retrieved August 09, 2016, from http://www.arc.gov/research/MapsofAppalachia.asp?MAP_ID=116

Apple, M. W. (2006). Educating the "right" way: Markets, standards, God, and inequality. New York: Routledge.

Au, W. (2014). Rethinking multicultural education: Teaching for racial and cultural justice (2nd ed.). Milwaukee, Wisconsin: Rethinking Schools.

Auerbach, C. \& Silverstein, L. (2003). Qualitative data: An introduction to coding and analysis (Qualitative studies in Psychology). New York: NYU Press.

Baden, A. (2007). Identity, psychological adjustment, culture, and race: Issues for transracial adoptees and the cultural-racial Identity model. In R. Javier (Ed.), Handbook of adoption: Implications for researchers, practitioners, and families (pp. 359-378). Thousand Oaks, CA: Sage. 
Baden, A. (2015). Culture camp, ethnic identity, and adoption socialization for Korean adoptees: A pretest and posttest study. New Directions for Child and Adolescent Development, 150, 19-31. doi:10.1002/cad.20119

Baden, A., Treweeke, L., \& Ahluwalia, M. (2012). Reclaiming culture: Reculturation of transracial and international adoptees. Journal of Counseling and Development: $J c d, 90(4), 387-399$.

Barbour, R. (2014). Analysing focus groups. In Flick, U. The SAGE handbook of qualitative data analysis (pp. 313-326). London: SAGE Publications Ltd. doi: $10.4135 / 9781446282243$

Bartholet, E. (2006). International adoption. In L. Askeland (Author), Children and youth in adoption, orphanages, and foster care: A historical handbook and guide (pp. 107-130). Westport, CT: Greenwood.

Bernstein, E. (2002). Middle school and the age of adjustment: A guide for parents. Westport, CT: Praeger.

Bertrand, M. (2014). Reciprocal dialogue between educational decision makers and students of color: Opportunities and obstacles. Educational Administration Quarterly, 50(5), 812-843.

Bhabha, H. (1994). The location of culture. London: Routledge.

Bhabha, H. K. (2012). The location of culture. New York: Routledge.

Bloor, M., Frankland, J., Thomas, M., \& Robson, K. (2001). Preparation and conduct. In Bloor, M., Frankland, J., Thomas, M. \& Robson, K. Introducing Qualitative Methods: Focus groups in social research (pp. 37-57). London: SAGE Publications Ltd. doi: 10.4135/9781849209175 
Blum, L. (2002). Racism: What it is and what it isn't. Studies in Philosophy and Education: An International Journal, 21(3), 203-218.

doi:10.1023/A:1015503031960

Boyd, D. (2014). It's complicated: The social lives of networked teens. Retrieved from https://ebookcentral.proquest.com

Breuning, M. (2013). Samaritans, family builders, and the politics of intercountry adoption. International Studies Perspectives, 14(4), 417-435. doi:10.1111/insp.12016

Bureau of Consular Affairs. (2016). "Statistics" Travel.state.gov. Bureau of Consular Affairs, U.S. Department of State, 2016. Web. 26 Aug. 2016.

Bureau of Consular Affairs. (2017). Statistics. Retrieved September 03, 2017, from https://travel.state.gov/content/adoptionsabroad/en/about-us/statistics.html

Burke, M., Jayakumar, U., \& Adamian, A. (2017). The fifth frame of colorblind ideology: Maintaining the comforts of colorblindness in the context of white fragility. Sociological Perspectives, 60(5), 912-936.

doi: $10.1177 / 0731121417721910$

Byrnes, J. \& Wasik, B. (2009). Picture this: Using photography as a learning tool in early childhood classrooms. Childhood Education, 85(4), 243-243.

Callahan, N. M. (2011). Race and identity in transracial adoption: Suggestions for adoptive parents, Adoption Advocate, 38. Retrieved July 15, 2016, from https://www.adoptioncouncil.org/publications/2011/08/adoption-advocate-no-38

Carp, E. (2009). Adoption in America: Historical perspectives. Ann Arbor: University of Michigan Press. 
Carr, P. \& Kefalas, M. (2009). Hollowing out the middle: The rural brain drain and what it means for America. Boston, MA: Beacon Press.

Carr, P. J. \& Kefalas, M. J. (2010). Reimagining Education IN SMALL TOWNS. School Administrator, 67(5), 30-33. Retrieved from http://www.libproxy.wvu.edu/login?url=http://search.ebscohost.com/login.aspx? direct $=$ true $\& d b=$ ehh $\& A N=50074111$

Carcary, M. (2009) The research audit trial - Enhancing trustworthiness in qualitative inquiry. The Electronic Journal of Business Research Methods, 1(7), 11-24. Retrieved February 15, 2020 from http://www.ejbrm.com/issue/download.html?idArticle=198\&origin=publication_d etail

Carter, L. \& Davila, C. (2017). Is it because I'm Black? Microaggressive experiences against black professionals in sport and exercise psychology. Professional Psychology: Research and Practice, 48(5), 287-293. doi:10.1037/pro0000145

Chai, D. \& Weseley, A. (2017). Is stem running out of steam for Asian Americans? College admissions officers' perceptions of applicants. Asian Journal of Social Psychology, 20(1), 45-53. doi:10.1111/ajsp. 12165

Chevalier, F. (2016, October 18). White people, please stop telling me I don't 'look Asian enough'. Retrieved March 12, 2020, from https://www.independent.co.uk/voices/mixed-race-white-people-please-stoptelling-me-i-don-t-look-asian-enough-a7367216.html

Child Welfare Information Gateway (2018). Rural child welfare practice. Washington, DC: U.S. Department of Health and Human Services, Children's Bureau 
CHLSS (Children's Home Society/Lutheran Social Service). (2017). Education \& events. Retrieved October 15, 2017, from https://chlss.org/education-events/

Choy, C. C. (November 1, 2010). Race at the center: The history of American cold war Asian adoption. Journal of American-East Asian Relations, 16(3), 163-182.

Chubbuck, S. \& Zembylas, M. (2016). International handbook of teacher education, Volume 2. In Social justice and teacher education: Context, theory, and practice (pp. 463-501). Singapore: Springer. doi:10.1007/978-981-10-0369-1_14

Cico, S., Vogeley, E., \& Doyle, W. (2011). Informed consent language and parents' willingness to enroll their children in research. IRB: Ethics \& Human Research, 33(2), 6-13. Retrieved from http://www.jstor.org/stable/23048304

Contributor, Dear Adoption (2017, October 03). Dear adoption, if I could. Retrieved October 15, 2017, from https://dearadoption.com/2017/10/03/dear-adoption-if-icould/

Cook, D. A. (2015). Shifting the center in teacher education: An introduction to the special issue on critical race theory and teacher education. Urban Review: Issues and Ideas in Public Education, 47(2), 233-236.

Cook, J. (1995). A history of placing-out: The orphan trains. Child Welfare, 74(1), 18197.

Cromartie, J., Von Reichert, C., \& Arthun, R. (2015). Why some return home to rural America and why it matters. Amber Waves, 21-30.

Davenport, D. (2013, June 18). Transracial adoption twist - black parents adopting white kids. Retrieved July 15, 2016, from https://creatingafamily.org/adoptioncategory/transracial-adoption-twist-black-parents-adopting-white-kids/ 
Davis, B. (2007). How to teach students who don't look like you: Culturally relevant teaching strategies. Thousand Oaks, CA: Corwin Press.

de Haymes, M. \& Simon, S. (2003). Transracial adoption: families identify issues and needed support services. Child Welfare, 82(2), 251-272.

De Lissovoy, N., \& Cedillo, S. (2016). Neoliberalism and power in education (pp. 1-6). doi:10.1007/978-981-287-532-7_155-1

Debiec, J. (2018, June 21). Sudden and lasting separation from parent can permanently alter brain development. Neuroscience News, Retrieved November 9, 2019, from https://neurosciencenews.com/immigration-separation-neurodevelopment9410/?fbclid=IwAR0HRvcM_dEwiihEfCkIGHt1jwpJS7JYBuUqNxz8hO8wU0iOg1JI3m1u9g.

Delale-O'Connor, L. (2011). Culture goes to camp. Contexts, 10(1), 60-61.

Dell' Angelo, T. (2014, September 29). Creating classrooms for social justice. Retrieved November 03, 2017, from https://www.edutopia.org/blog/creating-classroomsfor-social-justice-tabitha-dellangelo

Dellinger, L. \& Druggish, R. (2003). Fostering collaboration between home and school through curriculum development: Perspectives of three Appalachian children. In R. Lalik (Author) \& A. I. Willis (Ed.), Multicultural issues in literacy research and practice (pp. 69-99). Mahwah, NJ: Lawrence Erlbaum Associates.

Dennen, V., Rutledge, S., Bagdy, L., Rowlett, J., Burnick, S. (2018). Avoiding drama: Student and teacher positioning within a school's social media ecosystem. Acm International Conference Proceeding Series, 271-275. doi:10.1145/3217804.3217927 
Deogracias, A. (2015). Danah boyd: It's complicated: The social lives of networked teens. Journal of Youth and Adolescence, 44(5), 1171-1174. doi:10.1007/s10964014-0223-7

Derman-Sparks, L., \& Ramsey, P. G. (2011). What if all the kids are white? Anti-bias multicultural education with young children and families (2nd ed.). New York: Teachers College Press.

DiAngelo, R. (2018). White fragility: Why it's so hard for white people to talk about racism. Boston: Beacon Press.

DiPasquale, C. (n.d.). History of the orphan trains. Retrieved September 10, 2017, from http://www.kancoll.org/articles/orphans/or_hist.htm

Diaz, C. (1992). Multicultural education for the 21st century (NEA school restructuring series). Washington, D.C.: NEA Professional Library, National Education Association.

Dolan, P., \& Frost, N. (Eds.). (2017). The Routledge handbook of global child welfare. London: Routledge.

Dole, K. N. (2005). Education and internationally adopted children: working collaboratively with schools. Pediatric Clinics of North America, 52(5), 1445-61.

Dow, W. (2016). Whiteness project. Retrieved December 27, 2019, from http://www.whitenessproject.org/.

Dowling, M. \& Brown, G. (August 01, 2009). Globalization and international adoption from China. Child \& Family Social Work, 14(3), 352-361. 
Dredger, K., Woods, D., Beach, C., \& Sagstetter, V. (2013). Engage me: Using new literacies to create third space classrooms that engage student writers. Journal of Media Literacy Education, 2(2), 1.

Ellsworth, E. (1997). Teaching position: Difference, pedagogy, and the power of address. New York: Teachers College Press.

Emerson, R. M., Fretz, R. I., \& Shaw, L. L. (2011). Writing ethnographic fieldnotes. Chicago: The University of Chicago Press.

Escobar, N. (2020, March 4). When Xenophobia Spreads Like A Virus. Retrieved March 07, 2020, from https://www.npr.org/2020/03/02/811363404/when-xenophobiaspreads-like-a-virus

Esposito, D. \& Biafora, F. A. (2007a). Toward a sociology of adoption. In R. Javier (Ed.), Handbook of adoption: Implications for researchers, practitioners, and families (pp.17-31). Thousand Oaks, CA: Sage.

Esposito, D. \& Biafora, F.A. (2007b). Identity, psychological adjustment, culture, and race: Issues for transracial adoptees and the cultural-racial Identity model. In R. Javier (Ed.), Handbook of adoption: Implications for researchers, practitioners, and families (pp. 359-378). Thousand Oaks, CA: Sage.

Esteban-Guitart, M. \& Moll, L.C. (2014). Lived experience, funds of identity and education. Culture and Psychology, 20(1), 70-81. doi:10.1177/1354067X13515940

Farrell, A. D., Henry, D. B., Mays, S. A., \& Schoeny, M. E. (2011). Parents as moderators of the impact of school norms and peer influences on aggression in middle school students. Child Development, 82(1). 
Ferlazzo, L. (2017, July 10). Author interview: 'Culturally sustaining pedagogies'. Retrieved March 17, 2020, from http://blogs.edweek.org/teachers/classroom_qa_with_larry_ferlazzo/2017/07/auth or_interview_culturally_sustaining_pedagogies.html

Ferrari, L., Ranieri, S., Barni, D., \& Rosnati, R. (2015). Transracial adoptees bridging heritage and national cultures: Parental socialisation, ethnic identity and selfesteem. International Journal of Psychology, 50(6), 413-421. doi:10.1002/ijop.12195

Flick, U. (Ed.). (2014). The SAGE handbook of qualitative data analysis. Los Angeles: SAGE.

Flintoff, A., Dowling, F., \& Fitzgerald, H. (2015). Working through whiteness, race and (anti) racism in physical education teacher education. Physical Education \& Sport Pedagogy, 20(5), 559-570.

Fogle, L. W. (2012). Second language socialization and learner agency: Adoptive family talk. Bristol: Multilingual Matters.

Frank, E., Hochman, G., \& Child Welfare Information Gateway (U.S.). (1990). Adoption and the stages of development (A factsheet for families). Washington, DC: Child Welfare Information Gateway, Children's Bureau/AYCF.

Friedman, J. (2003). Assimilation. In K. Christensen, \& D. Levinson, Encyclopedia of community (2nd ed.). Thousand Oaks, CA: Sage Publications. Retrieved from http://www.libproxy.wvu.edu/login?url=http://search.credoreference.com/content/ entry/sagecommun/assimilation/0?institutionId $=735$ 
Freitas, H., Oliveira M., Jenkins M., \& Popjoy O. (February 1998). The Focus Group, a qualitative research method. ISRC, Merrick School of Business, University of Baltimore (MD, EUA), WP ISRC No. 010298.

García Coll, C. \& Marks, A. (2009). Immigrant stories: Ethnicity and academics in middle childhood. New York: Oxford.

Gay, G. (2000). Culturally responsive teaching: Theory, research, and practice. New York: Teachers College Press.

Gay, G. (March 07, 2008). Teaching children of catastrophe. Multicultural Education,15, 2, 55-61.

Gay, G. (January 01, 2013). Teaching to and through cultural diversity. Curriculum Inquiry, 43(1), 48-70.

Gillham, B. (2000). Case study research methods. London: Continuum.

Gliner, B. (2014). Bob Gliner \& Dana McCauley on "Schools That Change Communities" Retrieved August 2, 2015, from https://www.youtube.com/watch?v=XcvVd6_Meus

Giroux, H. (1991). Border pedagogy and the politics of postmodernism. Social Text, 28(28), 51-67.

Giroux, H. (2013). Politics after hope: Obama and the crisis of youth, race, and democracy. Boulder: Paradigm.

Goff, P., Jackson, M., Di Leone, B., Culotta, C., \& DiTomasso, N. (2014). The essence of innocence: Consequences of dehumanizing black children. Journal of Personality and Social Psychology, 106(4), 526-526. 
Goldstein, B. P. (October 01, 2002). Black children with a white parent--social work education. Social Work Education, 21(5), 551-563.

Gonzalez, J. (2017). A collection of resources for teaching social justice. Retrieved November 03, 2017, from https://www.cultofpedagogy.com/social-justiceresources/

González, N., Moll, L., \& Amanti, C. (2005). Funds of knowledge: Theorizing practice in households, communities, and classrooms. Mahwah, N.J.: Erlbaum.

Gorski, P. C. (2012, January 1). Complicating "White Privilege": Race, Poverty, and the ... Retrieved March 14, 2020, from http://www.edchange.org/publications/Complicating-White-Privilege.pdf

Gorski, P. (2013). Reaching and teaching students in poverty: Strategies for erasing the opportunity gap. New York: Teachers College Press.

Gorski, P. C. \& Swalwell, K. (March 01, 2015). Equity Literacy for All. Educational Leadership, 72(6), 34-40.

Grant, C., \& Sleeter, C. (2009). Turning on learning: Five approaches for multicultural teaching plans for race, class, gender and disability ( $5^{\text {th }}$ Ed.). Hoboken, N.J.: Wiley.

Greene, C.W. \& Parsons, N. K. (Producers), Lee, B. (Director). (2008). Adopted: The movie: We can do better [Motion picture]. U.S.A: Point Made Films.

Greenwood, J. (September 01, 2001). Within a third space. Research in Drama Education, 6(2), 193-205. 
Greenwood, J. (2005). Journeying into the third space: A study of how theatre can be used to interpret the emergent space between cultures. Youth Theatre Journal, 19(1), 1-16.

Greenwood, J. \& Wilson, A. M. (2006). Te Mauri Pakeaka: A journey into the third space. Auckland, N.Z: Auckland University Press.

Groenke, S.L. \& Nespor, J. (2010) "The drama of their daily lives": racist language and struggles over the local in a rural high school. In K. A. Schafft, \& A. Y. Jackson (Eds.), Rural education for the twenty-first century: Identity, place, and community in a globalizing world (pp. 53-71). University Park, PA: Pennsylvania State University Press.

Grotevant, H. D., Dunbar, N., Kohler, J. K., \& Lash Esau, A. M. (2007). Adoptive identity. In R. A. Javier (Ed.), Handbook of adoption: Implications for researchers, practitioners, and families (pp. 77-89). Thousand Oaks, CA: Sage.

Gutiérrez, K. D., Baquedano-López, P., \& Tejeda, C. (1999). Rethinking diversity: Hybridity and hybrid language practices in the third space. Mind, Culture, and Activity, 6(4), 286-303.

Hague Conference on Private International Law. (n.d.). HCCH | Full text. Retrieved August 06, 2016, from https://www.hcch.net/en/instruments/conventions/fulltext $/$ cid $=69$

Hall, B. \& Steinberg, G. (2013). Inside transracial adoption: Strength-based, culturesensitizing parenting strategies for inter-country or domestic adoptive families that don't "Match". London: Jessica Kingsley Publishers. 
Hancock, D. \& Algozzine, B. (2011). Doing case study research: A practical guide for beginning researchers (2nd ed.). New York: Teachers College Press.

Harf, A., Skandrani, S., Sibeoni, J., Pontvert, C., Revah-Levy, A., \& Moro, M. R. (2003, November 31). Cultural Identity and Internationally Adopted Children: Qualitative Approach to Parental Representations. Retrieved August 02, 2016, from http://www.ncbi.nlm.nih.gov/pmc/articles/PMC4361487/

Harré, R. \& Van Langenhove, L. (1991). Varieties of positioning. Journal for the Theory of Social Behaviour, 21(4), 393-407. doi:10.1111/j.14685914.1991.tb00203.x

Herman, E. (2008). Kinship by design: A history of adoption in the modern united states. Chicago: University of Chicago.

Herman, E. (Ed.). (2012, February 24). International adoptions. Retrieved September 04, 2017, from http://pages.uoregon.edu/adoption/topics/internationaladoption.htm

Herman, E. (2013). Objects of salvation. The Women's Review of Books, 30(6), 30-31.

Herrera, S. (2016). Biography-Driven culturally responsive teaching (2nd ed.). New York: Teachers College Press.

Hines, M. (2016). The embeddedness of white fragility within white pre-service principals' reflections on white privilege. Critical Questions in Education, 7(2), 130-145.

Hoffman, J. \& Peña, E. (2013). Too Korean to be White and too White to be Korean: Ethnic identity development among transracial Korean American adoptees. Journal of Student Affairs Research and Practice, 50(2), 152-170. doi:10.1515/jsarp-2013-0012 
Holt International. (2016). Holt has always been about the children. Retrieved July 3 , 2016, from http://www.holtinternational.org/about/historical.shtml

Hübinette, T. (2004). Adopted Koreans and the development of identity in the "third space.” Adoption \& Fostering, 28(1), 16-24. doi:10.1177/030857590402800104

Hübinette, T. (2007). Disembedded and free-floating bodies out of place and out of control: Examining the borderline existence of adopted Koreans. Adoption and Culture: The Interdisciplinary Journal of the Alliance for the Study of Adoption and Culture, 1(1), 129-162.

Hubinette, T. \& Tigervall, C. (2009). To be non-white in a colour-blind society: Conversations with adoptees and adoptive parents in sweden on everyday racism. Journal of Intercultural Studies, 30(4), 335-353.

Hurley, D. (2005). Seeing white: Children of color and the disney fairy tale princess. Journal of Negro Education, 74(3), 221-221.

Iyall Smith, K. \& Leavy, P. (2008). Hybrid identities: Theoretical and empirical examinations (Studies in critical social sciences, v. 12). Leiden: Brill. doi:10.1163/ej.9789004170391.i-411

IES National Center for Educational Statistics. (2017, August). Characteristics of public elementary and secondary school teachers in the United States. Retrieved February 9, 2018, from https://nces.ed.gov/pubs2017/2017072.pdf

Jardine, D. (2006). On the origins of constructivism. In Piaget \& education primer (pp. 17-35). New York: Peter Lang. 
Javier, R. A., Baden, A. L., Biafora, F. A., \& Camacho-Gingerich, A. (2007). Handbook of adoption: Implications for researchers, practitioners, and families. Thousand Oaks: SAGE Publications.

Jerng, M. (2010). Claiming others: Transracial adoption and national belonging. Minneapolis: University of Minnesota Press.

Johnson, K. (2016). China's hidden children: Abandonment, adoption, and the human costs of the one-child policy. Chicago: University of Chicago Press.

Johnston, W. R. (2014). Historical international adoption statistics, United States and world. Retrieved August 03, 2016, from http://www.johnstonsarchive.net/policy/adoptionstatsintl.html

Juárez, B. \& Hayes, C. (2010). Social justice is not spoken here: Considering the nexus of knowledge, power and the education of future teachers in the United States. Power and Education, 2(3), 233-252. doi:10.2304/power.2010.2.3.233

Kaplan, I., Miles, S., \& Howes, A. (2011). Images and the ethics of inclusion and exclusion: Learning through participatory photography in education. Journal of Research in Special Educational Needs, 11(3), 195-202. doi:10.1111/j.14713802.2010.01192.x

Kiang, L., Tseng, V., \& Yip, T. (2016). Placing Asian American child development within historical context. Child Development, 87(4), 995-1013. doi:10.1111/cdev.12578

Kilgore, S. R. (2014, January 31). Placed Episode 9 Ryan. Retrieved August 11, 2016, from https://www.youtube.com/watch?v=swWULQ51yYw 
Kilgore, S. R. (2015, October 12). YoonMee: Beyond Korea. Retrieved August 11, 2016, from https://www.youtube.com/watch?v=qmakDueCXSo

Kim, A., Yeh, C., \& ERIC Clearinghouse on Urban Education. (2002). Stereotypes of Asian American students (ERIC digest, digest no. 172). New York, NY: ERIC Clearinghouse on Urban Education.

Kim, J., \& Hall, B. (2016). School issues. In R. Fong and R. McRoy (Eds), Transracial and intercountry adoptions: Cultural guidance for professionals (p. 417). Columbia University Press, New York Chichester, West Sussex.

Kline, S. L., Karel, A. I., \& Chatterjee, K. (October 01, 2006). Covering adoption: General depictions in broadcast news. Family Relations, 55(4), 487-498.

Koro-Ljungberg, M. \& Douglas, E. P. (April 01, 2008). State of qualitative research in engineering education: Meta-analysis of JEE Articles, 2005-2006. Journal of Engineering Education, 97(2), 163-175.

Kozleski, E. B. (n.d.). Culturally responsive teaching matters! - The equity alliance. Retrieved August 15, 2016, from http://www.equityallianceatasu.org/sites/default/files/Website_files/CulturallyRes ponsiveTeaching-Matters.pdf

Krauss, S. E. (2005, December 1). Research paradigms and meaning making: A primer. The Qualitative Report, 10(4), 758-770. Retrieved November 12, 2017, from http://www.nova.edu/ssss/QR/QR10-4/krauss.pdf

Kreider, R. \& Lofquist, D. A. (2014). Adopted children and stepchildren: 2010 - Census (U.S. Department of Commerce, Ed.). Retrieved August 2, 2016, from https://www.census.gov/prod/2014pubs/p20-572.pdf 
Krogstad, J. M. \& Fry, R. (2014, August 18). Dept. of Ed. projects public schools will be 'majority-minority' this fall (Pew Research Center, Ed.). Retrieved November 03, 2017, from http://www.pewresearch.org/fact-tank/2014/08/18/u-s-public-schoolsexpected-to-be-majority-minority-starting-this-fall/

Kubo, K. (2010). Desirable difference: The shadow of racial stereotypes in creating transracial families through transnational adoption. Sociology Compass, 4(4), 263-282. doi:10.1111/j.1751-9020.2010.00274.x

Kvale, S. \& Brinkmann, S. (2015). Interviews: Learning the craft of qualitative research interviewing. (3rd Ed.). London: Sage.

Kwong, P., \& Lee, S. J. (1998). Unraveling the "model minority" stereotype: Listening to asian american youth. The Journal of Asian Studies, 57(3), 809.

Ladson-Billings, G. (1995). Toward a theory of culturally relevant pedagogy. American Educational Research Journal, 32(3), 465-91.

Ladson-Billings, G. (2000). Fighting for our lives: Preparing teachers to teach African American students. Journal of Teacher Education, 51(3), 206-14.

Lalik, R., Dellinger, L., \& Druggish, R. (2003). Fostering collaboration between home and school through curriculum development: Perspectives of three Appalachian children. In Willis, A. I., Garcia, G. E., \& Barrera, R. B. (Eds.), Multicultural issues in literacy research and practice (pp. 69-99). Mahwah, NJ: Lawrence Erlbaum Associates.

Landsman, J., Salcedo, R. M., \& Gorski, P. (2015). Voices for diversity and social justice: A literary education anthology. Lanham, Maryland: Rowman \& Littlefield. 
Langrehr, K., Yoon, E., Hacker, J., \& Caudill, K. (2015). Implications of transnational adoption status for adult Korean adoptees. Journal of Multicultural Counseling and Development, 43(1), 6-24. doi:10.1002/j.2161-1912.2015.00061.x

Laybourn, W. (2017). Korean transracial adoptee identity formation. Sociology Compass, 11(1). doi:10.1111/soc4.12444

Lee, R. (2003). The transracial adoption paradox: History, research, and counseling implications of cultural socialization. Counseling Psychologist, 31(6), 711-744.

Lee, S. J. (2004). Up against whiteness: Students of color in our schools. Anthropology Education Quarterly, 35(1), 121-125. doi:10.1525/aeq.2004.35.1.121

Leslie, L., Smith, J., Hrapczynski, K., \& Riley, D. (2013). Racial socialization in transracial adoptive families: Does it help adolescents deal with discrimination stress? Family Relations, 62(1), 72-81. doi:10.1111/j.1741-3729.2012.00744.x

Levy, R. (2008). 'Third spaces' are interesting places: Applying 'third space theory' to nursery-aged children's constructions of themselves as readers. Journal of Early Childhood Literacy, 8(1), 43-66. doi:10.1177/1468798407087161

Lewin, T. (1990, February 11). South Korea slows export of babies for adoption. Retrieved September 17, 2017, from http://www.nytimes.com/1990/02/12/us/south-korea-slows-export-of-babies-foradoption.html?mcubz=0

Lewis, A. E. (2003). Race in the schoolyard: Negotiating the color line in classrooms and communities. New Brunswick, N.J: Rutgers University Press. 
Liem, D. B., \& O'Brien, S. S. (2000). First person plural-adoption history. Retrieved September 17, 2017, from http://www.pbs.org/pov/archive/firstpersonplural/historical/skadoptions2.html

Lihua H. (2001). Chinese adoption: Practices and challenges. Child Welfare, 80(5), 52940.

Lin, A. I. (2010). Racial microaggressions directed at Asian Americans. In Microaggressions and marginality (pp. 85-103). Hoboken, NY: Wiley.

Lin, M., Kwan, V., Cheung, A., \& Fiske, S. (2016). Stereotype content model explains prejudice for an envied out group: Scale of anti-Asian American stereotypes. Personality and Social Psychology Bulletin, 31(1), 34-47. doi: $10.1177 / 0146167204271320$

Logan, S. (2017). The myth of colorblindness: Helping educators recognize the role of race in the prek-12th grade classrooms (pp. 77-99). doi:10.4018/978-1-52252520-2.ch004

Love, B. (2019). We want to do more than survive: Abolitionist teaching and the pursuit of educational freedom. Boston, MA: Beacon.

Maryland State Board of Education. (2020). Chapter 13A.01.06. Educational Equity. Retrieved March 16, 2020, from http://mdrules.elaws.us/comar/13a.01.06 Maryland Department of Planning (2011, May 25). Maryland state data center: Census historical-1990. Retrieved March 20, 2018, from http://census.maryland.gov/censusHistorical.shtml

Maryland Department of Planning (2017). Public school enrollment projections 2017 2026. Retrieved March 20, 2018, from 
http://www.mdp.state.md.us/msde/School_Enrollment/PublicSchoolEnrollmentPr ojections.pdf

Maryland State Department of Education (2014). MSDE Fact Book 2013-2014 -

Maryland State Department of ... Retrieved August 3, 2016, from

http://marylandpublicschools.org/MSDE/divisions/bus_svcs/docs/Fact_Book_201

3-2014.pdf

Maryland State Department of Education (2017). Demographics. Retrieved September, 24, 2017, from

http://reportcard.msde.maryland.gov/Demographics.aspx?K=11AAAA\&WDATA $=$ Local + School + System

May, J. C., Nichols, T., \& Lacher, D. B. (2011). Connecting with kids through stories: Using narratives to facilitate attachment in adopted children. London: Jessica Kingsley Publishers.

McCullough, D., Waletzky, J., Marritz, E., Steele, G., Bacon, M., Edward Gray Films, . . . Public Broadcasting Service (U.S.) (Directors), \& Gray, E. (Producer). (2011). American experience: The orphan trains [Motion picture on Online video]. Films Media Group.

McGrath, B., \& Brennan, M. A. (2011). Tradition, cultures and communities: exploring the potentials of music and the arts for community development in Appalachia .Community Development, 42(3), 340-358.

Meese, R. L. (2002). Children of intercountry adoptions in school: A primer for parents and professionals. Westport, Conn: Bergin \& Garvey. 
Melosh, B. (2002). Strangers and kin: The American way of adoption. Cambridge, Mass.: Harvard University Press.

Mercer, J. (2013). Child development: Myths and misunderstandings (2nd ed.). Thousand Oaks, CA: SAGE.

Merriam, S. B. (2002). Qualitative research in practice: Examples for discussion and analysis. San Francisco: Jossey-Bass.

Meulenberg, C. (2004). Definitely probably one: A generation comes of age under china's one-child policy. World Watch, 17(5), 31-33.

Mezmur, B. D. (March 01, 2009). 'As painful as giving birth': A reflection on the Madonna adoption saga. Comparative and International Law Journal of Southern Africa, 41(3), 383-402.

Millar, P. \& Warrican, S. (2015). Handbook of research on cross-cultural approaches to language and literacy development. In Constructing a third space (pp. 87-117). Information Science Reference. doi:10.4018/978-1-4666-8668-7.ch004

Miller, R., Latham, B., \& Cahill, B. (2016). Humanizing the education machine: How to create schools that turn disengaged kids into inspired learners. Newark: Wiley.

Moje, E, Ciechanowski, K., Kramer, K., Ellis, L., Carrillo, R., \& Collazo, T. (January 01, 2004). Working toward third space in content area literacy: An examination of everyday funds of knowledge and Discourse. Reading Research Quarterly, 39(1), $38-70$.

Moje, E. \& Wade, S. (1997). What case discussions reveal about teacher thinking. Teaching and Teacher Education, 13(7), 691-712. 
Moll, L. (1992). Bilingual classroom studies and community analysis: Some recent trends. Educational Researcher, 21(2), 20-24. doi:10.3102/0013189X021002020

Moghaddam, F., \& Harré, R. (2010). Words of conflict, words of war: How the language we use in political processes sparks fighting. Santa Barbara, Calif.: Praeger.

Mueller, J. C. (2017). Producing colorblindness: Everyday mechanisms of White ignorance. Social Problems, 64(2), 219-238.

Myers, J. (2008). A short history of child protection in America. Family Law Quarterly, 42(3), 449-463.

National Center for Educational Statistics (NCES). (2017, May). Racial/ethnic enrollment in public schools. Retrieved November 03, 2017, from https://nces.ed.gov/programs/coe/indicator_cge.asp

Nelson, K. P. (2009, January). Mapping multiple histories of Korean American ... Retrieved September 4, 2017, from https://www.uskoreainstitute.org/wpcontent/uploads/pdf/USKI_WP_0901.pdf

Newsome, W. S., Hennon, C. B., Peterson, G. W., \& Wilson, S. M. (2008). Appalachian families and poverty. In K. R. Bush (Ed.), Handbook of families and poverty (pp. 104-118). Los Angeles, CA: Sage.

Nishina, A. \& Juvonen, J. (2005). Daily reports of witnessing and experiencing peer harassment in middle school. Child Development, 76(2), 435-450.

Norris, M. (n.d). Welcome to The Race Card Project! Send your six words on race. Retrieved March 12, 2020, from https://theracecardproject.com/ 
Novelli, M. \& Sayed, Y. (2016). Teachers as agents of sustainable peace, social cohesion and development: Theory, practice \& evidence. Education as Change, 20(3), 1537. https://doi-org.www.libproxy.wvu.edu/10.17159/1947-9417/2016/1486

O'Connor, C., Hill, L. D., \& Robinson, S. R. (2009). Who's at risk in school and what's race got to do with it? Review of Research in Education, 33(1), 1-34. https://doi.org/10.3102/0091732X08327991

O'Connor, S. (2017, June 20). Brace, Charles Loring. Retrieved September 10, 2017, from https://socialwelfare.library.vcu.edu/people/brace-charles-loring

Office Of Planning, Evaluation and Policy Development, U.S. Department Of Education. (2017, July). The state of racial diversity in the educator workforce. Retrieved February 9, 2018, from https://www2.ed.gov/rschstat/eval/highered/racialdiversity/state-racial-diversity-workforce.pdf

Oliver-Hoyo, M. \& Allen, D. (2006). The use of triangulation methods in qualitative educational research. Journal of College Science Teaching, 35(4), 42-47.

Palinkas, L. A., Horwitz, S. M., Green, C. A., Wisdom, J. P., Duan, N., \& Hoagwood, K. (2016, September 1). Purposeful Sampling for Qualitative Data Collection and Analysis in Mixed Method Implementation Research. Retrieved February 14, 2020, from https://www.ncbi.nlm.nih.gov/pmc/articles/PMC4012002/\#R36

Paris, D. \& Winn, M. (Eds.). (2014). Humanizing research: Decolonizing qualitative inquiry with youth and communities. Los Angeles: Sage.

Park, G. (2011). "Are we real Americans?": Cultural production of forever foreigners at a diversity event. Education and Urban Society, 43(4), 451-467. 
Park Nelson, K. (2016). Invisible Asians: Korean American adoptees, Asian American experiences, and racial exceptionalism. New Brunswick, New Jersey: Rutgers University Press.

Parrillo, V. N. (2008). Multiculturalism. In V. N. Parrillo, Encyclopedia of social problems. Thousand Oaks, CA: Sage Publications. Retrieved from http://www.libproxy.wvu.edu/login?url=http://search.credoreference.com/content/ entry/sagesocprob/multiculturalism/0?institutionId $=735$

Patton, S. L. (2000). BirthMarks: Transracial adoption in contemporary America. New York: New York University Press.

Pettersen, W. (1966, January 9). Success story, Japanese-American style; success story, Japanese-American style. The New York Times, Retrieved February 1, 2020, from https://www.nytimes.com/1966/01/09/archives/success-story-japaneseamericanstyle-success-story-japaneseamerican.html

Phompun, C., Thongthew, S., \& Zeichner, K. M. (2013). The use of the hybridity theory and the third space concept to develop a teaching identities enhancement program for student teachers. Silpakorn University Journal of Social Sciences, Humanities, and Arts, 13(1), 197-214.

Pichardo, E. M. (2012). Home and school come together: family literacy as a third space. Hamline University. Saint Paul, Minnesota.

Picower, B., \& Kohli, R. (Eds.). (2017). Confronting racism in teacher education: Counternarratives of critical practice. Retrieved from https://ebookcentral.proquest.com 
Pyke, K. \& Dang, T. (2003). "fob" and "whitewashed": Identity and internalized racism among second generation Asian Americans. Qualitative Sociology, 26(2), 147172. doi:10.1023/A:1022957011866

Pollock, M. (2004). Colormute: Race talk dilemmas in an American school. Princeton, N.J.: Princeton University Press.

Post Adoption Support Service at Relationships Australia (SA). (2009, July). Intercountry Adoption: Information for teachers. Retrieved August 8, 2016, from http://www.adoptchange.org.au/Assets/72/1/ICAandSchoolseversion.pdf

Quiroz, P. (2008a). Transnational adoption: Reflections of the "diaper diaspora”. International Journal of Sociology and Social Policy, 28(11-12), 440457. doi:10.1108/01443330810915170

Quiroz, P. (2008b). From race matching to transracial adoption: Race and the changing discourse of us adoption. Critical Discourse Studies, 5(3), 249-264. doi:10.1080/17405900802131777

Raleigh, E. (2016). The color line exception: The transracial adoption of foreign-born and biracial Black children. Women, Gender, and Families of Color, 4(1), 86-107. University of Illinois Press. Retrieved October 8, 2017, from Project MUSE database.

Reinoso, M., Juffer, F., \& Tieman, W. (2013). Children's and parents' thoughts and feelings about adoption, birth culture identity and discrimination in families with internationally adopted children. Child \& Family Social Work, 18(3), 264-274. doi:10.1111/j.1365-2206.2012.00841.x 
Rodriguez De La Sierra, L., \& Schachter, J. (2013). Late teenage years: From seventeen to adulthood. Karnac Books.

Russ, K. A. (2010). Working with clients of Appalachian culture. Retrieved September 24, 2017, from http://nursing.utk.edu/wpcontent/uploads/sites/36/2016/06/Appalachian-Culture.pdf

Rutherford, J. (1990). The Third Space. Interview with Homi Bhabha. In Identity: Community, Culture, Difference (pp. 207-221). London: Lawrence and Wishart.

Saldaña, J. (2013). The coding manual for qualitative researchers. Los Angeles [i.e. Thousand Oaks, Calif: Sage.

Salkind, N. (2010). Encyclopedia of research design. Thousand Oaks, Calif.: Sage.

Satterwhite, E. (2013). Navigating myths of Appalachian exceptionalism. In Race, ethnicity and gender in Appalachia: Appalachia in the classroom: Teaching the region (pp. 3-32). Athens, OH: Ohio University Press.

Schafft, K., \& Jackson, A. (2010). Rural education for the twenty-first century: Identity, place, and community in a globalizing world. University Park: Pennsylvania State University Press.

Schniedewind, N., \& Davidson, E. (2014). Open minds to equality: A sourcebook of learning activities to affirm diversity and promote equity ( ${ }^{\text {th }}$ Ed.). Milwaukee, Wisconsin: Rethinking Schools.

Schofield, J. (1982). Black and white in school trust, tension, or tolerance? (Praeger studies in ethnographic perspectives on American education). New York: Praeger.

Schuster Institute for Investigative Journalism (Ed.). (2011, February 23). Capsule history of international adoption: adoption law: A history of fictions. Retrieved 
September 04, 2017, from

https://www.brandeis.edu/investigate/adoption/history.html

Schwartz, S., Luyckx, K., \& Vignoles, V. (2011). Handbook of identity theory and research. New York: Springer.

Selman, P. \& Milbrandt, J. (2015). Global trends in intercountry adoption: 2003-2013. In R. Ballard, N. Goodno, \& R. Cochran (Eds.), The intercountry adoption debate: Dialogues across disciplines (pp. 9-48). Newcastle upon Tyne: Cambridge Scholars Publishing.

Sherfinski, M. (2014). Contextualizing the tools of a classical and Christian homeschooling mother-teacher. Curriculum Inquiry, 44(2), 169-203.

Sherfinski, M., \& Chesanko, M. (2016). Disturbing the data: Looking into gender and family size matters with us evangelical homeschoolers. Gender, Place \& Culture, 23(1), 18-35. doi:10.1080/0966369X.2014.991703

Sleeter, C. \& Grant, C. (2016). Race, class, and gender in an urban school a case study. Urban Education, 20(1), 37-60. doi:10.1177/004208598502000104

Sleeter, C. E. (2017). Critical race theory and the whiteness of teacher education. Urban Education, 52(2), 155-169.

Small, S. A. \& Uttal, L. (2005). Action-oriented research: Strategies for engaged scholarship. Journal of Marriage and Family, 67(4), 936-948.

Smith, J. F. (2006). Chapter 15: Identity, race, and culture in adoption. In,Adoptive Families in a Diverse Society (pp. 243-258). Rutgers, NJ: Rutgers University Press. 
Soja, E. W. (1996). Third space: Journeys to Los Angeles and other real-and-imagined places. Cambridge, Mass: Blackwell.

Soja, E. W. (January 01, 2011). Beyond postmetropolis. Urban Geography, 32(4), 451469.

Sokoloff, B. (1993). Antecedents of American adoption. Future of Children, 3(1), 17-25.

Southern Poverty Law Center (2016). The Trump effect: The impact of the 2016 election on the nation's schools survey, comments. Retrieved February 24, 2018, from https://www.splcenter.org/sites/default/files/trump_effect_final_comments_2.pdf

Southern Poverty Law Center. (2017, August 11). The Trump Effect | Spring 2016. Retrieved August 15, 2017, from https://www.tolerance.org/magazine/publications/the-trump-effect-spring-2016

Spear, N. (2009). Adopted children's outcomes as young adults in regards to to educational attainment and income. The Park Place Economist, 17(online) Retrieved November 26, 2017, from https://www.iwu.edu/economics/PPE17/spear.pdf

Stake, R. E. (1995). The art of case study research. Thousand Oaks: Sage Publications.

Stake, R. (2006). Multiple case study analysis. New York: Guilford Press

Steeples, C. (2004). Using action or participatory research methods for research on networked learning. In S. Banks, P. M. Goodyear, V. Hodgson, C. Jones, V. Lally, \& D. McConnell (Eds.), Proceedings of the 4th international networked learning conference. (pp. 113-118). Lancaster: University of Lancaster. from:http://www.networkedlearningconference.org.uk/past/nlc2004/Proceedings/ Contents.htm\#Symposia 
Stevens, M. (2019, September 17). Andrew Yang knows you may disagree with him about Shane Gillis. Retrieved March 07, 2020, from https://www.nytimes.com/2019/09/17/us/politics/shane-gillis-snl-andrewyang.html

Stevenson, B. (January 01, 2015). Third spaces and video-stimulated recall: an exploration of teachers' cultural role in an Indigenous education context. Educational Action Research, 23(2), 290-305.

Stokes, P. (2014). Philosophy: 100 essential thinkers: the ideas that have shaped our world. London: Arcturus.

Sue, D. W. (2010). Microaggression, marginality, and oppression: an introduction. In Microaggressions and marginality (pp. 3-22). Hoboken, NY: Wiley.

Sue, D. W. (2015). Race talk and the conspiracy of silence: Understanding and facilitating difficult dialogues on race. Hoboken: Wiley.

Susan, M. (2009). Third space theory. Oxford University Press.

Schwartz, S., Luyckx, K., \& Vignoles, V. (2011). Handbook of identity theory and research. New York: Springer.

Tanner, S. (2018). Saying one thing and doing another: Whiteness and education in the neoliberal era. Journal of Curriculum Theorizing, 32(3), Retrieved November 24, 2019, from https://www.academia.edu/36971590/Saying_One_Thing_and_Doing_Another_ Whiteness_and_Education_in_the_Neoliberal_Era

Tashiro, S. \& Conrad, C. (2009). Stereotypes, Asian Americans, and ages: An empirical strategy applied to computer use at work. The American Journal of Economics 
and Sociology, 68(2), 427-444. Retrieved from

http://www.jstor.org/stable/27739778

Third Space London. (n.d.). Third space. training for life. Retrieved June 20, 2017, from https://www.thirdspace.london/

Tigervall, C., \& Hübinette, T. (January 01, 2010). Adoption with complications:

Conversations with adoptees and adoptive parents on everyday racism and ethnic identity. International Social Work, 53(4), 489-509.

Tolbert, S. (December 01, 2015). "Because they want to teach you about their culture": Analyzing effective mentoring conversations between culturally responsible mentors and secondary science teachers of indigenous students in mainstream schools. Journal of Research in Science Teaching, 52(10), 1325-1361.

Tuan, M. (2008). Domestic and international transracial adoption: A synopsis of the literature. Sociology Compass, 2(6), 1848-1859. doi:10.1111/j.17519020.2008.00164.x

Tuan, M. \& Shiao, J. L. (2011). Choosing ethnicity, negotiating race: Korean adoptees in america. New York: Russell Sage Foundation.

Tuan, Y. (1977). Space and place: The perspective of experience. Minneapolis: University of Minnesota Press.

United States Census Bureau. (2015). Population estimates, July 1, 2015, (V2015).

Retrieved August 01, 2016, from http://www.census.gov/quickfacts/table/PST045215/24023

U.S. Department of Health \& Human Services. (2017, February 21). Adoption USA:A chartbook based on the 2007 national survey of adoptive parents-Race, ethnicity, 
and gender. Retrieved February 09, 2018, from

https://aspe.hhs.gov/report/adoption-usa-chartbook-based-2007-national-surveyadoptive-parents/race-ethnicity-and-gender

U.S. Department of Health and Human Services, Administration for Children and Families, Administration on Children, Youth and Families, \& Children's Bureau. (2015, January). The AFCARS report. Retrieved July 31, 2017, from https://www.acf.hhs.gov/sites/default/files/cb/afcarsreport22.pdf

University of Texas Austin, Counseling and Mental Health Center. (2020). Model Minority Stereotype for Asian Americans. Retrieved January 19, 2020, from https://cmhc.utexas.edu/modelminority.html

Van Langenhove, L. \& Harré, R. (1994). Cultural stereotypes and positioning theory. Journal for the Theory of Social Behaviour, 24(4), 359-372. doi:10.1111/j.1468-5914.1994.tb00260.x

Van Langenhove, L. \& Harré, R. (2010). Cultural stereotypes and positioning theory People and societies: Rom harré and designing the social sciences. London: Routledge.

Van Manen, M. (1990). Researching lived experience: Human science for an action sensitive pedagogy (SUNY series in the philosophy of education). State University of New York Press.

Vashchenko, M., D'Aleo, M., \& Pinderhughes, E. (2012). "Just beyond my front door": Public discourse experiences of children adopted from china. American Journal of Community Psychology, 49(1-2), 246-257. 
Voigt, K. \& Brown, S. (2013). International adoptions in decline as number of orphans grows. Retrieved September 04, 2017, from http://www.cnn.com/2013/09/16/world/international-adoption-main-storydecline/index.html

Wentzel, K. R. \& Caldwell, K. (1997). Friendships, peer acceptance, and group membership: Relations to academic achievement in middle school. Child Development, 68(6), 1198-1209.

Wickes, K. \& Slate, J. (1997). Transracial adoption of Koreans: A preliminary study of adjustment. International Journal for the Advancement of Counselling, 19(2), $187-187$.

Wilkey, J. (2017, April 27). What/where/who is Appalachia? This Appalachian Life. Retrieved January 30, 2018, from https://www.thisappalachialife.com/singlepost/2017/04/27/WhatWhereWho-is-Appalachia

Wilhelm, J. D. (2010). Creating "third spaces": promoting learning through dialogue. Voices from the Middle, 18(2), 55-58.

Williams, A. \& Katz, L. (2001). The use of focus group methodology in education: Some theoretical and practical considerations. International Electronic Journal for Leadership in Learning, 5(3).

Williford, A., Boulton, A. J., Forrest-Bank, S. S., Bender, K. A., Dieterich, W. A., \& Jenson, J. M. (2016). The effect of bullying and victimization on cognitive empathy development during the transition to middle school. Child \& Youth Care Forum, 45(4), 525-541. 
Wind L., Brooks, D., \& Barth, R. (2007). Influences of risk history and adoption preparation on post-adoption services use in U.S. adoptions. Family Relations, 56(4), 378-389.

Witenstein, M. A. \& Saito, L. E. (2015). Exploring the educational implications of the third space framework for transnational Asian adoptees. Berkeley Review of Education, 5(2), 117-136.

Wong, C. (2012). Reinventing the central Asian rawap in modern China: Musical stereotypes, minority modernity, and Uyghur instrumental music. Asian Music, 43(1), 34-63.

Woods, A. (2020, March 06). Woman knocked unconscious defending Chinese friend over coronavirus harassment. Retrieved March 07, 2020, from https://nypost.com/2020/03/06/woman-knocked-unconscious-defending-chinesefriend-over-coronavirus-harassment/

Wright, M. A. (2000). I'm chocolate, you're vanilla: Raising healthy black and biracial children in a race-conscious world [a guide for parents and teachers]. San Francisco: Jossey-Bass.

Wood, M. (2009). Mixed ethnicity, identity and adoption: research, policy and practice. Child \& Family Social Work, 14(4), 431-439.

Yin, R. K. (2003). Case study research: Design and methods. Thousand Oaks, Calif: Sage Publications.

Young, S. (2017). Wild, wonderful, white criminality: Images of "white trash" Appalachia. Critical Criminolog, 25(1), 103-117. doi:10.1007/s10612-016-9326-7 
Zhang, Q. (2015). Perceived intergroup stereotypes, threats, and emotions toward Asian Americans. Howard Journal of Communications, 26(2), 115-131. doi:10.1080/10646175.2014.1001097

Zulfikar, T. (2016). "I feel different though": Narratives of young immigrant Muslims in Australian public schools. Cogent Education, 3(1). 
Appendix A 


\section{Student Questionnaire}

Name:

1. What gender do you consider yourself?

2. What is your age?

3. What race do you consider yourself to be?
a) White/Caucasian
c) Asian
e) Mixed race
b) Black/African Am.
d) Hispanic
f) Other

4. What grade are you currently in?

5. What extra-curricular activities do you participate in? (Please list)

6. What school activities/classes are your favorites? (Please list) 
7. Do you have any favorite family activities? (Please list)

8. What are some of the cultural events you have participated in? (ex. Maple Sugar Festival, Lunar New Year) 


\section{Parent Questionnaire}

You are not obligated to answer any question on this questionnaire.

Parents Names-

Parent Completing the survey

Your age-

Age of parent not completing this survey -

What race do you consider yourself to be?

\begin{tabular}{|c|c|c|c|c|}
\hline a) & c) Asian & e) Mixed & & \\
\hline White/Caucasian & & race & $\begin{array}{l}\text { Black/African } \\
\text { Am. }\end{array}$ & Hispanic \\
\hline
\end{tabular}

What is your highest educational level?
a) Grade school/
c) Some college/
e) Undergraduate
g) Graduate/
junior high
technical school
college degree
professional
b) High school/GED
d) Associate degree
or technical diploma

f)

How old were you when you adopted your child-

Other parent's age at adoption-

How old was your child upon arrival to the United States? 

a) Newborn to six
b) Six months to 12
c) 12 months to 24
d) Two to five months old months old months old (1-2 years old yrs old)

What age is your child now?

What gender is your child?

What race do you consider your child to be?
a) White/Caucasian
c) Asian
e) Mixed race
b) Black/African Am.
d) Hispanic
f) Other

Country of Birth-

How many people live in your child's current household (including you)?
a) Two
b) Three to five
c) Six to eight
d) More than eight

Siblings (both those that live in the household and do not)

How many — \#brothers _ _ _ \#
\#parents.

How many adopted members of your family?

From which country/ies?

17. What is the yearly income (approximately) for the household where your child lives?
a) Less than $\$$
b) $\$ 30,000-60,000$
c) $\$ 60,000-90,000$
d) Over $\$ 90,000$ 30,000 
Does your child have health concerns that effect he/she educationally?
a) Yes
b) No

List some favorite family activities:

List any activities that your child regularly participates in:

23. Please list any cultural activities have you attended with your child?

Please list any activities that as a family are directly linked to your child's race or ethnicity. 


\section{Teacher Questionnaire}

1. What gender do you consider yourself?

2. What is your age?

3. What race do you consider yourself to be?
a) White/Caucasian
c) Asian
e) Mixed race
b) Black/African Am.
d) Hispanic
f) Other

4. What is your highest educational certification level? (Circle all that apply)
a) Undergraduate degree
b) Master's Degree
d) Doctorate
Degree
e) National
Board
Certified

5. How long have you been teaching?

How long in your present position-

6. What grades and topics have you taught during your career?

7. What grade and subject to you presently teach? 
8. How long have you been teaching in your present position?

9 What kind of diversity is present in your classes? 


\section{Administrator Questionnaire}

1. What gender do you consider yourself?

2. What is your age?

3. What race do you consider yourself to be?
a) White/Caucasian
c) Asian
e) Mixed race
b) Black/African Am.
d) Hispanic
f) Other

4. What is your highest educational certification level? (Circle all that apply)
a) Undergraduate degree
b) Master's Degree
d) Doctorate
Degree
e) National Board Certified

5. What is your highest administrator level?
a) Admin I
b) Admin II

How long have you been an administrator?

How long in your present position?

6. What teaching experience have you had prior to becoming an administrator?

9. What kind of diversity is present in your school? 
Have you notice changes in the diversity of your school?

What examples of the children dealing with diversity can you share? 
Appendix B 


\section{Student Interview Questions}

\section{Interview 1: Family/community relationship and support}

1. You have mentioned on the questionnaire that you are involved in . How long have you been involved in this activity?

What do you like most about being able to participate in this activity?

2. You mentioned you have participated in (cultural event/s). What did you like or dislike about these events?

3. I see you and your parent/s do regularly. Do you enjoy this activity? Why or why not?

4. When you are out with your parents do most people in the community recognize you and your family? How do you feel when people don't connect you with your parents, that you look different from them?

5. What does "being supported" look like to you?

6. Have you been back to (birth country)? Would you like to go back? Why or why not?

\section{Interview 2: School relationships and support}

1. Your favorite class is . Why?

2. What is your least favorite class? Why is that class your least favorite?

3. How has being Asian affected you in school? Can you describe one or more of those situations?

4. What type of strategies do you have on hand to deal with comments or situations that make you uncomfortable?

5. Where do these instances happen? Were there any adults around that saw what happened? What did they do?

6. Have teachers asked you questions about where you're from, if you speak another language? How did/would that make you feel?

7. What kind of changes would you like to see in school, that deal with race?

8. What school activities do you participate in? Have you developed good friendships from these activities? 


\section{Interview 3: Peer Relationship and support}

1. Do you have any friends who are Asian? Are any local? What types of things do you talk about? Does race ever come up? Do you have a particular instance you can describe about a discussion you had with your Asian friend?

2. Your friends who are not Asian, do you feel particularly close to any of them? Have you ever had any talks about being Asian and adopted? What have been their reactions to this?

3. Do you ever watch or listen to ___ (birth culture) movies, music, youtubers, books, etc? If you do, do you have any favorites?

4. What do you think about living here in Peak County? Do you like it, not like it, why?

5. What type of place do you picture yourself living in the future, rural, urban? Why? 


\section{Parent Interview Questions}

1. You have mentioned cultural activities that you have or are attending? Why do you choose to attend these activities?

2. What are some activities you have participated in that are directly linked to your child's race or culture?

3. What types of activities do you do to incorporate your child's birth culture?

3. What are some difficult topics that you have felt that you needed to discuss with your child?

4. What was their response to you your discussion?

5. Are there discussions or activities that you have to empower your child? Could you describe one example?

6. Has your child ever mentioned an uncomfortable situation that happened in school? How did you handle it with your child?

7. What are some good things that are going on in the schools that you feel support your child?

8. What are some examples of activities or situations that you have heard of that have happened around school that you feel have not supported your child? 


\section{Teacher Interview Questions}

1. You have mentioned that you have seen diversity in your classroom. How has this diversity changed your classroom?

2. How have students reacted to the diversity in their classrooms? Please describe.

3. Do you think it is advantageous or disadvantageous for a child of color to live in Peak County? Can you provide more information on that answer?

4. You have had Asian or Transnationally adopted Asian students in your classroom. Can you describe any situations that you felt that child might have been uncomfortable or needed support?

5. In what ways do you think teachers can help TRAA child become comfortable in an uncomfortable situation? 


\section{Administrator Questions}

1. You have stated that you have been an administrator for years. What changes have you seen in the race population at your school?

2. Do you think it is advantageous or disadvantageous for a child of color to live in Peak County? Can you provide more information on that answer?

3. Have you dealt with situations that involve race or ethnicity? Would you please describe one or more of these instances?

4. How do you handle racism administratively in this school?

5. Do you think teachers need training in this predominately white school in dealing with race? How would you like to see this happen?

6. Do Caucasian students need more information about Caucasian/white culture? Could you explain that more for me with examples? 


\section{Focus Group Questions}

1. Do you think it is advantageous or disadvantageous for a child of color to live in Peak County? Can you provide more information on that answer?

2. Can any of you recall any instances of when race was the cause of any problems at this school?

3. How are teachers trained to talk about race in the classroom? Should teachers be trained to talk about race?

4. I am going to relay a situation that has happened to a TRAA in a school situation, not this school or even a school in this county. What are some strategies that you think the teacher could implement to make this child, and all children of color, feel more comfortable in school/classroom in this situation?

5. Do you think the fact that the county is $97 \%$ white effects the people of color in this school?

6. What would you like to know about TRAAs?

7. What strategies could be implemented in the school to work with transnationally adopted students from Asia? 